\title{
Isolation, molecular characterisation and chromosomal location of repetitive DNA sequences in Brassica
}

\author{
Dissertation \\ zur Erlangung des Doktorgrades \\ der Fakultät für Agrarwissenschaften \\ der Georg-August-Universität Göttingen
}

vorgelegt von

Karla Galvão Bezerra dos Santos

geboren in Recife, Pernambuco, Brasilien 
D7

1. Referent: Prof. Dr. Heiko C. Becker

2. Korreferent: Prof. Dr. Wolfgang Köhler

Tag der mündlichen Prüfung: 18. November 2004 


\section{Table of Contents}

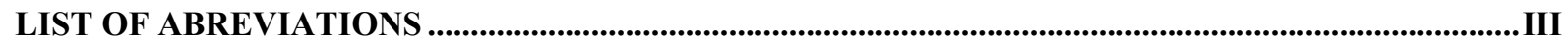

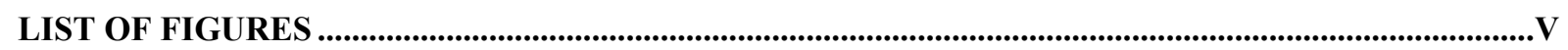

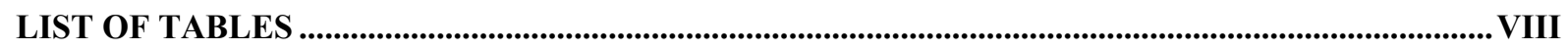

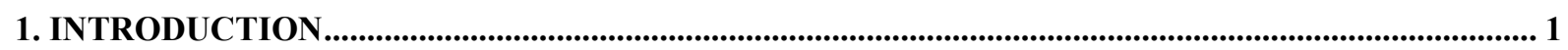

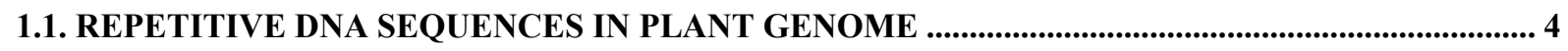

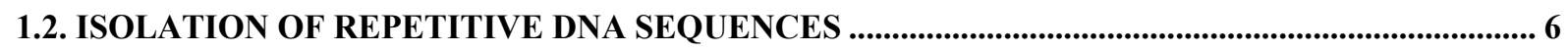

1.3. TYPE AND CHROMOSOMAL LOCALISATION OF REPETITIVE DNA.................................... 7

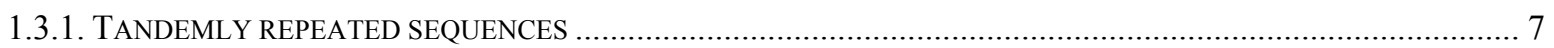

1.3.2. DISPERSED REPEATED SEQUENCES - TRANSPOSABLE ELEMENTS ........................................................ 10

1.4. REPETITIVE DNA SEQUENCES AS CYTOGENETIC TOOLS ............................................... 11

1.5. MOLECULAR CYTOGENETICS OF BRASSICA SPECIES ........................................................... 14

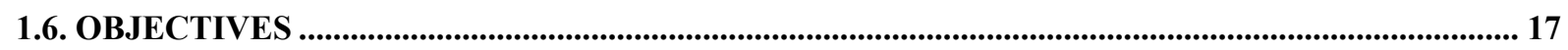

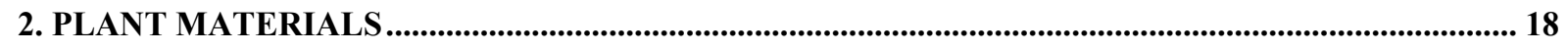

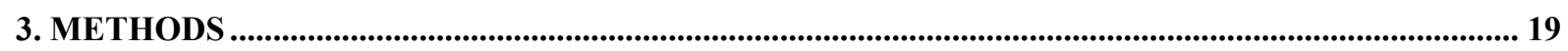

3.1. PLANT DNA EXTRACTION AND QUANTIFICATION ................................................................... 19

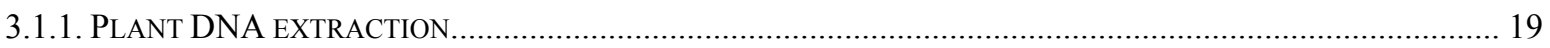

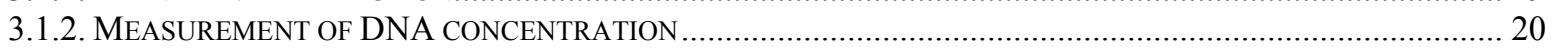

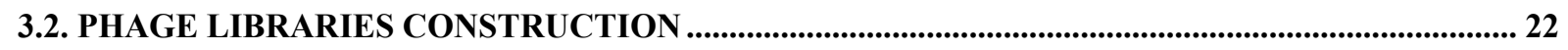

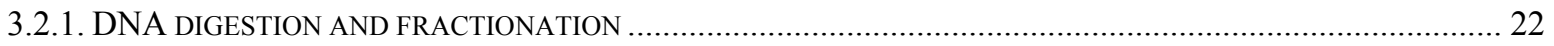

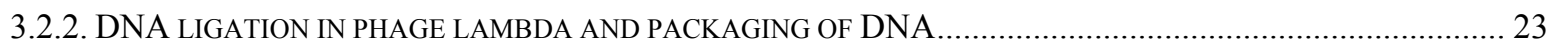

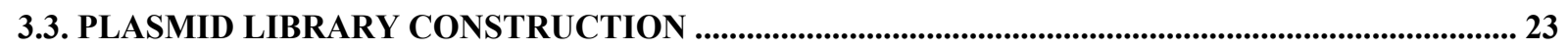

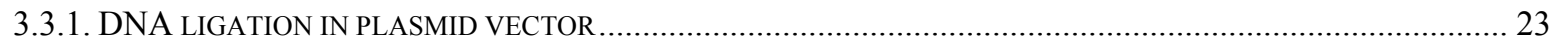

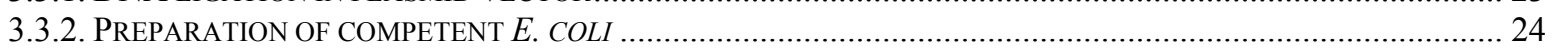

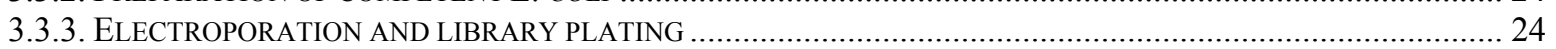

3.4. PLATING LAMBDA LIBRARIES, PLAQUE LIFTS AND HYBRIDISATION PROCEDURE........ 26

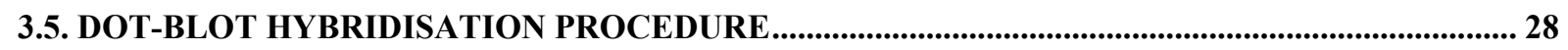

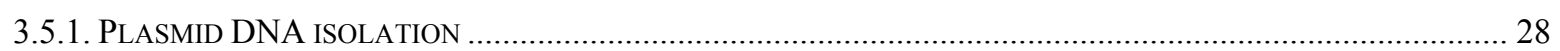

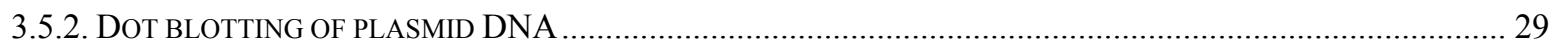

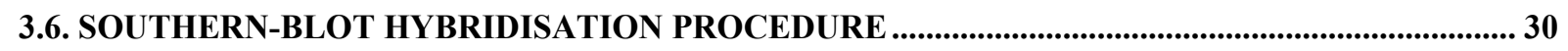

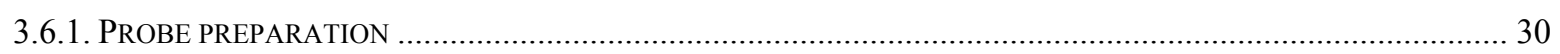

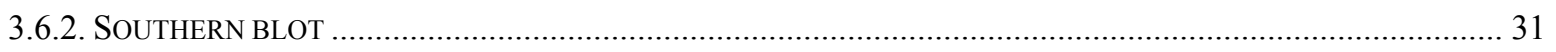

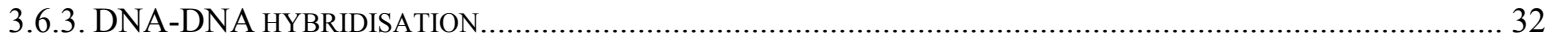

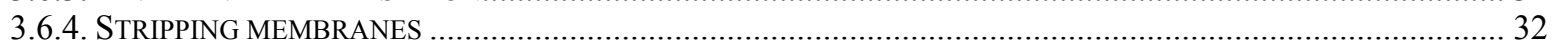

3.7. DNA SEQUENCING AND COMPUTER ANALYSIS OF SEQUENCE DATA.................................. 33

3.8. FLUORESCENT IN SITU HYBRIDISATION (FISH) ........................................................................ 33

3.8.1. ACCUMULATION, FIXATION AND SQUASH PREPARATION OF PLANT CHROMOSOMES............................... 34

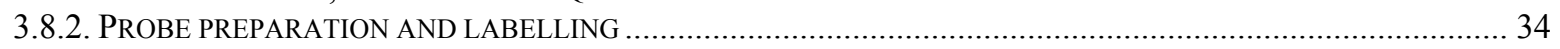




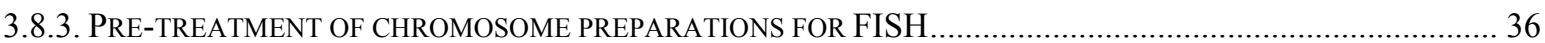

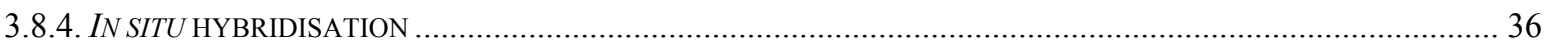

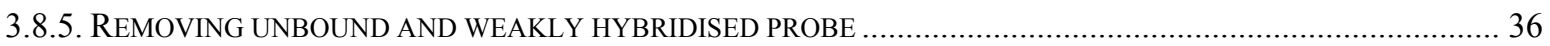

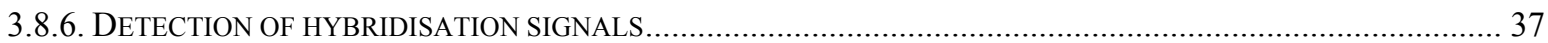

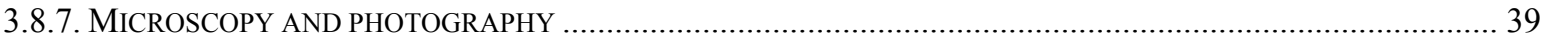

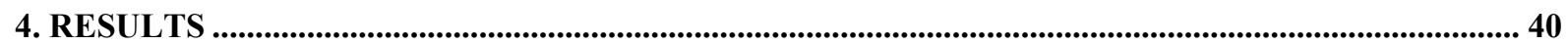

4.1. SEARCHING FOR BRASSICA OLERACEA SPECIES-SPECIFIC REPETITIVE SEQUENCES.... 40

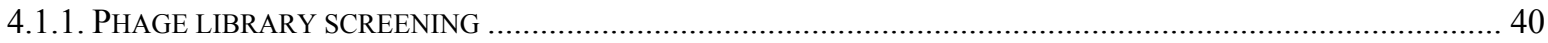

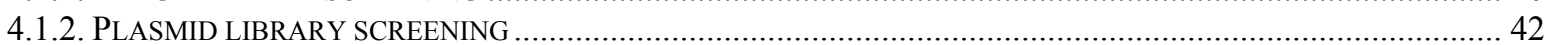

4.2. GENOMIC ORGANISATION OF THE PUTATIVE C GENOME-SPECIFIC OR ENRICHED

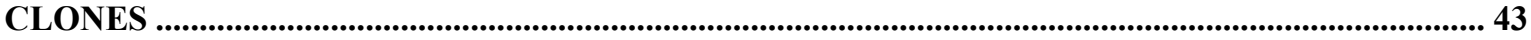

4.3. SEQUENCE COMPOSITION OF REPETITIVE DNA FROM BRASSICA OLERACEA AND

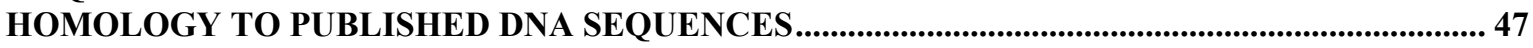

4.4. CYTOGENETIC CHARACTERISATION AND CHROMOSOME ORGANISATION OF REPETITIVE DNA SEQUENCES IN BRASSICA NAPUS AND ITS RELATIVES B. OLERACEA AND B. RAPA

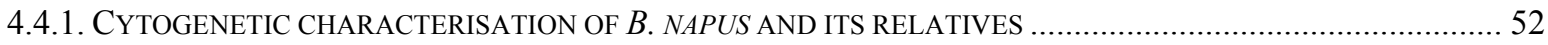

4.4.2. CHROMOSOME ORGANISATION OF REPETITIVE DNA SEQUENCES IN BRASSICA ....................................56

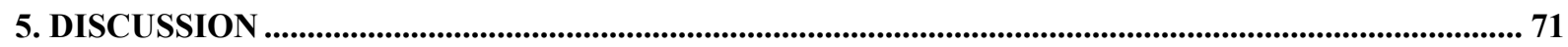

5.1. SEARCH FOR B. OLERACEA SPECIES-SPECIFIC REPETITIVE SEQUENCES......................... 71

5.2. CYTOGENETIC CHARACTERISATION OF B. NAPUS AND ITS RELATIVES ........................ 75

5.3. CHROMOSOME ORGANISATION OF RDNA AND HIGHLY REPEATED SEQUENCES IN

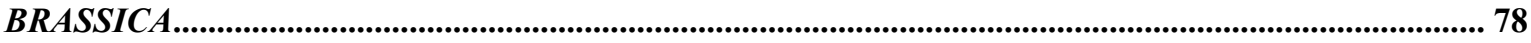

5.4. CHARACTERISATION OF NEWLY ISOLATED DISPERSED REPETITIVE SEQUENCES OF

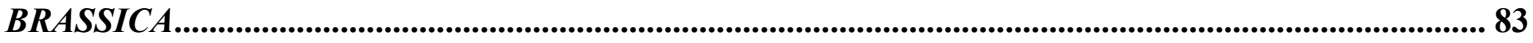

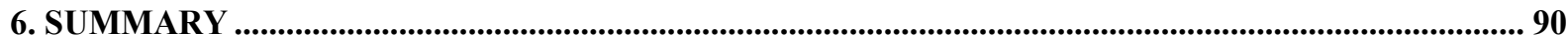

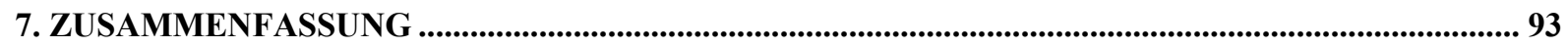

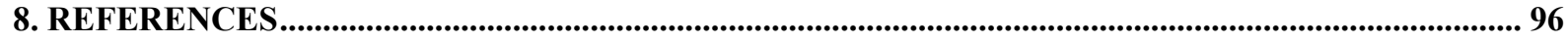

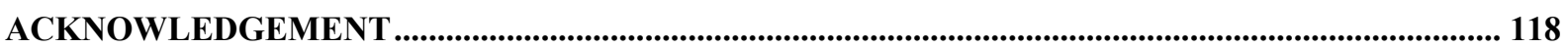

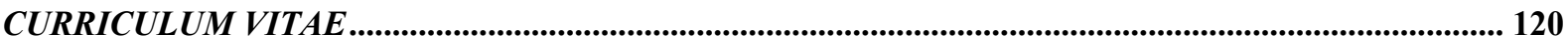




\section{List of Abreviations}

A

bp

BLAST

BSA

C

ca.

Cot-1 DNA fraction

CTAB

DAPI

DDBJ

$\mathrm{dH}_{2} \mathrm{O}$

DIG

DMF

DNA

DNAse

dNTP

dTTP

dUTP

e.g.

E. coli

EDTA

$\mathrm{En} / \mathrm{Spm}$

et al.

EMBL

F

FISH

FITC

g

GenBank

G

GISH

IPTG

$\mathrm{h}$

$\mathrm{kb}$

1

LB

$\mathrm{M}$

$\mathrm{m}$

$\min$

M13 primer adenine

base pairs

basic local alignment search tool

bovine serum albumin

cytosine

circa

repetitive sequence fraction of genomic DNA

cetryltrimethylammonium bromide

4',6'-diamidino-2-phenylindole

DNA data bank of Japan

distilled water

digoxigenin

$\mathrm{N}, \mathrm{N}$-dimethylformamide

deoxyribonucleic acid

deoxyribonuclease

deoxyribonucleoside triphosphate

deoxythymidine triphosphate

deoxyuridine triphosphate

exempli gratia (for example)

Escherichia coli

ethylenediaminetetraacetic acid

enhancer/supressor-mutator

et alteri (and others)

European molecular biology laboratory

farad

fluorescent in situ hybridization

fluorescein isothiocyanate

gram

genetic sequence database

guanine

genomic in situ hybridization

isopropyl- $\beta-\mathrm{D}$-thiogalactopyranoside

hour

kilo base pairs

litre

Luria-Bertrani

molarity

meter

minute

universal promer 


\begin{tabular}{|c|c|}
\hline $\begin{array}{l}\mathrm{N} \\
2 \mathrm{n} \\
\text { NCBI } \\
\text { NOR }\end{array}$ & $\begin{array}{l}\text { normality } \\
\text { diploid chromosome number } \\
\text { national center for biotechnology information } \\
\text { nucleolus organise region }\end{array}$ \\
\hline $\begin{array}{l}\mathrm{OD}_{600} \\
\mathrm{O} / \mathrm{N} \\
\mathrm{ORF}\end{array}$ & $\begin{array}{l}\text { optical density at } 600 \mathrm{~nm} \\
\text { over night } \\
\text { open reading frame }\end{array}$ \\
\hline $\begin{array}{l}\mathrm{P}^{32} \\
\mathrm{pBo} 1 \\
\mathrm{pBo} 2 \\
\mathrm{PBS} \\
\mathrm{PCR} \\
\mathrm{pH} \\
\text { PVP }\end{array}$ & $\begin{array}{l}\text { radioactive phosphorus } \\
\text { plasmid library } 1 \text { from } B \text {. oleracea total DNA } \\
\text { plasmid library } 2 \text { from } B \text {. oleracea fractionated DNA } \\
\text { phosphate buffered saline } \\
\text { polymerase chain reaction } \\
\text { negative logarithm of the hydrogen ion concentration in an } \\
\text { aqueous solution }\end{array}$ \\
\hline $\begin{array}{l}\text { rDNA } \\
\text { RNAse } \\
\text { rRNA } \\
\text { rpm } \\
\text { RT }\end{array}$ & $\begin{array}{l}\text { ribosomal DNA } \\
\text { ribonuclease } \\
\text { ribosomal RNA } \\
\text { rotations pro minute } \\
\text { room temperature }\end{array}$ \\
\hline $\begin{array}{l}\text { S } \\
\text { SDS } \\
\text { sec } \\
\text { SSC }\end{array}$ & $\begin{array}{l}\text { Svedberg unity of sedimentation }\left(1 \mathrm{~S}=10^{-13} \mathrm{sec}\right) \\
\text { sodium dodecylsulfate } \\
\text { second } \\
\text { standard saline citrate }\end{array}$ \\
\hline $\begin{array}{l}\text { TIGR } \\
\mathrm{T} \\
\text { Tris }\end{array}$ & $\begin{array}{l}\text { the institute for genomic research } \\
\text { thymidine } \\
\text { tris(hydroxymethyl) aminomethane }\end{array}$ \\
\hline $\mathrm{U}$ & unit \\
\hline $\begin{array}{l}\mathrm{V} \\
\mathrm{v} / \mathrm{v}\end{array}$ & $\begin{array}{l}\text { volt } \\
\text { volume to volume }\end{array}$ \\
\hline $\mathrm{w} / \mathrm{v}$ & weight to volume \\
\hline X-gal & 5-bromo-4-chloro-3-indolyl- $\beta$-galactosidase \\
\hline YEB & yeast extract broth \\
\hline
\end{tabular}

Prefix for the units used in this work: $\mathrm{p}$, pico $\left(10^{-12}\right) ; \mathrm{n}$, nano $\left(10^{-9}\right) ; \mu$, micro $\left(10^{-6}\right) ; \mathrm{m}$, milli $\left(10^{-3}\right)$; c, centi $\left(10^{-2}\right)$; $\mathrm{k}$, kilo $\left(10^{3}\right)$; M, mega $\left(10^{6}\right)$. 


\section{List of Figures}

Figure 1. Summary of the relationships among cultivated Brassica species (after U, 1935, modified). The chromosome number, genome designations and number of chromosomes with hybridisation sites for repetitive sequences are given. The repetitive sequences indicated are: 5S and 45S rDNA (Hasterock et al., 2001), HindIII family (for repeat pBcKB4, Harrison and Heslop-Harrison, 1995), B. rapa species-specific repeat pCS1 (Iwabuchi et al., 1991 and Schrader, personal communication) and $B$. nigra species-specific repeat pBNBH35 (Schelfhout et al., 2004). nt= not tested or not mentioned.

Figure 2. Autoradiogram from replica filters in the first screening of the B. oleracea lambda library 1 after hybridisation with total genomic DNA of (a) B. oleracea and (b) B. rapa. The insert on the right side shows a magnification of the boxed area in the respective filters, representing the same region in both filters. Clones with repetitive DNA show strong hybridisation signals. Circled clones show differential hybridisation between the replica membranes and were collected to a second screening as candidates for species-specificity......

Figure 3. Autoradiogram of replica filters from a putative species-specific clone (lambda clone Bo-93) selected in the first screening, after hybridisation with B. oleracea (a) and $B$. rapa (b) total genomic DNA

Figure 4. Dot-blot hybridisation of $\mathrm{pBo}$ clones with B. oleracea (a) and B. rapa (b) total genomic DNA. Clones with repetitive DNA (e.g. D1, E2, F2, C6) show strong hybridisation signals

Figure 5. Dot-blot hybridisation of $\mathrm{pBo}$ clones confirmed as enriched in $\mathrm{C}$ genome after hybridisation with $B$. oleracea (C) and B. rapa (A) total genomic DNA

Figure 6. Southern blot hybridisation of genomic DNA digested with EcoRI or HindIII from different Brassica with $\mathrm{C}$ genome-enriched clones. Brassica species: B. oleracea Vitamina (lane 1) and Market Victor (lane 2); B. napus Express (lane 3) and Iris (lane 4); B. rapa NPZ35 (lane 5) and Perko (lane 6); B. incana (lane 7) and B. oleracea alboglabra (lane 8). Molecular weight marker (Lambda EcoRI/HindIII, lane M) is given in kb

Figure 7. Southern blot hybridisation of genomic DNA digested with EcoRI or HindIII from different Brassica species with repetitive non species-specific clones. Brassica species: $B$. oleracea Vitamina (lane 1) and Market Victor (lane 2); B. napus Express (lane 3) and Iris (lane 4); B. rapa NPZ-35 (lane 5) and Perko (lane 6); B. incana (lane 7) and B. oleracea 
alboglabra (lane 8). Molecular weight marker (Lambda EcoRI/HindIII, lane M) is given in $\mathrm{kb}$.

Figure 8. Nucleotide sequences, size and base composition of DNA fragments from $B$. oleracea cloned in pBo1.6, pBo1.27, pBo2.157, pBo2.94 and pBo1.173. The complete sequences are shown in groups of ten nucleotides from 5' $-3^{\prime}$ with the Tsp509I sites bordering the fragments shown in bold. The variations of the telomeric repeat TTTAGGG found in pBo1.6 is shown as blocks and the nucleotide sequences from which HindIII restriction site could arise by single base change found in $\mathrm{pBo} 2.157$ are underlined

Figure 9. Karyotypes of B. oleracea, B. rapa and B. napus after DAPI staining, based on Figure $10 \mathrm{a}, \mathrm{b}$ and $\mathrm{c}$, respectively. Scale bar $=10 \mu \mathrm{m}$

Figure 10. Interphase nuclei and mitotic metaphases of (a) B. oleracea, (b) B. rapa and (c, d) B. napus stained with DAPI. Scale bar $=10 \mu \mathrm{m}$ for all panels

Figure 11. Interphase nuclei and mitotic metaphases of B. oleracea (a), B. rapa (b) and prometaphase of B. napus (c) stained with DAPI after FISH. Scale bar $=10 \mu \mathrm{m}$ for all panels.. 55 Figure 12. FISH with $45 \mathrm{~S}$ rDNA probe hybridised to somatic metaphase chromosomes of $B$. oleracea ( $\mathrm{a}, \mathrm{c}, \mathrm{e})$. Panels b, $\mathrm{d}$ and f show the same cells counterstained with DAPI. Arrows indicate the small locus. Scale bar $=10 \mu \mathrm{m}$ for all panels

Figure 13. FISH with "5+45S rDNA" probe hybridised to somatic metaphase chromosomes of B. oleracea (a, c, e, g). Panels b, d, f and h show the same cells counterstained with DAPI. Arrows and arrowheads indicate the small 45S locus and the adjacent 5S loci, respectively. Scale bar $=10 \mu \mathrm{m}$ for all panels.

Figure 14. FISH with "5+45S rDNA" probe hybridised to somatic metaphase chromosomes of B. oleracea (a), B. rapa (c) and B. napus (e). Panels b, $\mathrm{d}$ and $\mathrm{f}$ show the same cells counterstained with DAPI. Chromosomal types I-V are indicated in e. Scale bar $=10 \mu \mathrm{m}$ for all panels.

Figure 15. FISH with probe pBo2.94 hybridised to somatic metaphase chromosomes of $B$. oleracea (a), B. napus (c) and B. carinata (e). Panels b, $\mathrm{d}$ and $\mathrm{f}$ show the same cells counterstained with DAPI. Scale bar $=8 \mu \mathrm{m}$ for $\mathrm{a}, \mathrm{b}$ and $10 \mu \mathrm{m}$ for $\mathrm{c}-\mathrm{f}$.

Figure 16. FISH with probe pBo1.173 hybridised to somatic metaphase chromosomes of $B$. oleracea (a), B. rapa (c), B. napus (e) and B. carinata (g). Panels b, d, f and h show the same cells counterstained with DAPI. Scale bar $=8 \mu \mathrm{m}$ for a-d and $10 \mu \mathrm{m}$ for e-h. 
Figure 17. FISH with probe pBo1.6 hybridised to somatic metaphase chromosomes of $B$. oleracea (a), B rapa (c) and B. napus (e). Panels b, d, and $\mathrm{f}$ show the same cells counterstained with DAPI. Arrows in e indicate chromosomes labelled over its almost entire length. Circled chromosome in $\mathrm{b}$ was outside the metaphase plate. Scale bar $=10 \mu \mathrm{m}$ for all panels.

Figure 18. FISH with probe pBo1.27 hybridised to somatic metaphase chromosomes of $B$. oleracea (a), B. rapa (c) and B. napus (e). Panels b, d, and $\mathrm{f}$ show the same cells counterstained with DAPI. Chromosomes with less and more hybridisation sites are indicated in a, c and e by arrowheads and arrows, respectively. Scale bar $=10 \mu \mathrm{m}$ for all panels

Figure 19. FISH with probe $\mathrm{pBo} 2.157$ hybridised to somatic metaphase chromosomes of $B$. oleracea (a), B. rapa (c) and B. napus (e). Panels b, d, and f show the same cells counterstained with DAPI. Scale bar $=10 \mu \mathrm{m}$ for all panels

Figure 20. FISH with probes pBo1.6 (a), pBo1.27 (c) and pBo2.157 (e) hybridised to interphase nuclei of B. oleracea and with probes pBo2.94 (g) and pBo1.173 (i) hybridised to interphase nuclei of $B$. napus. Panels $\mathrm{b}, \mathrm{d}, \mathrm{f}, \mathrm{h}$ and $\mathrm{j}$ show the same cells counterstained with DAPI. Scale bar $=10 \mu \mathrm{m}$ for all panels 


\section{List of Tables}

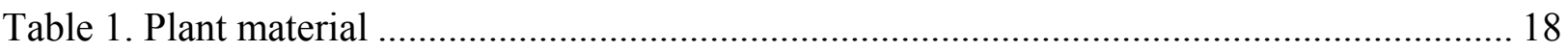

Table 2. Length and GC content of the sequenced pBo clones............................................ 47

Table 3. Comparison of the newly isolated repetitive DNA sequences from Brassica with sequences of the EMBL/GenBank/DDBJ databases.............................................................. 50

Table 4. Number and types of chromosomes after FISH with probe "5+45S rDNA" in the diploid complement of B. napus and its progenitors

Table 5. Number of chromosomes with strong pericentromeric hybridisation sites for probe pBo2.94 and pBo1.173 in four Brassica species

Table 6. Characteristics of newly isolated repetitive DNA sequences from B. oleracea. Homology to known sequences, chromosome location after FISH and frequency of signals on the chromosomes of B. oleracea, B. rapa and B. napus 


\section{Introduction}

The genus Brassica (tribe Brassiceae, family Brassicacea) includes six world-wide important cultivated species: B. oleracea, B. rapa (syn. B. campestris), B. nigra, B. napus, B. carinata and B. juncea. According to its use, they can be categorised in vegetable, oilseed (edible or industrial oils), condiment and forage crops, with some species presenting this whole range of use. Due in part to the many edible forms, Brassica crops are used in the cuisine of many cultures and are a valuable source of minerals, vitamins (particularly vitamin $\mathrm{C}$ ), dietary fibres, and other possible salubrious factors such as anticancer compounds (Rosa, 1999). The seeds of $B$. nigra and $B$. juncea are utilised as condiment mustard and different cultivars of $B$. oleracea, B. rapa and B. napus are used in several countries as forage crops. $B$. oleracea and B. rapa comprise many of the vegetables in our daily diet. Several of these vegetables exhibit high variability in plant morphology, with root, stems, leaves, and terminal or axial buds being sometimes drastically modified (Becker et al., 1999). Brassica oil seed crops (B. napus, B. rapa, B. juncea and B. carinata) have become the world's most important edible oil source after soybean and palm, representing more than $11 \%$ of the global vegetable oil production in 2003 (FAO, 2003).

The cytogenetic relationships amongst the Brassica crops were established in 1935 by the Korean scientist $U$. This author showed that the three diploid species, $B$. nigra $(2 n=16$, genome BB), B. oleracea $(2 n=18$, genome $C C)$ and $B$. rapa $(2 n=20$, genome AA) gave origin, through interspecific hybridisation, to the three amphidiploid species, $B$. napus $(2 \mathrm{n}=38$, genome AACC), $B$. juncea $(2 n=36$, genome AABB), and B. carinata $(2 n=34$, genome BBCC) $(U, 1935)$. $U$ put these species in a triangle to explain their relationships, known after him as "U's triangle" (see Figure 1). Comparative mapping in the Brassica genus has indicated that present-day diploid species are actually derived from hexaploid ancestors and that the chromosomal evolution in Brassicaceae seems to involve a high rate of chromosomal 
rearrangements (Lagercrantz and Lydiate, 1996, Lagercrantz, 1998, Lukens et al., 2003).

Studies on genome organisation are important not only for our understanding of genome function and evolution, but also for the design of strategies for manipulating genomes (Lapitan, 1992, Heslop-Harrison, 2000). Cytogenetic techniques provide important information on genomic relationships based on karyotype and meiotic pairing analyses and on genome organisation at the chromosomal level. Analyses of meiotic pairing were, for example, one of the earliest tools used to assay the relationship between Brassica species (Moringa, 1928-1934, cited by Prakash and Tsunoda, 1980, U, 1935). Fluorescent in situ hybridisation (FISH) offers a powerful system to characterise the organisation of DNA sequences along the chromosomes. This technique has become a primary tool for the identification of chromosomes by using labelled DNA probe to hybridise to denatured DNA of chromosomes spread on microscope slides. A reliable identification of the chromosomes from crop species is important in several areas of plant breeding, as in the characterisation of substitution or addition lines, to assay chromosome variation following in vitro culture and regeneration and to integrate genetic and physical maps. Repetitive DNA sequences have been shown to be very useful for the chromosome identification and characterisation of genomes. Therefore, the investigation of DNA sequences that are repeated many hundred or thousand of times in the genome of crop plants may be a valuable tool for plant breeding. 


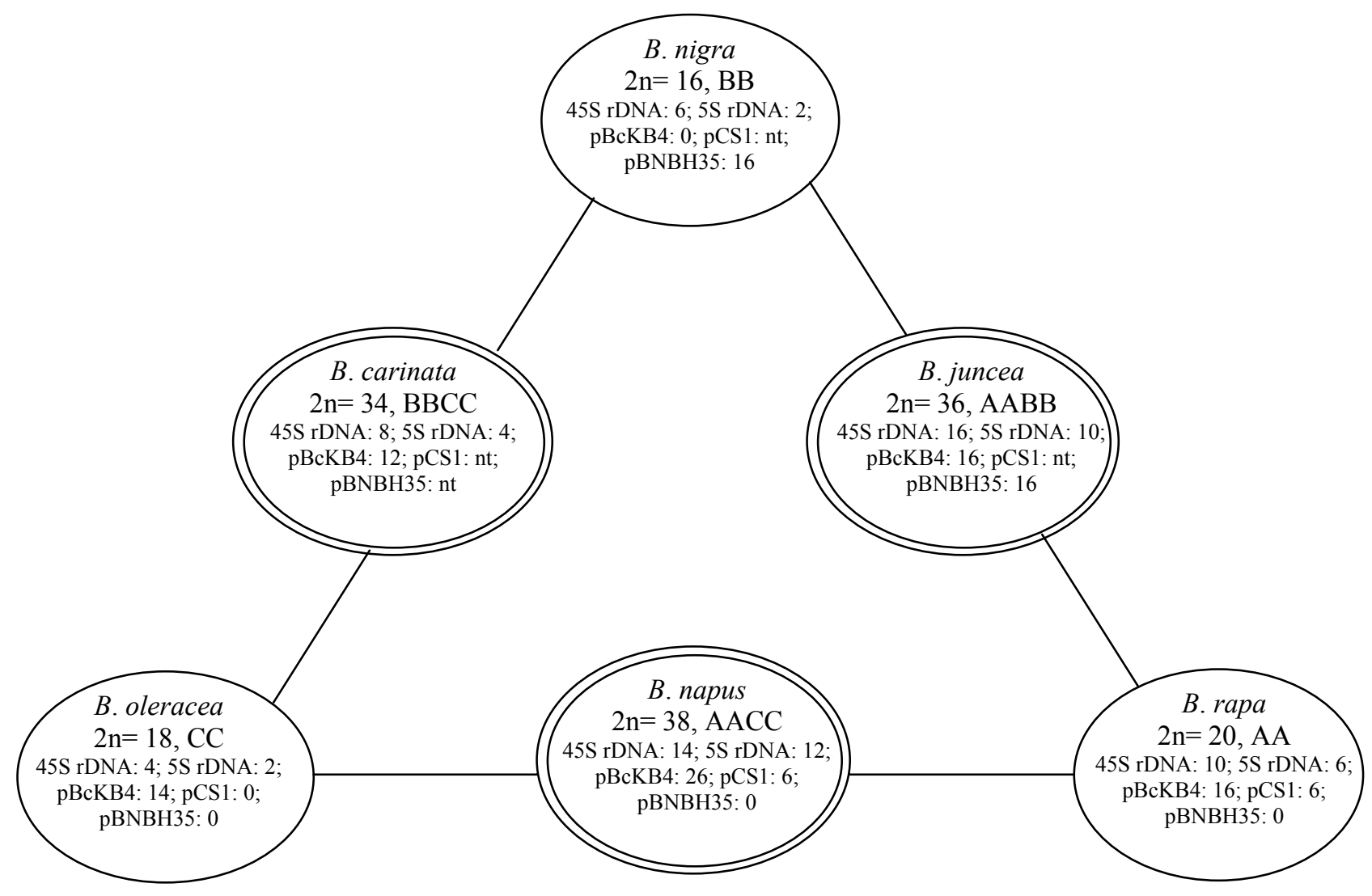

Figure 1. Summary of the relationships among cultivated Brassica species (after U, 1935, modified). The chromosome number, genome designations and number of chromosomes with hybridisation sites for repetitive sequences are given. The repetitive sequences indicated are: $5 S$ and 45S rDNA (Hasterock et al., 2001), HindIII family (for repeat pBcKB4, Harrison and Heslop-Harrison, 1995), B. rapa species-specific repeat pCS1 (Iwabuchi et al., 1991 and Schrader, personal communication) and B. nigra species-specific repeat pBNBH35 (Schelfhout et al., 2004). nt= not tested or not mentioned. 


\subsection{Repetitive DNA sequences in plant genome}

Several studies have shown that low copy sequences are generally conserved in the genomes of related species (e.g. Schmidt, 2002), whereas repeated sequences, that may be closely juxtaposed to such low copy sequences, are more rapidly changed during evolution (e.g. Li et al., 1995, Zhao et al., 1998a, Lapitan, 1992, Schmidt and Heslop-Harrison, 1998). In plants repetitive DNA sequences represent at least $20 \%$ and sometimes more than $90 \%$ of the total genome (Flavell, 1974, 1980).

In order to understand the structure and function of plant genomes, it is necessary to have a clear concept of the nature, topographical arrangements and genetic role of repetitive DNAs. Unlike in animal species, where repeated sequences have been studied since a long time, studies of higher-plant repetitive DNA are increasing in the last years and only in recent publications a detailed characterisation of these sequences, with respect to their features, genomic organisation, chromosomal localisation and evolutionary origins has been performed (e.g. Zhao et al., 1998a, Kubis et al., 1998, Nouzova et al., 1999). The biological function of most repetitive sequences seems to be complex and difficult to elucidate and is still a matter of debate. Although it has been suggested that they play no role (referred therefore as "junk DNA") there is evidence that they may influence different aspects of cell development. While conclusive information about the function of repetitive DNA sequences is rare (e.g. Jasinska and Krzyzosiak, 2004), they may be involved in chromosome movement and pairing, recombination events, regulation of gene expression, determination of chromosome structure, genome response to environmental stimuli and physiological changes, cell proliferation and organism growth (see references in Lapitan, 1992, Xia et al., 1993 and Kubis et al., 1998). Repetitive sequences, in particular tandem arrays, are proposed to play a key role in stabilising DNA packaging and higher-order chromatin condensation (HeslopHarrison, 2000) and were proposed to have a substantial impact on speciation (Bedbrook et al., 1980, Flavell, 1980). The molecular characterisation of repetitive DNA sequences and knowledge about their distribution should provide further insights into the organisation and evolution of plant genomes.

Many types of repetitive DNA sequences exist, some of them are ubiquitously distributed throughout the eukaryotic genomes, like microsatellites and transposable 
elements (Kumar and Bennetzen, 1999, Bowen and Jordan, 2002, Zane et al., 2002). Microsatellites, also denominated as simple sequence repeats (SSR), are one of the most simple repetitive sequences, with only 1-6 bp repeat motifs (Zane et al., 2002). On the other hand, some repetitive sequences have very long repeat units, like the rDNA, that may be 6-40 kb long (Ahuja, 2001). However, a length of 160-180 bp, the extent of sequence wrapped around a single nucleosome, or 320-360 bp, corresponding to dinucleosomes, is frequently found for repeat units of repetitive DNA in both plants and animals (Harrison and Heslop-Harrison, 1995, HeslopHarrison, 2000, Macas et al., 2002).

Individual sequence classes may represent $10 \%$ or even $50 \%$ of a genome (Kubis et al., 1998), but they vary widely in characteristics, like monomer size, GC content, copy number and localisation (see examples in PlantSat, 2004). Genomes of different species, even within the same family, can vary widely in genome size (see e.g. Bennett and Leicht, 1997, Bennett et al., 2000), reflecting the large variation in the proportion of repeated DNA sequences present in their genomes (Flavell, 1974, 1980, Heslop-Harrison, 2000, Ahuja, 2001). A particular sequence may be present in many species within a taxonomic family, or it can exhibit species-, genome- and even chromosome-specificity (e.g. Anamthawat-Jónsson and Heslop-Harrison, 1992, Bournival et al., 1994, Li et al., 1995, Wang et al., 1995, Zhao et al., 1998a, b, Ananiev et al., 2002) indicating that some repetitive sequences evolve rapidly, while others may be conserved.

Repetitive DNA elements in eukaryotic species are not uniformly distributed throughout the genome, some are arranged in tandem whereas others are widely dispersed. In Southern blot hybridisation, dispersed repetitive DNA sequences show hybridisation pattern typically as a smear (e.g. Santini et al., 2002, Shibata and Hizume, 2002, Dechyeva et al., 2003), whereas tandemly repeated sequences give typically a leader-like pattern of hybridisation (see e.g. Li et al., 1995, Houben et al., 2000, Dechyeva et al., 2003). Repetitive sequences, dispersed or tandemly repeated, including species-specific ones, with variable lengths of repeat units, have been extensively documented in plant genomes. A survey of the variety of plant DNA sequences tandemly repeated can be found in PlantSat (2004). 


\subsection{Isolation of repetitive DNA sequences}

Presently the isolation of repetitive sequences, tandemly organised or dispersed in the genome, has been mostly obtained through the screening of plasmid DNA libraries. Normally genomic DNA is used as probe for colony or dot blot filter hybridisations, although satellite DNAs (Cot-1 DNA fraction) have also been utilised (for an example see Houben et al., 2000). In cases where species-specific sequences were searched, genomic DNAs from closely related species were used as probes on replica filters or on one filter with successive rounds of hybridisation. The DNA used to construct the library can be obtained from different sources. Genomic DNAs digested with a restriction endonuclease, or more frequently a specific size fraction of the digestion products, are the most frequent DNA sources. Several repetitive sequences were isolated in this way, for instance from Beta procumbens (Dechyeva et al., 2003), Brassica (Gupta et al., 1990, 1992, Kapila et al., 1996b, Itoh et al., 1991, Iwabuchi et al., 1991), Gossypium (Zhao et al., 1995, 1998a), Helianthus (Santini et al., 2002), Medicago (Calderini et al., 1997), Musa (Valárik et al., 2002) and Vicia faba (Frediani et al., 1999).

Prominent bands visible on agarose gel electrophoresis are very fruitful sources of repetitive DNA. In Vicia faba, for example, Nouzova et al. (1999) have cloned five new repetitive sequences by using DNA extracted from bands visible on agarose gels after digestion of genomic DNA with 34 different restriction enzymes. All newly described sequences were highly specific for $V$. faba, with little or no hybridisation to DNA of other Vicia species, and no hybridisation to DNA of other legumes tested. Several other examples can be found in the literature (e.g. Beta, Schmidt et al., 1991, 1998, Kubis et al., 1997, Crepis capillaris, Jamilena et al., 1993, Ornithogalum longibracteatum, Pedrosa et al., 2001).

In some cases, DNA obtained from chromosomes or chromosomal regions by microdissection were also used to construct plasmid DNA libraries, which were screened for repetitive sequences (e.g. Jamilena et al., 1995, Busch et al., 1995, Hizume et al., 2001, Shibata and Hizume, 2002). In Allium cepa, for instance, samples of chromosome 6 were dissected from metaphase plates and used as template in a DOP-PCR (degenerate oligonucleotide-primed polymerase chain reaction). The DNA obtained after this PCR (amplicon) was utilised to construct a 
DNA library, which was screened for repetitive sequences. Genome-characterising sequences producing GISH (genomic in situ hybridisation)-like signals were isolated and investigated in $A$. wakegi, a natural hybrid between $A$. cepa and $A$. fistulosum. The chromosome organisation of these repetitive DNAs were analysed to gain an understanding of genome evolution in Allium (Shibata and Hizume, 2002).

There are, however, other ways to find repetitive sequences. In Avena sativa, for example, genome-specific repetitive DNA sequences were first identified in a random set of genomic DNA cosmid clones by gel-blot hybridisation, using labelled genomic DNAs from different Avena species as probes (Ananiev et al., 2002). RAPD markers specific for rye (Secale cereale) were identified as repetitive elements related to retrotransposons and could be used in FISH to characterise translocation lines from wheat-rye hybrids (Ko et al., 2002). In the genus Vicia two new families of tandem repeats were isolated by using a modified genomic self-priming PCR, a method that applies the genomic DNA itself as primer for PCR reactions (Macas et al., 2000).

\subsection{Type and chromosomal localisation of repetitive DNA}

Two classes of repeated DNA sequences can be easily recognised, as already mentioned: (1) tandemly repeated sequences, like telomeres and rDNA, and (2) dispersed repeated sequences, constituted mainly by transposable elements and remnants thereof, which can be thoroughly dispersed in the genome or enriched/depleted in some regions of the chromosomes. Intermediate forms of organisation were also found. Notably, telomeres, rDNA and retroelement sequences are all ancient - they are found in animals and plants, and might be considered as early derivatives of the 'RNA-world' from which DNA-based organisms evolved.

\subsubsection{Tandemly repeated sequences}

Tandem repeats consist of short repeat units arranged one after another and clustered in certain chromosomal domains, especially in centromeres and telomeres (Lapitan, 1992, Kubis et al., 1998). Sequences organised in this way were first isolated from genomic DNA by centrifugation, because they may form a distinct band (called "satellite band") separated from the main genomic DNA band in an equilibrium density gradient centrifugation, due to their GC-content which differs from the 
average present in genomic DNA. Therefore, they are known as satellite DNA. Satellite DNAs consist of essentially identical repeating units, but some satellites contain more than one repeated sequence (Flavell, 1980). The lengths of the repeating units in satellite DNAs range from a few base pairs to thousands of base pairs, and the number of such repeats in the chromosomes ranges from a few hundred to over a million without interruption (Flavell, 1980). Satellite DNA is often localised in the constitutive heterochromatin, the permanently condensed and largely inactive portion of the chromatin, which is normally present in both homologous of a chromosome (Flavell, 1980, Avramova, 2002, Grewal and Elgin, 2002). However, satellite DNA in regions other than the heterochromatin was also found (Kamstra et al., 1997, Nouzova et al., 1999).

In plants the heterochromatic chromosomal regions are usually present in the subtelomere/telomere (telomere-associated sequences, TASs), around centromeres and, less frequently, at interstitial sites of the chromosomes. TASs are tandemly repeated sequences of high complexity, they are variable in nature and often exhibit a high variation of copy number even between closely related species or lines and are often species-specific. These repeats vary in length and degree of repetitiveness also between chromosomes in the same genome (see references in Chen et al., 1997 and Zhong et al., 1998).

Since they are closely associated with constitutive heterochromatin such tandemly repeated sequences are assumed to be important for chromosome structure (HeslopHarrison, 2000, Vershinin and Heslop-Harrison, 1998). However, defined functions are only well established for two classes of tandemly organised repeats: the rDNA and telomeric sequences.

\section{Ribosomal RNA genes (rDNA)}

The ribosomal RNA genes (45S and $5 S$ rDNA) encode the structural RNA components of ribosomes. The 45S rDNA loci consist of tandem arrays of repeating units containing the 18S, $5.8 \mathrm{~S}$ and $25 \mathrm{~S}$ rRNA genes and the transcribed and nontranscribed spacers, each unit being ca. $10 \mathrm{~kb}$ long in most plants. Hundreds or thousands of copies of these repeat units may be present, together representing up to ca. $10 \%$ of the genome (Heslop-Harrison, 2000). As a rule, $45 S$ rDNA sequences are markers for the nucleolus organiser region (NOR), visible in mitosis as a 
secondary constriction, whereas the $5 S$ rDNA can be localised elsewhere in the genome. In some cases sites of 5S rDNA colocalise with those of 45S rDNA sequences. Loci for $45 \mathrm{~S}$ rDNA are also found in chromosomes without secondary constriction. The rRNA genes are localised at one or more sites (loci) per chromosome set. The characteristic position of these genes along the chromosomes provides useful markers for chromosome identification (see section 1.4). The units themselves are highly conserved, and probes isolated originally from wheat can be used to localise the 45S and 5S rRNA genes in most eukaryotic species. Changes in chromosomal distribution of the units generally correlate with the rates of speciation, and they have been used to examine evolutionary relationships between related species (see section 1.4).

\section{Telomeric sequences}

Telomeres, the nucleoprotein structure localised at the very ends of eukaryotic chromosomes, play a critical role in maintaining chromosomal stability and function. The telomeric sequences, at the ends of most plant and animal chromosomes, allow a linear replication unit to be maintained, protect chromosome ends and overcome the 'end replication problem' (ends of linear DNA cannot be replicated completely during DNA synthesis, and chromosomes will naturally shorten with each successive round of DNA replication if no mechanism to avoid that is available). In addition to stabilising chromosomes, telomeres are proposed to play important roles in nuclear architecture and chromosome organisation (Biessmann and Manson, 1997, Pardue and DeBaryshe, 1999, McKnight et al., 2002, Riha and Shippen, 2003).

Telomere repeats are remarkably conserved among eukaryotes, and sequence variation among most of the major taxonomic groups does not exceed one or two nucleotides ( $\mathrm{Li}$ et al., 2000). Angiosperm telomeric DNA was first isolated from Arabidopsis thaliana by Richards and Ausubel (1988), who showed that Arabidopsis telomeres consisted of repeats of a 7-bp motif, the 5'-TTTAGGG-3'. Since then it has been shown that the majority of plant species possess the Arabidopsis-type telomeric sequences at the chromosome ends, however repeat array length varies significantly among plants and even between different strains and different chromosomes within a species (Richards, 1995, Fuchs et al., 1995, Vershinin and Heslop-Harisson, 1998, Zhong et al., 1998), e.g. from 2-5 kb in A. thaliana (Richards and Ausubel, 1988), to 13-223 $\mathrm{kb}$ in tomato (Zhong et al., 1998). The presence of telomeric repeats at 
nontelomeric locations has been detected in a variety of species, and in several cases this is associated with chromosome fusion-fission processes that occurred during evolution (Richards et al., 1991, Richards, 1995, Fuchs et al., 1995).

The Arabidopsis-type telomeric sequence was initially thought to be ubiquitous in plants, with the family Alliaceae being the only exception (Fuchs et al., 1995, Pich and Schubert, 1998). However, recently plants from several monocot genera (Adams et al., 2000a, 2001, Weiss and Scherthan, 2002, Sýkoravá et al., 2003b, WeissSchneeweiss et al., 2004) and in three dicotyledonous species, Cestrum, Vestia and Sessea (Sykorava et al., 2003a), were reported as lacking the TTTAGGG repeat. In several cases the typical Arabidopsis-type telomeric sequence has been partially or fully replaced by the human type telomeric sequence (TTAGGG) (Sýkoravá et al., 2003b). This was, however, not the case in Allium cepa (Sýkoravá et al., 2003b). In this species a satellite DNA repeat, and possibly rDNA or transposon-like sequences, represent the most probable candidate sequences that may have acquired telomeric function(s) (Pich and Schubert, 1998).

\subsubsection{Dispersed repeated sequences - Transposable elements}

Transposable elements (TEs) are discrete segments of DNA that are distinguished by their ability to move and replicate within genomes. These sequences have been found in all genomes in which they have been sought and are ubiquitous in plants. TEs play a major role in plant gene and genome evolution, they contribute substantially to the structure, size and variability of plant genomes. TEs can comprise over $50 \%$ of the nuclear DNA content in many higher plants with large and complex genomes (Kumar and Bennetzen, 1999, Kidwell, 2002). In eukaryotes, TEs have been divided into two broad categories, depending on their mode of transposition. Class 1 (RNA) elements move via an RNA intermediate, which is reverse transcribed prior to its integration into the genome. RNA elements, widely known as retrotransposons, have either long terminal repeats (LTR retrotransposons) or terminate at one end with a poly $(A)$ tract (non-LTR retrotransposons: long and short interspersed nuclear elements- LINEs and SINEs, respectively). LTR retrotransposons have been further classified as either Ty1/copia-like or Ty3/gypsylike elements, based on the order of their encoded proteins that include a reverse transcriptase and integrase required for reverse transcription and integration. Class 2 (DNA) elements move via a DNA intermediate, by a cut-and-paste mechanism. They 
are flanked by terminal inverted repeats and have subterminal repeated sequence motives, that are essential for their autonomous activity, whereas proteins encoded by the internal part of the element, for example transposase, may also be provided by independent transposon copies in trans. Based on the similarity of the transposases, the proteins that catalyse transposition and integration, DNA transposons have been grouped into superfamilies like Tc/mariner, hAT, Enhancer/Supressor-mutator(En/Spm), Mutator- (Mu) and PIF/Pong elements (see references in Staginnus et al., 2001 and Zhang and Wessler, 2004).

Retrotransposons, or their remnants, represent a major fraction of interspersed repetitive DNA in eukaryotes, especially in plant species. Their amplification and dispersion contributed to genomic plasticity, perhaps allowing plants the adaptive response to environmental stresses made necessary by their inability to move (Kumar and Bennetzen, 1999).

\subsection{Repetitive DNA sequences as cytogenetic tools}

Repetitive sequences can assist in the construction of a karyotype with unambiguous identification of chromosomes, a requirement for the integration of genetic and physical maps.

$45 S$ and $5 S$ rDNA sequences have since a long time been used as markers for chromosome identification, improving the construction of karyotypes of several plant species (e.g. Picea glauca, Brown et al., 1993, Beta vulgaris, Schmidt et al., 1994, Pinacea, Lubaretz et al., 1996, Phaseolus, Moscone et al., 1999, Nicotiana, Kitamura et al., 2000, Lilium, Lim et al., 2001). Together with information about chromosome length and centromere position these sequences can characterise the chromosome complement of some species with small numbers of chromosomes like Arabidopsis thaliana $(2 n=10$, Murata et al., 1997) and barley $(2 n=14$, Brown et al., 1999). The rDNA genes were also useful to gain insights into the phylogeny and chromosomal evolution of different groups of species, e.g. Hordeum (Molnar et al., 1989), Triticum (Jiang and Gill, 1994), Vicia (Raina and Ogihara, 1995, Raina et al., 2001), Allium (Lee et al., 1999), Aloe (Adams et al., 2000b), Clivia (Ran et al., 2001), and Passiflora (de Melo and Guerra, 2003). Actually, the repetitive DNA sequences most 
widely used for chromosome identification and analyses of phylogeny and chromosomal evolution, both in plants and animals, are the rDNA genes.

Apart from the rDNA repeats, other repetitive DNAs have also been used as tools for the identification of chromosomes in different species, e.g. rye (Cuadrado et al., 1995), maize (Chen et al., 2000a, b, Sadder and Weber, 2001), pea (Neumann et al., 2001), lentil (Galasso et al., 2001) and Vicia (Navrátilová et al., 2003). In norway spruce, for example, the chromosomes are metacentric and the identification of homologous pairs is hampered by similar length and only slight differences at the morphological level. Vischi et al. (2003) were able to construct an unambiguous karyotype for this species by using three repetitive DNA sequences as probes in FISH combined with chromosome measurements.

The potential to characterise specific chromosomes makes repetitive sequences also very useful for the analyses of transgenic plants. Traditionally these plants are characterised using phenotypic and Southern analyses, but FISH has been efficiently used for visualisation, chromosomal localisation and estimation of numbers of transgene loci in transgenic plants (see for example Moscone et al., 1996, Dong et al., 2001, Snowdon et al., 2001). Recent results obtained in transformed plants from different species indicate that FISH, using the transgene sequence together with repetitive sequences as probes, is also a powerful tool for characterisation of transgene locus structure that significantly augments conventional Southern analysis in the evaluation of transgene plant material (Fransz et al., 1996, Svitashev et al., 2000, Jin et al., 2002, Kohli et al., 2003).

Karyotypic analysis using cloned repetitive sequences has been shown to be a powerful approach to the study of phylogeny and has some advantages over molecular studies based on sequence data, as it examines evolutionary changes over several different loci with little or no sequence similarities, and with potentially independent evolutionary constraints and cellular function (Lim et al., 2000). The analysis of a great number of repetitive sequences in the genome of related species can provide important informations concerning their relatedness. In the genus Nicotiana, for example, ten repetitive sequences, including the rRNA genes, some satellite DNAs and sequences related to geminiviral DNA, were used to establish a hypothesis about the phylogenetic relationships in this group (Lim et al., 2000). The analysis of the chromosomal distribution of these sequences in different species 
allowed the characterisation of chromosomes, the identification of homeologous chromosomes and the construction of a phylogenetic tree for this genus.

Moreover, repetitive sequences are useful for studying the behaviour of plant genomes. Polyploidization, for instance, has played a major role in the evolution of many plant species like tobacco, cotton, and wheat. However, little is known regarding the subsequent evolution of DNA sequences after being combined in a common nucleous. Such subsequent processes were analysed in the polyploid cotton (Gossypium barbadense L., AD genome) by using several dispersed repetitive sequences specific to Old World (A genome) and New World ( $D$ genome) diploid ancestors (Zhao et al., 1998b). The presence of (otherwise) A genome specific repetitive sequences in the $D$ genome of $G$. gossypioides and in the polyploid $G$. barbadense provided genome-wide support for the proposal that this diploid species, rather than its sister species $G$. raimondii, may be the closest living descendent of the New World D genome cotton ancestor (Zhao et al., 1998a, b).

A clear utility of repetitive DNA sequences in plant breeding is in the detection of chromatin introgression following sexual or somatic hybridization, especially in the form of chromosome addition lines, at a very early stage of development (e.g. Triticeae, Anamthawat-Jónsson and Heslop-Harrison, 1992, Bournival et al., 1994, Solanaceas, see references in Rokka et al., 1998, Medicago, Calderini et al., 1997, rye-wheat hybrids, Ko et al., 2002). Cao and Sleper (2001), for example, have successfully used the TF436 genome-specific repetitive DNA sequence in Southern blot hybridisation to monitor chromatin introgression from Festuca mairei into Lolium perenne.

GISH is one of the most popular and effective techniques for detecting alien chromatin introgression into breeding lines, however GISH analysis alone does not reveal the genetic identity of the alien chromosomes, whereas repetitive sequences that identify individual chromosomes can do.

Repetitive sequences may also be useful for other aims, as analyses of meiotic behaviour in hybrids (e.g. Jenkins et al., 2000), analyses of somaclonal variation caused by in vitro culture (e.g. Kubis et al., 2003), to study structural alterations, such as amplification and interchanges in chromosomes (see references in Rokka et al., 1998). 
Repetitive sequences are frequently used as probe in Southern or in situ hybridisations, but they can also be transformed to PCR based markers, depending on the nature of the sequence and the objective of the study.

\subsection{Molecular cytogenetics of Brassica species}

Detailed cytogenetic analyses of Brassica species have been severely hindered by the small size and uniform morphology of their chromosomes. However, the development of molecular cytogenetics, allowing a better characterisation of chromosomes with small size and limited morphological differentiation, has opened the opportunity to better characterise the genome of Brassica crops at the cytological level. In the past 10 years in situ hybridisation has been successfully applied in Brassica species by using single and repetitive sequences as well as total genomic DNA as probes.

The genome structure of the amphidiploid species from the "U's triangle" was analysed by GISH, applying genomic DNA from $B$. nigra, $B$. oleracea or $B$. rapa as a probe (Snowdon et al., 1997a, Bellin and dos Santos, 2002). The B genome was successfully differentiated from the $A$ and $C$ genomes in $B$. juncea and $B$. carinata, however, the differentiation of the $A$ and $C$ genomes in $B$. napus failed, due to the high degree of cross-hybridisation between the chromosomes and the genomic DNA of both genomes. GISH was also used to identify donor chromatin in hybrids between B. napus and Eruca sativa (Fahleson et al., 1997), Raphanus sativus (Snowdon et al., 1997a, 1999), Lesquerella fendleri (Skarzhinskaya et al., 1998), Sinapis arvensis (Snowdon et al., 2000b), synthetic rapeseed (B. carinata x B. rapa) (Li et al., 2004), Crambe abyssinica (Wang et al., 2004). In all these studies, the addition of donor chromosomes to the $B$. napus genome was successfully assessed by GISH, but only in few cases intergenomic translocations could be detected (Snowdon et al., 1999, Skarzhinskaya et al., 1998), although Southern blot hybridisation had revealed the presence of donor DNA also in hybrids with only 38 chromosomes (Skarzhinskaya et al., 1998). A small amount of donor DNA, probably too small to be detected by GISH, was given as possible reason for the absence of a GISH signal in the hybrids. However, the fact that Brassica chromosomes are frequently labelled only at the centromeric regions after $\mathrm{GISH}$, which would hamper the detection of small 
translocations in the distal regions of the chromosome arm, may also have contributed for the failure to detect alien DNA.

Besides the analysis of genome structure of the amphidiploid species and hybrids, analyses of genome evolution in Brassica were performed by using Arabidopsis BAC clones as FISH probe in B. rapa, an approach called comparative FISH mapping (Jackson et al., 2000). The results found by these authors, i. e. chromosomal duplication playing the major role in the evolution of the $B$. rapa genome, supported the hypothesis that Brassica diploids are secondary polyploids, as indicated by comparative genetic mapping results (Lagercrantz and Lydiate, 1996, Lagercrantz, 1998) and by cytogenetic analyses (Röbbelen, 1960, Armstrong and Keller, 1981, 1982).

In situ hybridisation has also been applied to localise repetitive and even single copy sequences on Brassica chromosomes. In B. rapa and B. napus, single copy genes from the self-incompatibility locus were visualised by FISH (Iwano et al., 1998, Kamisugi et al., 1998). In B. oleracea var. alboglabra an integration between the cytogenetic and linkage maps was performed by using FISH with different combinations of probes containing Brassica DNA sequences that have been genetically mapped (Howell et al., 2002). Most of the probes were large genomic DNA fragments inserted in bacterial artificial chromosomes (BACs) and required the use of repetitive DNA (Cot-1 DNA fraction) to reduce nonspecifc hybridisation. The use of such an approach for the localisation of a DNA sequence that cannot readily be mapped by genetic studies can be very time consuming. Several rounds of FISH, increasing the chance to loose important cells, may be required in some situations to identify the chromosome where the target sequence is localised. The availability of one or a few repetitive sequences, able to identify all the chromosomes, would be a simpler alternative for this purpose. Moreover, repetitive probe(s) from $A$ and $C$ genome should be more easily assigned to $B$. napus chromosomes.

Concerning the repetitive sequences analysed in Brassica crops, the localisation of rRNA genes, especially the 45S rDNA cistrons, has been reported by different authors (Maluszynska and Heslop-Harrison, 1993, Snowdon et al., 1997b, 2000a, 2002, Fukui et al., 1998, Armstrong et al., 1998, Hasterock and Maluszyska 2000a, b, Hasterock et al., 2001, Schrader et al., 2000, Ziolkowiski and Sadowski, 2002). In Figure 1 the number of rDNA loci in Brassica species from the "U's triangle" is 
indicated. The number and distribution of rDNA in the chromosomes of these Brassica species is highly variable. Furthermore, the number of rDNA loci of amphidiploid species is not always equal to the sum of loci in the ancestral species (Maluszynska and Heslop-Harrison, 1993, Snowdon et al., 1997b, Hasterock and Maluszyska 2000a) and intraspecific variation for the number of rRNA genes loci seems to exist (e.g. Armstrong et al., 1998, Ziolkowiski and Sadowski, 2002).

The identification, and in few cases the chromosomal localisation, of other repetitive DNA sequences has also been reported for Brassica crops. So far, only in B. napus a transposon-like DNA, the S1 SINE retrotransposon, has been localised by FISH (Goubely et al., 1999), although several transposon-like sequences have been identified in the genome of $B$. oleracea by database comparison (Zhang and Wessler, 2004). A highly repeated HindIII DNA sequence family was identified in the early 80ths and repeats from this family were isolated several times from Brassica species with the $A$ and $C$ genomes (Benslimane et al., 1986, Reddy et al., 1989, Harbinder and Lakshmikumaran, 1990, Lakshmikumaran and Ranade, 1990, Xia et al., 1993, 1994, Harrison and Heslop-Harrison, 1995). Harrison and Heslop-Harrison (1995) studied a representative of this family in the three diploid species and in their amphidiploids through Southern blot and in situ hybridisations. They found that this satellite DNA was present on a different number of chromosomes in $B$. rapa and $B$. oleracea (indicated in Figure 1), but was absent from the B. nigra genome. Xia et al. (1993), however, found a small amount of this sequence in the $B$. nigra genome through Southern blot hybridisation. Differences in the hybridisation procedure were appointed as responsible for this discrepancy (Harrison and Heslop-Harrison, 1995).

Five other repetitive sequences, one tandemly repeated (pBN34) and four dispersed (pBNBH35, pBNMbo5, pBN4, pBNE8), have been isolated from the $B$. nigra genome (Gupta et al., 1990, 1992, Kapila et al., 1996b). Southern blot hybridisations with different members of the Brassicacea were performed with these repeated DNA sequences. Two of them, pBNBH35, and pBN4, were found to be absent from the A and $C$ genome in high stringency hybridisations, but hybridised to Sinapis arvensis DNA, showing that $B$. nigra has a closer relationship with the $S$. arvensis genome than with $B$. oleracea and $B$. rapa, which is in agreement with other studies (Prakash and Hinata, 1980, Song et al., 1988). Recently, one of these five $B$. nigra repetitive DNA sequences was analysed by FISH (Schelfhout et al., 2004). The subfragment of 
pBNBH35 used as FISH probe in Brassica crops with the A, B and C genomes hybridised at the centromeric/pericentromeric regions of all $B$ genome chromosomes, but was absent from $\mathrm{A}$ and $\mathrm{C}$ genome chromosomes.

In $B$. rapa, Iwabuchi et al. (1991) isolated a repetitive sequence, the pCS1, which was completely absent from the genome of the closely related $B$. oleracea. Using radioactive in situ hybridisation (ISH), this $A$ genome specific sequence was localised at the centromeric regions of three pairs of $B$. rapa chromosomes. Itoh et al. (1991) used a variant form of pCS1, the $\mathrm{pCT} 10$, for ISH. This variant contains an additional sequence that hybridised also with $B$. oleracea DNA in Southern blots, but was specific for the A genome at the chromosomal level. By using a mixture of pCS1 and PCT10 as ISH probe four pairs of $B$. rapa chromosomes could be identified and the asymmetric nature of $B$. rapa/B. oleracea somatic hybrids could be demonstrated.

\subsection{Objectives}

The objectives of this work were to find repetitive sequences able to differentiate at the chromosomal level the highly homeologous $A$ ( $B$. rapa) and $C$ (B. oleracea) genomes of Brassica in order to assist in the physical identification of $B$. napus chromosomes. For these purpose $C$ genome specific repetitive sequences, tandemly organised or dispersed in the genome, were searched in genomic DNA libraries of $B$. oleracea. Selected sequences were analysed in the genome of $B$. oleracea, $B$. rapa and $B$. napus by Southern blot and fluorescent in situ hybridisations, and their sequences were compared with DNA databases.

The discovery of repetitive sequences specific to the $C$ genomes of Brassica, besides providing information on chromosome and genome evolution in this group, might allow the identification of some or all $C$ genome chromosomes from $B$. napus. The ability to identify the chromosomes in $B$. napus is not only important for the future integration of genetic and physical maps, but also for the genomic localisation of transgene inserts in genetically transformed oilseed rape. 


\section{Plant Materials}

The Brassica species and cultivars used in this work, with their genome composition, source and accession number, are listed in Table 1.

Table 1. Plant material.

\begin{tabular}{|c|c|c|c|c|}
\hline Species & Subspecies & Cultivar & Genome (2n) & accession \\
\hline \multirow[t]{4}{*}{ B. oleracea } & italica & Vitamina & CC (18) & IPK ${ }^{a} / \mathrm{BRA} 1425 / 77$ \\
\hline & capitata & Market Victor & & $\mathrm{IPbPz}$ / 2457 \\
\hline & oleracea & & & IPbPz/ 3507 \\
\hline & alboglabra & & & IPbPz/ 165/83 \\
\hline B. incana & & & CC (18) & $\mathrm{IPbPz} / 61$ \\
\hline \multirow[t]{3}{*}{ B. rapa } & & NPZ-35* & $\mathrm{AA}(20)$ & $\mathrm{NPZ}{ }^{\mathrm{c}}$ \\
\hline & & Perko & AAAA $(40)$ & $\mathrm{KWS}^{\mathrm{d}}$ \\
\hline & & $\operatorname{Rex}$ & $\mathrm{AA}(20)$ & NPZ \\
\hline \multirow[t]{3}{*}{ B. napus } & & Express & AACC (38) & NPZ \\
\hline & & Iris & & NPZ \\
\hline & & Jockey & & NPZ \\
\hline B. nigra & & & $\mathrm{BB}(16)$ & IPK/ CR 2093/79- BRA 21 \\
\hline B. juncea & & & AABB (36) & IPK/ CR 2425/82- BRA 57 \\
\hline B. carinata & & & $\mathrm{BBCC}(34)$ & IPK/ BRA 489/77 \\
\hline
\end{tabular}

*breeding material from $\mathrm{NPZ}{ }^{\mathrm{C}}$

${ }^{a}$ IPK- Institut für Pflanzengenetik und Kulturpflanzenforchung, Gatersleben

${ }^{\mathrm{b}} \mathrm{IPbPz}$ - Institut für Pflanzenbau und Pflanzenzüchtung, Göttingen

${ }^{\mathrm{c}}$ Norddeutsche Pflanzenzucht Hans-Georg Lembke KG

${ }^{\mathrm{d}}$ KWS Saat AG 


\section{Methods}

\subsection{Plant DNA extraction and quantification}

Plant genomic DNA was isolated using a CTAB-extraction method modified from Rogers and Bendich (1988) (Section 3.1.1). The DNA concentration was measured with a Bio-Rad VersaFluor ${ }^{\mathrm{TM}}$ Fluorometer (Bio-Rad Laboratories, CA, USA) (Section 3.1.2).

\subsubsection{Plant DNA extraction}

- 5-10 $\mathrm{g}$ of fresh or frozen young leaf material was grounded with liquid nitrogen to a fine powder.

- $10 \mathrm{ml}$ of warm $\left(65^{\circ} \mathrm{C}\right) 2 \times$ CTAB buffer and proteinase $\mathrm{K}$ (final concentration 100 $\mu \mathrm{g} / \mathrm{ml}$ ) was added to the homogenate, mixed well and incubated under agitation for $30 \mathrm{~min}$ at $65^{\circ} \mathrm{C}$.

- One volume of chloroform/isoamyl alcohol (24:1) was added to the homogenate in a $50 \mathrm{ml}$ centrifuge tube, mixed well and the solution was centrifuged for $10 \mathrm{~min}$ at $4^{\circ} \mathrm{C}$ and $12000 \mathrm{rpm}$ (Sigma centrifuge 4K 10, rotor n. 12166).

- The aqueous phase was transferred to a new $50 \mathrm{ml}$ tube and $1 / 10$ volume of $10 \%$ CTAB solution was added.

- One total volume of chloroform/isoamyl alcohol (24:1) was added and carefully mixed well.

- The mixture was centrifuged for $10 \mathrm{~min}$ at $4^{\circ} \mathrm{C}$ and $12000 \mathrm{rpm}$ and the aqueous phase was again transferred to a new $50 \mathrm{ml}$ tube.

- One volume of warm $\left(65^{\circ} \mathrm{C}\right)$ CTAB precipitation buffer was added and carefully, but thoroughly mixed.

- The CTAB-DNA complex was pelleted by centrifugation for $10 \mathrm{~min}$ at $20^{\circ} \mathrm{C}$ and $12000 \mathrm{rpm}$ and resuspended in $2 \mathrm{ml}$ warm $\left(65^{\circ} \mathrm{C}\right)$ High salt TE buffer.

- The DNA was precipitated with 2 volume of cold $96 \%(\mathrm{v} / \mathrm{v})$ alcohol, mixed well but carefully and stored at $-20^{\circ} \mathrm{C}$ overnight.

- The DNA solution was centrifuged for $15 \mathrm{~min}$ at $4^{\circ} \mathrm{C}$ and $12000 \mathrm{rpm}$ (Biofuge, rotor n. 3754, Heraeus, Hanau) and the pellet was washed with $70 \%$ (v/v) alcohol, 
recentrifuged for $5 \mathrm{~min}$ and dried in an excicator before resuspension in $1 \mathrm{ml} 1 \mathrm{x}$ TE buffer with RNAse $(10 \mu \mathrm{g} / \mathrm{ml}) 1 \mathrm{~h}$ at $37^{\circ} \mathrm{C}$.

- The DNA solution was stored at $4-6^{\circ} \mathrm{C}$ until use.

Solutions used in plant DNA extraction:

2x CTAB buffer

$10 \%$ CTAB solution

CTAB precipitation buffer

High salt TE buffer

10x TE buffer stock solution

$$
\begin{aligned}
& 100 \mathrm{mM} \text { Tris- } \mathrm{HCl}(\mathrm{pH} 8) \\
& 20 \mathrm{mM} \text { EDTA } \\
& 1.4 \mathrm{M} \mathrm{NaCl} \\
& 1 \%(\mathrm{w} / \mathrm{v}) \text { PVP } 40000 \\
& 2 \%(\mathrm{w} / \mathrm{v}) \text { CTAB }
\end{aligned}
$$

$10 \%(w / v)$ CTAB

$0.7 \mathrm{M} \mathrm{NaCl}$

$50 \mathrm{mM}$ Tris- $\mathrm{HCl}(\mathrm{pH} \mathrm{8)}$

$10 \mathrm{mM}$ EDTA

$1 \%(w / v)$ CTAB

$10 \mathrm{mM}$ Tris- $\mathrm{HCl}(\mathrm{pH} \mathrm{8)}$

$1 \mathrm{mM}$ EDTA

$1 \mathrm{M} \mathrm{NaCl}$

$100 \mathrm{mM}$ Tris- $\mathrm{HCl}(\mathrm{pH} 8)$

10 mM EDTA

\subsubsection{Measurement of DNA concentration}

- Bio-Rad VersaFluor ${ }^{\mathrm{TM}}$ Fluorometer (Bio-Rad Laboratories, CA, USA) was used.

- The fluorometer was switched on 20 min before use.

- The gain was set to MED (medium) and the rage adjusted to read 00000.

- $2 \mathrm{ml}$ of Hoechst working solution was added to 7 cuvettes (all solutions had room temperature before measurement). 
- A standard curve was set up by adding 1000, 500, 200, 100, 50, 20 and 0 ng (blank) standard DNA, respectively to the seven $2 \mathrm{ml}$ cuvettes.

- The instrument was zeroed with the blank cuvette and after 5-10 seconds the range of the instrument was set to 1000 with the highest concentration cuvette (1000).

- The cuvette with 500 ng standard DNA was placed into the instrument and after 5-10 seconds the relative fluorescence unit (RFU) was recorded.

- The former step was repeated until all standard samples were read. After determination of standard curve sample DNAs were measured by adding and mixing $2 \mu$ of the DNAs to a cuvette with $2 \mathrm{ml}$ of Hoechst working solution.

- The cuvette with the sample DNAs were placed into the instrument and after 5-10 seconds the relative fluorescence unit (RFU) was recorded.

- The sample concentration was determined by comparing its relative fluorescence unit values with the standard curve and by dividing the result by the volume of the DNA solution added to the cuvette.

Solutions used for measurement of the DNA concentration:

10x TEN buffer stock solution

$100 \mathrm{mM}$ Tris

$2 \mathrm{M} \mathrm{NaCl}$

10 mM EDTA

$\mathrm{pH} 7.4$

Hoechst 33258 stock solution

$1 \mathrm{mg} / \mathrm{ml}$ Hoechst 33258 dye in sterile (store in the dark at $4^{\circ} \mathrm{C}$ ) water

Hoechst work solution

$0.1 \mathrm{mg} / \mathrm{ml}$ Hoechst 33258 dye in 1x TEN

(store in dark)

Standard DNA

Calf thymus DNA at $100 \mu \mathrm{g} / \mathrm{ml}$ and 10 $\mu \mathrm{g} / \mathrm{ml}$ in $1 \times$ TEN buffer 


\subsection{Phage libraries construction}

The Phage libraries were constructed using the "ZAP Express ${ }^{R}$ Predigested Vector Kit" and "ZAP Express ${ }^{R}$ Predigested Gigapack ${ }^{R}$ Cloning Kit", digested with EcoRI from the company Stratagene (Europe).

Genomic DNA from B. oleracea italica was digested with the enzyme Tsp509I, a fourbase cutting enzyme that produces ends compatible to EcoRI, fractionated on a $1.5 \%$ $(w / v)$ agarose gel and DNA size fractions were eluted from the gel (Section 3.2.1). Three libraries were constructed inserting $250 \mathrm{ng}$ of digested B. oleracea DNA into the EcoRI site of the lambda phage vector: Library 1 with a DNA fraction of 200-1000 bp; Library 2 with a fraction of 1000-2000 bp; and Library 3 with unfractionated total DNA digested with Tsp509I (Section 3.2.2).

\subsubsection{DNA digestion and fractionation}

- $100 \mu \mathrm{g}$ of $B$. oleracea italica was digested overnight with Tsp509l (3U/ $\mu \mathrm{g})$, in appropriate buffer, at $65^{\circ} \mathrm{C}$.

- Digested DNA was precipitated with 0.1 volume of $3 \mathrm{M} \mathrm{NaAc}, \mathrm{pH} 5.2$, and 2.5 volume of $96 \%(\mathrm{v} / \mathrm{v})$ cold ethanol for $1 \mathrm{~h}$ at $-70^{\circ} \mathrm{C}$.

- The precipitated DNA was centrifuged for $30 \mathrm{~min}$ at $13000 \mathrm{rpm}$ (Biofuge, rotor $\mathrm{n}$. 3754, Heraeus, Hanau), washed with cold $70 \%$ (v/v) ethanol, centrifuged $15 \mathrm{~min}$ at $13000 \mathrm{rpm}$, dried in an exsiccator and redissolved in $20 \mu \mathrm{l} \mathrm{TE}$ buffer for $4 \mathrm{~h}$ at $45^{\circ} \mathrm{C}$.

- To isolate DNA fractions, the redissolved DNA was loaded on a $1.5 \%(\mathrm{w} / \mathrm{v})$ agarose gel, run for $1 \mathrm{~h}$, at $90 \mathrm{~V}$, in TAE buffer and stained with ethidium bromide $(1 \mu \mathrm{g} / \mathrm{ml}$ in water) for $30 \mathrm{~min}$.

- DNA fractions between 200-1000 bp and 1000-2000 bp were excised from the gel and eluted using the E.Z.N.A. gel extraction kit from PeqLab, following supplier's instructions. 


\subsubsection{DNA ligation in phage lambda and packaging of DNA}

Ligation of insert DNA and packaging of DNA were carried out according to the protocols provided in the Instruction Manual from "ZAP Express ${ }^{\mathrm{R}}$ Predigested Vector Kit" and "ZAP Express ${ }^{\mathrm{R}}$ Predigested Gigapack ${ }^{\mathrm{R}}$ Cloning Kit", Stratagene (Europe).

\subsection{Plasmid library construction}

The plasmid library was constructed using the pUC19 plasmid vector digested with EcoRI (MBI Fermentas, St. Leon-Rot). Total DNA or a DNA fraction ranging from 1000 to $2000 \mathrm{bp}$ from B. oleracea italica genomic DNA digested with the enzyme Tsp509I (Section 3.2.1) was ligated to pUC19 (Section 3.3.1). With the ligation, competent $E$. coli cell of strain XL1 were transformed by electroporation and cells were plated on appropriate medium (Sections 3.3.2 and 3.3.3). To extend the total DNA library the ligation and transformation were later repeated with unfractionated total DNA. A total of 205 recombinant white colonies from the fractionated library and 959 from the total DNA library (212 from the first ligation and 747 from the second ligation) were transferred with toothpicks to $\mathrm{YT}$-ampicillin $(60 \mu \mathrm{g} / \mathrm{ml})$ medium and grow overnight. A sample of $350 \mu \mathrm{l}$ from each clone was stored at $-20^{\circ} \mathrm{C}$ after adding glycerol to a final concentration of $15 \%(\mathrm{v} / \mathrm{v})$.

\subsubsection{DNA ligation in plasmid vector}

- The following components were added to a $1.5 \mathrm{ml}$ reaction tube:

$250 \mathrm{ng}$ of DNA digested with the enzyme Tsp509l (total DNA or 1-2 kb factioned DNA) from $B$. oleracea italica

$0.5 \mu$ of pUC19 (500 ng/ul, MBI Fermentas, St. Leon-Rot)

$1.5 \mu \mathrm{l} 10 \mathrm{x}$ ligase buffer (Stratagene, Europe)

$1.5 \mu \mathrm{l} 10 \mathrm{mM}$ rATP $(\mathrm{pH} 7.5)$

Water to a final volume of $14.5 \mu \mathrm{l}$

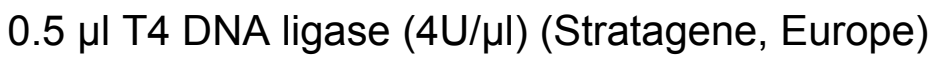

- Components were mixed, spun and incubated overnight at $20^{\circ} \mathrm{C}$.

- T4 DNA ligase was inactivated by heating to $65^{\circ} \mathrm{C}$ for $10 \mathrm{~min}$ and the ligation mixture was purified using a QIAprep column (Qiagen, Hilden), according to the 
manufacturer's specifications for purification of plasmid DNA prepared by other methods.

\subsubsection{Preparation of competent E. coli}

- LB agar plate containing tetracycline $(12.5 \mu \mathrm{g} / \mathrm{ml})$ was inoculated with $E$. coli XL1 and incubated overnight at $37^{\circ} \mathrm{C}$.

- From a single colony $4 \mathrm{ml}$ LB-tetracycline $(12.5 \mu \mathrm{g} / \mathrm{ml})$ liquid medium was inoculated and incubated for $5-8 \mathrm{~h}$, at $37^{\circ} \mathrm{C}$ under vigorous shaking.

- $400 \mathrm{ml}$ LB was inoculated with the $4 \mathrm{ml}$ of bacterial culture and incubated at $37^{\circ} \mathrm{C}$ under vigorous shaking until the $\mathrm{OD}_{600}$ was at 0.5-0.9 (from here on buffer, tips, tubes, rotors, etc were kept ice-cold).

- The bacterial culture was than chilled in ice-water for 15-30 min followed by centrifugation at $4^{\circ} \mathrm{C}$, at $3000 \mathrm{rpm}$ (Sigma centrifuge $4 \mathrm{~K} 10$, rotor $\mathrm{n}$. 12254), for 15 min to collect the bacteria.

- The bacterial pellet was carefully resuspended in $400 \mathrm{ml}$ ice-cold sterile Millipore water and bacteria were again collected by centrifugation for $15 \mathrm{~min}$ at $4^{\circ} \mathrm{C}$ and $3000 \mathrm{rpm}$.

- The pellet was carefully resuspended in $200 \mathrm{ml}$ ice-cold sterile Millipore water, and the bacteria were centrifuged at $3000 \mathrm{rpm}$ for $15 \mathrm{~min}$ at $4^{\circ} \mathrm{C}$ and the pellet was carefully resuspended in $8 \mathrm{ml}$ ice-cold sterile glycerine.

- Bacteria were centrifuged at $3000 \mathrm{rpm}$, for $15 \mathrm{~min}$ at $4^{\circ} \mathrm{C}$ and pellet was carefully resuspended in 0.8-1.2 $\mathrm{ml}$ ice-cold sterile glycerine.

- Aliquots of $40 \mu \mathrm{l}$ were flash-frozen in liquid nitrogen and stored at $-70^{\circ} \mathrm{C}$ until use.

\subsubsection{Electroporation and library plating}

- Competent cells were slowly thawed on ice, mixed with $4 \mu$ of the ligation mixture and left for $1 \mathrm{~min}$ on ice.

- The transformation mix was transferred to the bottom of an ice-cold cuvette and an electric pulse was applied using the Gene Pulser ${ }^{R}$ II Electroporation system from BioRad (BioRad, USA) at the following settings: voltage of $2.5 \mathrm{kV}$; capacitance of $25 \mu \mathrm{F}$; impedance at Low ohms; Voltage Booster resistance at 200 ohms; impulse at ca. $5 \mathrm{msec}$. 
- Immediately after electroporation $450 \mu \mathrm{l}$ of YEB medium was added to the cuvette, mixed carefully with a Pasteur pipette and transferred to a $10 \mathrm{ml}$ tube.

- The bacterial suspension was incubated under shaking at $200 \mathrm{rpm}$ for $1 \mathrm{~h}$ at $37^{\circ} \mathrm{C}$.

- 50-100 $\mu \mathrm{l}$ of transformed cells were plated on YT-agar plates containing ampicillin $(200 \mu \mathrm{g} / \mathrm{ml})$, X-Gal $(60 \mu \mathrm{g} / \mathrm{ml})$ and IPTG $(60 \mu \mathrm{g} / \mathrm{ml})$.

Solutions used in the Plasmid library construction:

YEB medium (pH 7.2)

$1 \mathrm{~g} / \mathrm{l}$ yeast extract

$5 \mathrm{~g} / \mathrm{l}$ beef extract

$5 \mathrm{~g} / \mathrm{l}$ Pepton (Casein)

$0.5 \mathrm{~g} / \mathrm{l} \mathrm{MgSO} 4 \times 7 \mathrm{H}_{2} \mathrm{O}$

$5 \mathrm{~g} / \mathrm{l}$ sucrose

LB medium ( $\mathrm{pH} 7.0)$

$10 \mathrm{~g} / \mathrm{l} \mathrm{NaCl}$

$10 \mathrm{~g} / \mathrm{l}$ Tryptone

$5 \mathrm{~g} / \mathrm{l}$ yeast extract

LB agar medium

$15 \mathrm{~g} / \mathrm{l}$ bacto-agar in LB medium

YT medium ( $\mathrm{pH} 7.0)$

$5 \mathrm{~g} / \mathrm{l} \mathrm{NaCl}$

$16 \mathrm{~g} / \mathrm{l}$ Tryptone

$10 \mathrm{~g} / \mathrm{l}$ yeast extract

YT agar medium

$15 \mathrm{~g} / \mathrm{l}$ bacto-agar in YT medium

Ampicillin stock solution

$100 \mathrm{mg} / \mathrm{ml}$ in water

Tetracycline stock solution

$25 \mathrm{mg} / \mathrm{ml}$ in ethanol

IPTG stock solution

$0.1 \mathrm{M}(23.8 \mathrm{mg} / \mathrm{ml}$ in water $)$

X-Gal stock solution

$50 \mathrm{mg} / \mathrm{ml}$ in DMF 


\subsection{Plating lambda libraries, plaque lifts and hybridisation procedure}

To plate the packaged ligation product, $1 \mu \mathrm{l}$ of the final packaging reaction was mixed with $200 \mu \mathrm{l}$ of $E$. coli XL1-Blue MRF' cells at an $\mathrm{OD}_{600}$ of 0.5 and incubated at $37^{\circ} \mathrm{C}$ for $15 \mathrm{~min}$. To this mixture $10 \mathrm{ml}$ of NZY top agar at $48^{\circ} \mathrm{C}$ was added, mixed well and plated onto $150 \mathrm{~mm}$ NZY agar plates. Plates were incubated overnight at $37^{\circ} \mathrm{C}$ and chilled for at least $2 \mathrm{~h}$ at $4^{\circ} \mathrm{C}$ before plate lift.

Replica membranes with the plaques were prepared in order to screen the libraries. To lift the plaques, nylon membranes (Hybond $\mathrm{N}+132 \mathrm{~mm}$ in diameter, Amersham Pharmacia Biotech, Freiburg) were placed onto each NZY plate for 1-2 min for the first membrane and for 3-4 min for the second membrane. For orientation needle pricks were made through the membranes and agar. Membranes were denatured for $5 \mathrm{~min}$ in filter paper wetted with denaturation solution $(1.5 \mathrm{M} \mathrm{NaCl}, 0.5 \mathrm{M} \mathrm{NaOH})$, neutralised $2 x$ for 3 min in filter paper wetted with neutralisation solution $(1.5 \mathrm{M} \mathrm{NaCl}$, $0.5 \mathrm{M}$ Tris/ $\mathrm{HCl} \mathrm{pH} \mathrm{7.5),} \mathrm{washed} \mathrm{in} \mathrm{2x} \mathrm{SSC} \mathrm{for} 1 \mathrm{~min}$, air dried and baked for $2 \mathrm{~h}$ at $80^{\circ} \mathrm{C}$.

Total genomic DNA from B. oleracea italica or B. rapa NPZ-35 were used as probe for screening the libraries. Genomic DNAs digested with EcoRI were labelled with ${ }^{32} \mathrm{P}$ by random primed labelling, using the Rediprime II DNA labelling kit (Amersham Pharmacia Biotech, Freiburg) following supplier's instructions.

Hybridisation of the membranes followed the method of Bernatzky and Tanksley (1986) with some modifications. Membranes were prehybridised in hybridisation solution for at least $4 \mathrm{~h}$ in a glass dish at $65^{\circ} \mathrm{C}$. Labelled probe, diluted in $300 \mu \mathrm{l}$ of hybridisation solution, was added to the glass dish and hybridisation was carried out overnight at $65^{\circ} \mathrm{C}$. After hybridisation, membranes were washed for $5 \mathrm{~min}$ in $2 \mathrm{x}$ SSC $/ 0.1 \%$ (w/v) SDS followed by washing for $5 \mathrm{~min}$ in $1 \mathrm{x}$ SSC/0.05\% (w/v) SDS. After washing, membranes were wrapped in plastic wrap and autoradiographed using Kodak X-OMAT AR film with a single intensifying screen at $-70^{\circ} \mathrm{C}$ for $48-72 \mathrm{~h}$.

The replica membranes were compared and plaques that showed hybridisation with only one genome were selected for a second screening. 
For the second screening, selected plaques were picked up from the agar plates with a Pasteur pipette and resuspended in $300 \mu \mathrm{l}$ of SM buffer. One to $2 \mu \mathrm{l}$ of the SMsuspension was used with $100 \mu \mathrm{l}$ of E. coli XL1-Blue MRF' cells at an $\mathrm{OD}_{600}$ of 0.5 to be plated in the same way as described above, but here $87 \mathrm{~mm}$ NZY agar plates and $4 \mathrm{ml}$ of NZY top agar were used. Preparation of the membranes, prehybridisation, probe preparation, hybridisation and washes were performed as described above for the library screening.

Solutions used in plating the lambda libraries and hybridisation:

NZY broth medium ( $\mathrm{pH} 7.0)$

$5 \mathrm{~g} / \mathrm{l} \mathrm{NaCl}$

$2 \mathrm{~g} / \mathrm{l} \mathrm{MgSO}_{4} \times 7 \mathrm{H}_{2} \mathrm{O}$

$5 \mathrm{~g} / \mathrm{l}$ yeast extract

$10 \mathrm{~g} / \mathrm{l} \mathrm{NZ}$ amine

NZY agar medium

$15 \mathrm{~g} / \mathrm{l}$ bacto-agar in NZY

NZY top agar medium

$7 \mathrm{~g} / \mathrm{l}$ agarose in NZY

SM buffer

$100 \mathrm{mM} \mathrm{NaCl}$

$100 \mathrm{mM} \mathrm{MgSO}_{4} \times 7 \mathrm{H}_{2} \mathrm{O}$

$50 \mathrm{mM}$ Tris- $\mathrm{HCl}(\mathrm{pH} 7.5)$

$0.01 \%(\mathrm{w} / \mathrm{v})$ gelatin

Filter sterilised $(0.2 \mu \mathrm{m})$

20x SSC stock solution

$3.0 \mathrm{M} \mathrm{NaCl}$

$0.3 \mathrm{M} \mathrm{Na}$-citrate $(\mathrm{pH} 7.0)$ 
100x Denhardt's stock solution

$$
\begin{aligned}
& 2 \%(w / v) \text { PVP-40 } \\
& 2 \%(w / v) \text { Ficoll } \\
& 2 \%(w / v) \text { BSA (fraction V). }
\end{aligned}
$$

Filter sterilised and stored at $-20^{\circ} \mathrm{C}$

Hybridisation buffer

$5 \times$ SSC

$0.6 \%(w / v)$ SDS

$50 \mathrm{mM} \mathrm{NaH}_{2} \mathrm{PO}_{4}$

5x Denhardt's

$1 \%(w / v)$ blocking reagent

filtered through a Miracloth filter (Calbiochem USA)

$8 \%$ blocking reagent

$8 \mathrm{~g}$ blocking reagent (Boehringer, Manheim)

stock solution (stored at $4^{\circ} \mathrm{C}$ ) $100 \mathrm{ml}$ 4x SSC

heated for dilution

\subsection{Dot-blot hybridisation procedure}

Plasmid DNAs from individual clones of the library were prepared by the alkalinelyses method modified from Birnboim and Doly (1979) (Section 3.5.1). Denatured plasmid DNA were dot blotted on nylon membranes (Hybond $\mathrm{N}+$, Amersham Pharmacia Biotech, Freiburg), using a Dot-Blot equipment (S\&S Minifold I, Schleicher and Schuell, Dassel) (Section 3.5.2). Total genomic DNAs from B. oleracea italica or B. rapa NPZ-35 were used as probes for screening for repetitive DNA sequences. Probe preparation, prehybridisation, hybridisation and stringent washing were performed as described for the phage library screening (Section 3.4).

\subsubsection{Plasmid DNA isolation}

- A white colony from the plasmid library was incubated overnight at $37^{\circ} \mathrm{C}$ in $3 \mathrm{ml}$ of YT/ampicillin $(50 \mu \mathrm{g} / \mathrm{ml})$.

- $1.5 \mathrm{ml}$ of the bacterial culture was transferred into a $2 \mathrm{ml}$ tube and centrifuged at max. speed for 30 seconds (Microliter Hettich centrifuge, Tuttlingen). 
- The medium was removed and the bacterial pellet was resuspended in $100 \mu \mathrm{l}$ of ice-cold solution SI by vigorous vortexing.

- $200 \mu$ l of freshly prepared solution SIl was added to the tube and mixed carefully by inversion. Tubes were stored for 2-5 min on ice.

- $150 \mu \mathrm{l}$ of ice-cold solution SIII was added to the tube and mixed carefully by inversion. Tubes were stored for $25 \mathrm{~min}$ on ice before centrifugation at max. speed for $15 \mathrm{~min}$.

- The supernatant was transferred to a fresh tube with two volumes of $96 \%(\mathrm{v} / \mathrm{v})$ ethanol, mixed and allowed to stand for $30 \mathrm{~min}$ for DNA precipitation.

- Tubes were than centrifuged at max. speed for 5 min and the supernatant was removed.

- The pellet was washed with $1 \mathrm{ml}$ of $70 \%(\mathrm{v} / \mathrm{v})$ ethanol, air dried, redissolved in 50 $\mu \mathrm{l}$ of TE containing $20 \mu \mathrm{g} / \mathrm{ml}$ of DNAse free RNAse, and stored at $-20^{\circ} \mathrm{C}$ until use.

Solutions used in Plasmid DNA isolation:

Solution SI

$50 \mathrm{mM}$ Glucose

$25 \mathrm{mM}$ Tris/ $\mathrm{HCl}(\mathrm{pH} \mathrm{8)}$

10 mM EDTA (pH 8)

Solution SII

$0.2 \mathrm{~N} \mathrm{NaOH}$

$1 \%(w / v)$ SDS

Solution SIII

$3 \mathrm{M}$ potassium acetate, $\mathrm{pH} 4.8$

\subsubsection{Dot blotting of plasmid DNA}

- Plasmid DNAs were denatured in a water bath at $100^{\circ} \mathrm{C}$ for $5 \mathrm{~min}$.

- After denaturation the DNA was rapidly transferred to an ice-cold water bath for 35 min, briefly centrifuged and kept on ice until use.

- Replica membranes were prepared by applying $5 \mu \mathrm{l}$ of samples on two Hybond $\mathrm{N}+$ membranes (Amersham pharmacia Biotech, Freiburg) fixed in a Dot-Blot equipment (S\&S Minifold I from Schleicher and Schuell, Dassel). 
- Suction was applied to the Dot-Blot equipment and after 30 min the membranes were taken out from the equipment and air dried.

- Dried membranes were placed on filter paper wetted in denaturation solution (1.5 $\mathrm{M} \mathrm{NaCl}, 0.5 \mathrm{M} \mathrm{NaOH})$ for $5 \mathrm{~min}$, in neutralisation solution $(1.5 \mathrm{M} \mathrm{NaCl}, 0.5 \mathrm{M}$ Tris/ $\mathrm{HCl}, 1 \mathrm{mM}$ EDTA $\mathrm{pH} 7.2)$ for $1 \mathrm{~min}$, and in fixation solution $(0.4 \mathrm{M} \mathrm{NaOH})$ for $20 \mathrm{~min}$.

- Membranes were air dried again and wrapped in plastic wrap until use.

\subsection{Southern-blot hybridisation procedure}

After comparing the dot blot replica membranes, clones that showed different intensities of hybridisation with the $A$ and $C$ genomes were selected for Southern blot analysis. Between 2-10 $\mathrm{gg}$ of genomic DNAs digested with Hindll or EcoRI were separated on a $0.8-1 \%(\mathrm{w} / \mathrm{v})$ agarose gel and blotted onto a Hybond $\mathrm{N}+$ membrane (Amersham Pharmacia Biotech, Freiburg). Probe DNAs were prepared by PCR using M13 forward and reverse primers (Section 3.6.1) and labelled with ${ }^{32} \mathrm{P}$ with Rediprime II DNA labelling system, according to supplier's instructions (Amersham Pharmacia Biotech, Freiburg). After blotting the genomic DNA (Section 3.6.2), membranes were prehybridised, hybridised overnight and washed under stringent conditions, all at $65^{\circ} \mathrm{C}$, before being autoradiographed using Kodak X-OMAT AR film (Section 3.6.3). Filters were stripped in order to be reused (Section 3.6.4).

\subsubsection{Probe preparation}

- Insert DNA was amplified from the respective plasmid by PCR as following:

50 ng plasmid DNA

$10 \mu l$ 10x PCR buffer

$10 \mu \mathrm{d}$ dNTP's (2 mM each)

$3 \mu \mathrm{l}$ forward M13 primer $(10 \mu \mathrm{M})$

$3 \mu \mathrm{l}$ reverse $\mathrm{M} 13$ primer $(10 \mu \mathrm{M})$

Water to complete $99.2 \mu \mathrm{l}$

$0.8 \mu \mathrm{l}$ Taq DNA polymerase $(5 \mathrm{U} / \mu \mathrm{l})$

- The PCR- profile for amplification was $1 \times 5 \min 94^{\circ} \mathrm{C}, 3 \min 75^{\circ} \mathrm{C}$, then $40 \times 30$ $\sec 94^{\circ} \mathrm{C}, 1.5 \min 55^{\circ} \mathrm{C}, 3 \min 72^{\circ} \mathrm{C}$. 
- After PCR, the solution with the amplified DNA was mixed with one volume of chloroform-isoamylalcohol (24:1), and the supernatant was recovered after centrifugation for $15 \mathrm{~min}$.

- The DNA was precipitated with 0.1 volume of $3 \mathrm{M} \mathrm{NaAc}, \mathrm{pH} 5.2$, and 2.5 volume of ice-cold $96 \%(\mathrm{v} / \mathrm{v})$ ethanol for $2-4 \mathrm{~h}$ at $-20^{\circ} \mathrm{C}$.

- The precipitated DNA was centrifuged $30 \mathrm{~min}$ at $4^{\circ} \mathrm{C}$ and $13000 \mathrm{rpm}$, washed with cold $70 \%(\mathrm{v} / \mathrm{v}$ ) ethanol, centrifuged $15 \mathrm{~min}$ at $13000 \mathrm{rpm}$, dried in excicator and redissolved in TE buffer.

- After at least 2 days in a refrigerator the DNA concentration was measured with a fluorometer as described (Section 3.1.2).

- The Probe DNAs were labelled with ${ }^{32} \mathrm{P}$ with the Rediprime II DNA labelling kit (Amersham Pharmacia Biotech, Freiburg), in accordance to supplier's instruction.

\subsubsection{Southern blot}

- Between 2-10 $\mu \mathrm{g}$ of genomic DNAs from Brassica species (Table 1) were

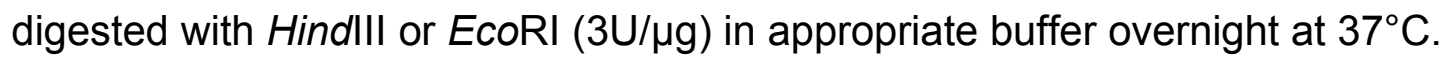

- Digested DNAs and $100 \mathrm{ng}$ of lambda EcoRI/Hindlll marker were loaded with loading buffer on a $0.8-1 \%(\mathrm{w} / \mathrm{v})$ agarose gel with ethidium bromide $(0.125 \mu \mathrm{g} / \mathrm{ml})$.

- Samples were run overnight at $40 \mathrm{~V}$ in TAE buffer. Afterwards gels were photographed.

- Partial depurination, denaturation and neutralization of the gels was achieved through incubating the gel in $0.25 \mathrm{M} \mathrm{HCl}$ for $10 \mathrm{~min}, 1.5 \mathrm{M} \mathrm{NaCl} / 0.5 \mathrm{M} \mathrm{NaOH}$ for $30 \mathrm{~min}$ and $1.5 \mathrm{M} \mathrm{NaCl} / 0.5 \mathrm{M}$ Tris/ $\mathrm{HCl} \mathrm{pH} 7.5$ for $30 \mathrm{~min}$, respectively. Between each treatment the gels were washed with water.

- Southern transfer was made by the classical capillary blotting technique (protocol provided by Amersham pharmacia biotech) for small gels, or by vacuum blotting (VacuGene ${ }^{T M} \mathrm{XL}$ Vacuum blotting System from Parmacia) for large gels, using Hybond XL or N+ membranes (Amersham Pharmacia Biotech, Freiburg).

- After DNA transfer membranes were baked for $2 \mathrm{~h}$ at $80^{\circ} \mathrm{C}$, cooled down and stored in refrigerator until use. 


\subsubsection{DNA-DNA hybridisation}

- Before hybridisation the membranes were prehybridised for at least $4 \mathrm{~h}$ at $65^{\circ} \mathrm{C}$ in $45 \mathrm{ml}$ of prehybridisation buffer.

- Prehybridisation buffer was replaced by $15 \mathrm{ml}$ of hybridisation buffer and the probe, diluted in $300 \mu$ of this buffer, was added.

- Membranes were hybridised overnight at $65^{\circ} \mathrm{C}$ in a hybridisation oven.

- After hybridisation membranes were washed with $200 \mathrm{ml}$ of $2 x$ SSC/0.1\% (w/v) SDS and $1 \times$ SSC/0.05\% (w/v) SDS, for 20 min each, at $65^{\circ} \mathrm{C}$ in the hybridisation tubes.

- The last wash step took place in a water bath with unrolled membranes in $500 \mathrm{ml}$ of $0.5 x$ SSC $/ 0.025 \%(w / v)$ SDS, for $10-20 \mathrm{~min}$ at $65^{\circ} \mathrm{C}$.

- After washing, the membranes were wrapped in plastic wrap, and autoradiographed using Kodak X-OMAT AR film with a single intensifying screen at $-70^{\circ} \mathrm{C}$ for $24-72 \mathrm{~h}$.

\subsubsection{Stripping membranes}

For removal of probes, moist membranes were incubated in $500 \mathrm{ml}$ of $0.2 \mathrm{M} \mathrm{NaOH}$ for $30 \mathrm{~min}$ at $45^{\circ} \mathrm{C}$, followed by an incubation in $500 \mathrm{ml}$ of $0.2 \mathrm{M} \mathrm{Tris} / \mathrm{HCl} \mathrm{pH} 7.5 / 0.1 \mathrm{x}$ $\mathrm{SSC} / 0.1 \%(\mathrm{w} / \mathrm{v}) \mathrm{SDS}$ for $30 \mathrm{~min}$ at $45^{\circ} \mathrm{C}$.

Solutions used in Southern blotting hybridisation:

6x Loading buffer stock solution $\quad 40 \%(w / v)$ sucrose

$0.25 \%(\mathrm{w} / \mathrm{v})$ xylene cyanol

$0.25 \%(w / v)$ bromophenol blue

50x TAE buffer stock solution $2 \mathrm{M}$ Tris

$17.4 \mathrm{~N}$ acetic acid

$50 \mathrm{mM}$ EDTA

20x SSC

see solutions in 3.3.1 
100x Denhardt's

Prehybridisation buffer

Hybridisation buffer

\subsection{DNA sequencing and computer analysis of sequence data}

For sequencing all plasmid DNA were prepared using the QIAprep kit (Qiagen, Hilden), according to the supplier's instructions.

The sequencing was carried out by the company MWG-Biotech, Comfort-Read service, using automated DNA sequencing. The DNA sequence was analysed using the BioEdit Sequence Alignment Editor program, version 4.7.8. All sequences were analysed for homology to known sequences using the BLAST service at NCBI for all organisms (http://www.ncbi.nlm.nih.gov) and at the TIGR service for the B. oleracea genome database (http://www.tigr.org/tdb/e2k1/bog1/index.shtml).

\subsection{Fluorescent in situ hybridisation (FISH)}

Fluorescent in situ hybridisation (FISH) was performed on Brassica chromosomes spreads obtained from root tips (Section 3.8.1), using as probes rDNA as control and insert DNAs from the clones selected in the plasmid library (Section 3.8.2). After pre- 
treatment of the cytological material (Section 3.8.3), chromosomes were denatured and hybridised overnight to labelled probes (Section 3.8.4). Stringent washes were performed (Section 3.8.5) before probe detection (Section 3.8.6). Before and after $\mathrm{FISH}$, slides were examined and chromosome spreads with good quality were recorded for further analyses (section 3.8.7).

\subsubsection{Accumulation, fixation and squash preparation of plant chromosomes}

- Seeds from Brassica oleracea oleracea, B. rapa Rex, B. napus Jockey and B. carinata BRA 489/77 were germinated on moist filter paper in a Petri dish, for 2-3 days at $24^{\circ} \mathrm{C}$ until the primary roots were $1-2 \mathrm{~cm}$ long. Cell division was synchronised by incubating the seedlings overnight at $4^{\circ} \mathrm{C}$, followed by a further $24 \mathrm{~h}$ at $24^{\circ} \mathrm{C}$.

- The roots were pre-treated with $2 \mathrm{mM}$ 8-hydroxyquinoline for $2 \mathrm{~h}$ at RT under agitation, briefly blotted dry on paper tissue, fixed in Farmer fixative (3:1 ethanol : acetic acid) for 4-16 $\mathrm{h}$ at RT and stored in the fixative at $-20^{\circ} \mathrm{C}$ until use.

- Before enzyme digestion roots were washed 2x for 5 min in water and for 15 min in enzyme buffer.

- Digestion with 2\% (w/v) cellulase (Onozuka r-10; Merck, Darmstadt) and 20\% $(\mathrm{v} / \mathrm{v})$ pectinase (Sigma-Aldrich, Munich) in enzyme buffer was carried out at $37^{\circ} \mathrm{C}$ for 45-60 $\mathrm{min}$.

- 1-3 root tips were squashed per slide in a drop of $45 \%$ (v/v) acetic acid and coverslip was removed in liquid nitrogen. Slides were air dried and stored in a refrigerator until use.

\subsubsection{Probe preparation and labelling}

Two probes were used in FISH experiments as positive control: (1) one to detect the 45S rDNA site and another (2) to detect the $5 S$ and $45 S$ rDNA sites. The probe (1) was named here as 45S rDNA probe, and was generated by PCR using total genomic DNA from Brassica as template and primers from the 25S rDNA region (JF 09- 5'GCG AGC GAA CCG GGA TAA GCC C 3’ and JF 10- 5'CGG AAT TTA CCG CCC GAT TGG GG 3`, Yokota et al., 1989), what generates an amplicon of about $220 \mathrm{bp}$ long. The PCR- profile for amplification of this probe was $1 \times 5 \min 94^{\circ} \mathrm{C}$, then $34 \times 50 \sec 94^{\circ} \mathrm{C}, 30 \sec 55^{\circ} \mathrm{C}, 1.5 \min 72^{\circ} \mathrm{C}$ and finally $1 \times 10 \min 72^{\circ} \mathrm{C}$. The probe 
(2), was named here as " $5+45 S$ rDNA". This probe was a plasmid containing a 1735 bp EcoRI fragment of the 18S rDNA region from the 45S rDNA of Aedes aegypti and 509 bp of $5 S$ rDNA from Matthiola incana. Plasmid DNA with " $5+45 S$ rDNA" and from selected clones were isolated using plasmid DNA extraction kit from Qiagen (Hilden), following supplier's instructions. Inserts from the clones selected in the plasmid libraries were amplified by PCR (Section 3.6.1) and used as probes after labelling.

Probes were labelled by one of the following methods: random priming, PCR or nick translation.

\section{Random primed labelling}

Inserts amplified by PCR (section 3.6.1) or plasmid DNA were labelled with digoxigenin-11-dUTP using DIG-High Prime DNA labelling kit (Roche, Mannheim), following supplier's instructions.

\section{PCR labelling}

- Inserted DNAs were amplified and labelled by PCR using Taq PCR core kit (Qiagen, Hilden) as follow:

$5.7 \mu \mathrm{l}$ water $+20 \mathrm{ng}$ selected plasmid DNA

$5 \mu \mathrm{l} 5 \mathrm{x} \mathrm{Q}$ sol

$2.5 \mu \mathrm{l} 10 \mathrm{x}$ PCR buffer

$2.5 \mu \mathrm{l}$ dNTP's without dTTP (2 mM each)

$1.6 \mu \mathrm{dTTP}(2 \mathrm{mM})$

$1.7 \mu \mathrm{I}$ DIG-11- dUTP (1 mM) (Boehringer Manheim)

$2.5 \mu$ f forward M13 primer $(10 \mu \mathrm{M})$

$2.5 \mu$ reverse M13 primer $(10 \mu \mathrm{M})$

$1 \mu \mathrm{l}$ Taq DNA polymerase $(1 \mathrm{U} / \mu \mathrm{l})$

- The PCR- profile for amplification was $1 \times 5 \min 94^{\circ} \mathrm{C}, 3 \min 75^{\circ} \mathrm{C}$, then $40 \times 30$ $\sec 94^{\circ} \mathrm{C}, 1.5 \min 55^{\circ} \mathrm{C}, 3 \min 72^{\circ} \mathrm{C}$.

- For PCR labelling of $45 S$ rDNA, primers, template and PCR profile used were the same as described in section 3.8.2.

\section{Nick translation}

Biotin-16-dUTP labelled probes were generated with the Biotin-Nick Translation Mix for in situ probes (Roche, Mannheim), following supplier's instructions, using either plasmid DNA or insert DNA amplified by PCR (section 3.6.1). 


\subsubsection{Pre-treatment of chromosome preparations for FISH}

- Before $\mathrm{FISH}$, slides were incubated for $30 \mathrm{~min}$ at $60^{\circ} \mathrm{C}$, to fix cells to the glass slides, followed by incubation for 5-10 min at RT.

- Slides were treated with DNAse-free RNAse in 2x SSC $(400 \mu \mathrm{g} / \mathrm{ml})$ for $1 \mathrm{~h}$ at $37^{\circ} \mathrm{C}(100 \mu \mathrm{l}$ per slide), washed $2 \mathrm{x}$ for 5 min with $2 x$ SSC at RT and $1 \times$ for 5 min with $10 \mathrm{mN} \mathrm{HCl}$ at $\mathrm{RT}$.

- Treatment with freshly diluted pepsin (1:100 dilution of $1 \mathrm{mg} / \mathrm{ml}$ pepsin in $0.01 \mathrm{~N}$ $\mathrm{HCl})$ was carried out for $20 \mathrm{~min}$ at $37^{\circ} \mathrm{C}(100 \mu \mathrm{l}$ per slide $)$.

- Slides were than washed 2x for 5 min with 2x SSC, 1x for 5 min with 1x PBS and fixed in $1 \%(v / v)$ aqueous formaldehyde (Sigma-Aldrich, Munich) in 1x PBS at RT $10 \mathrm{~min}$.

- Slides were washed 2x for 5 min in 1x PBS, dehydrated in an ethanol dilution series (2 min each in 70\%, 90\%, and 96\% ethanol (v/v)) and air dried for $1 \mathrm{~h}$.

\subsubsection{In situ hybridisation}

- Slides and probes were denatured separately before hybridisation.

- Slides were denatured in $200 \mu \mathrm{l}$ of $70 \%(\mathrm{v} / \mathrm{v})$ formamide in $2 x$ SSC on a metal plate sitting with maximal heat contact in a water bath, at $70-72^{\circ} \mathrm{C}$ for $3.5-4 \mathrm{~min}$. After denaturation slides were immediately dehydrated in an ice-could ethanol series of $70 \%, 90 \%$ and $96 \%$ (v/v) for 2 min each. Finally, the slides were air dried for at least $30 \mathrm{~min}$ at RT.

- Hybridisation mix (15 $\mu \mathrm{l}$ per slide) containing 50-150 ng of the probe, was denatured at $75^{\circ} \mathrm{C}$ for $10 \mathrm{~min}$ and rapidly cooled down 5 min on ice before being added to slides. The slides were hybridised at $37^{\circ} \mathrm{C}$ overnight.

\subsubsection{Removing unbound and weakly hybridised probe}

After hybridisation slides were washed stringently $2 x$ for 5 min in $2 x$ SSC, $2 x$ for 5 min in $0.1 x$ SSC and $2 x$ for 5 min in $2 x \mathrm{SSC}$, all at $42^{\circ} \mathrm{C}$, followed by one wash for 5 $\min$ in 2x SSC at RT and one wash for $7 \mathrm{~min}$ in $4 \mathrm{x} \mathrm{SSC/} 0.1 \%(\mathrm{v} / \mathrm{v})$ Tween 20 (probes labelled with biotin) or 1x PBS (probes labelled with digoxygenin) at RT. 


\subsubsection{Detection of hybridisation signals}

\section{Detection of biotin labelled probes}

(Fluorescein-streptavidin, Biotinylated-anti-Streptavidin and Vectashield were from Vector Laboratories, Peterborough, England).

- To block unspecific antibody binding, $100 \mu \mathrm{l}$ of $3 \%$ (w/v) BSA in $4 x$ SSC/ $0.1 \%$ (v/v) Tween 20 was applied on the slide, covered with a plastic coverslip and incubated for $30 \mathrm{~min}$ at $37^{\circ} \mathrm{C}$.

- The plastic coverslip was carefully removed with forceps. To detect the hybridised probe $100 \mu \mathrm{l}$ of Fluorescein-streptavidin $(10 \mu \mathrm{g} / \mathrm{ml}$ in $1 \%(\mathrm{w} / \mathrm{v}) \mathrm{BSA})$ was added to the slide and incubated at $37^{\circ} \mathrm{C}$ for 20-60 min.

- Slides were then washed 3x for 2-10 min in 4x SSC/ 0.1\% (v/v) Tween 20.

- Signals were amplified through incubation with $50 \mu$ B Biotinylated-anti-Streptavidin antibody $(10 \mu \mathrm{g} / \mathrm{ml}$ in $1 \%(\mathrm{w} / \mathrm{v}) \mathrm{BSA})$ for $20-60 \mathrm{~min}$ at $37^{\circ} \mathrm{C}$, washed again $3 \mathrm{x}$ for 2$10 \mathrm{~min}$ in $4 \mathrm{x} \mathrm{SSC} / \mathrm{0.1 \%}$ (v/v) Tween 20 and amplified signals were detected again using $100 \mu \mathrm{l}$ of Fluorescein-streptavidin $(10 \mu \mathrm{g} / \mathrm{ml}$ in $1 \%(\mathrm{w} / \mathrm{v}) \mathrm{BSA})$ for 20 $\min$ to $1 \mathrm{~h}$ at $37^{\circ} \mathrm{C}$.

- After washing 3x 2-10 min in 4x SSC/ 0.1\% (v/v) Tween 20, chromosomes were stained with $7-8 \mu \mathrm{l}$ of DAPI $(1 \mu \mathrm{g} / \mathrm{ml}$ in Vectashield antifade) per slide.

\section{Detection of digoxygenin labelled probes}

(Fluorescent Antibody Enhance set for DIG detection (Boehringer, Mannheim) was used).

- Antibody stock solutions were freshly diluted before use to $1: 25$ in $1 \%(\mathrm{v} / \mathrm{v})$ blocking solution (Boehringer, Mannheim) (final concentration 1ng/ $\mu \mathrm{l})$.

- Slides were immersed in $50 \mathrm{ml} \mathrm{1 \%} \mathrm{(v/v)} \mathrm{blocking} \mathrm{solution} \mathrm{in} \mathrm{a} \mathrm{coplin} \mathrm{jar} \mathrm{for} 30 \mathrm{~min}$ at RT in order to block unspecific antibody binding.

- The probe was detected by incubating the slides at $37^{\circ} \mathrm{C}$ for $1 \mathrm{~h}$ in $50 \mu \mathrm{l}$ mouseanti-DIG antibody dilution $(1 \mathrm{ng} / \mu \mathrm{l})$.

- Unspecifically bound antibodies were removed by washing the slides $3 x$ for 2-5 $\min$ in $2 x \mathrm{SSC} / 0.2 \%(\mathrm{v} / \mathrm{v})$ Tween.

- Amplification of signals was made through incubation of slides at $37^{\circ} \mathrm{C}$ for $1 \mathrm{~h}$ in $50 \mu$ anti-mouse-DIG antibody dilution (1ng/ $\mu \mathrm{l})$. 
- Unspecifically bound antibodies were removed by washing the slides $3 x$ for 2-5 $\min$ in $2 x \mathrm{SSC} / 0.2 \%(\mathrm{v} / \mathrm{v})$ Tween.

- Amplified signals were detected with $50 \mu \mathrm{l}$ anti-DIG-fluorescein $(1 \mathrm{ng} / \mu \mathrm{l})$ for $1 \mathrm{~h}$ at $37^{\circ} \mathrm{C}$.

- Unspecifically bound antibodies were removed by washing the slides $3 x$ for 2-5 $\min$ in $2 x \mathrm{SSC} / 0.2 \%(\mathrm{v} / \mathrm{v})$ Tween. Chromosomes were counterstained with 7-8 $\mu \mathrm{l}$ of DAPI $(1 \mu \mathrm{g} / \mathrm{ml}$ in Vectashield antifade) per slide.

Solutions used in FISH:

10x enzyme buffer stock solution

20x SSC

10x PBS stock solution

Hybridisation mix

BSA

DAPI stock solution
$4 \mathrm{mM}$ citric acid

$6 \mathrm{mM}$ tri-sodium-citrate

$\mathrm{pH} 4.8$

see solutions in 3.3.1

$1.4 \mathrm{M} \mathrm{NaCl}$

$85 \mathrm{mM} \mathrm{Na}_{2} \mathrm{HPO}_{4}$

$15 \mathrm{mM} \mathrm{KH}_{2} \mathrm{PO}_{4}$

$30 \mathrm{mM} \mathrm{KCl}$

$\mathrm{pH} 7.4$

$50 \%(\mathrm{v} / \mathrm{v})$ formamide

$10 \%(w / v)$ dextran sulfate

$2 \mathrm{xSSC}$

$3 \%(\mathrm{w} / \mathrm{v}) \mathrm{BSA}$ in $4 \mathrm{x} \mathrm{SSC} / 0.1 \%(\mathrm{v} / \mathrm{v})$

Tween 20. Filter sterilised and stored at $20^{\circ} \mathrm{C}$

$100 \mu \mathrm{g} / \mathrm{ml}$ in water 


\subsubsection{Microscopy and photography}

The slides were examined with a Zeiss Axiolab Epifluorescent or a fluorescent Olympus BX-60 (Olympus Optical co. LTD, Japan) microscopes equipped with filter sets for DAPI (4,6-diamidino-2-phenylindole), and FITC (fluorescein isothiocyanate). Photographs were taken on Kodak Ektochrome P1600 professional reversal film for colour slides with a MC 80 camera attached to the Zeiss Axiolab microscope or with a CCD (Charged-Couple Device) camera (camera colour view 12) attached to the Olympus microscope using the analyses software Analysis 3.0 (Soft Imaging System $\mathrm{GmbH}$, Münster). Images were processed uniformly before scoring the results by using image processing software (Adobe Photoshop version 5.5; Adobe System, San Jose, Calif.). For the karyotype construction colour images were then converted to grayscale mode ( 8 bits) and inverted. Black and white pictures were again uniformly processed before printing.

For the karyotype descriptions the total length and the ratio of the short and the long arms of the chromosomes from 3 metaphases stained with DAPI were measured. Karyotypes were constructed using the Adobe Photoshop software. The morphology of the chromosomes was classified according to the system suggested by Levan et al. (1964), using the terms metacentric and submetacentric. The number and distribution of signals of each probe were averaged in at least 3 metaphases for each species, when nothing else is mentioned. 


\section{Results}

\subsection{Searching for Brassica oleracea species-specific repetitive sequences}

\subsubsection{Phage library screening}

The first library (library 1) constructed for searching for species-specific repetitive sequences in $B$. oleracea was a lambda phage library. A DNA fraction ranging from 200 to $1000 \mathrm{bp}$ from B. oleracea total DNA digested with Tsp509l was used for this purpose. In order to find clones with repetitive DNA, replica filters with plaques from this library were made and screened using either $B$. oleracea or $B$. rapa total genomic DNA labelled with ${ }^{32} \mathrm{P}$ as probe. Figure 2 presents one autoradiogram from replica filters after the colony hybridisation. Strong spots represent clones with repetitive DNA ("positive clones") and are seen in few plaques, whereas most of the plaques show no or a very faint hybridisation signal ("negative clones"). Clones with repetitive DNA which hybridised strongly with only one of the genomic probe were selected for a second screening as putative species-specific. Two of such clones are represented in the detail of Figure 2.

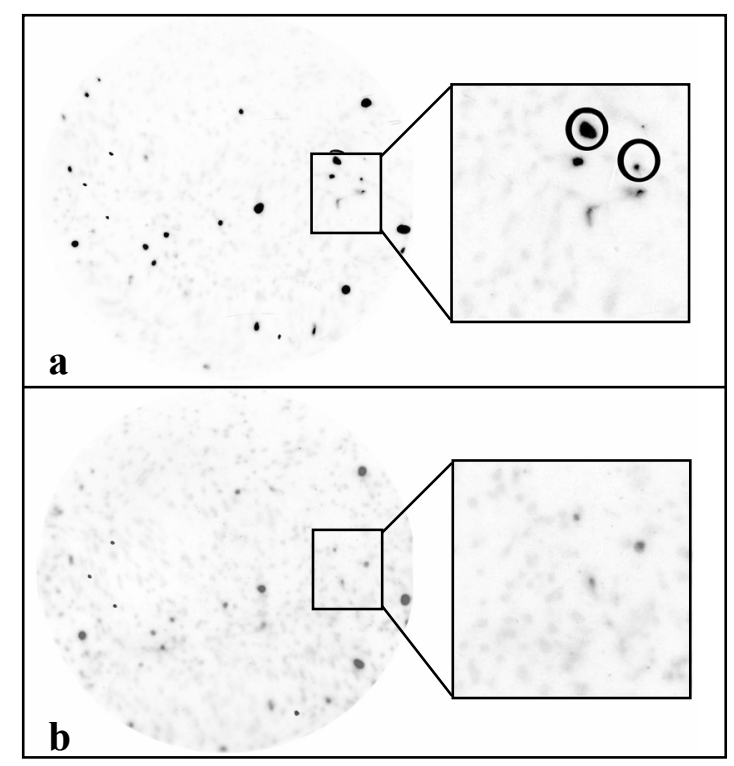

Figure 2. Autoradiogram from replica filters in the first screening of the B. oleracea lambda library 1 after hybridisation with total genomic DNA of (a) B. oleracea and (b) $B$. rapa. The insert on the right side shows a magnification of the boxed area in the 
respective filters, representing the same region in both filters. Clones with repetitive DNA show strong hybridisation signals. Circled clones show differential hybridisation between the replica membranes and were collected to a second screening as candidates for species-specificity.

About 80,000 plaques of the lambda library 1 were screened, but only 350 clones showed strong hybridisation signals with total genomic DNA from Brassica, indicating the presence of repetitive DNA. This means that only $0.45 \%$ of the clones contained repetitive sequences. From the 350 positive clones in the first screening, ca. $60 \%$ hybridised with total DNA from both genomes (212 clones) and, accordingly, were repetitive but not species-specific, whereas about 40\% (138 clones) hybridised either with $B$. oleracea (68 clones) or with $B$. rapa (70 clones), being putative speciesspecific clones.

To confirm the species-specificity of the 138 clones a second screening was performed. None of these clones was confirmed as containing species-specific repetitive DNA, they hybridised either with DNA of both genomic probes (90 clones) or showed no hybridisation signal (48 clones). Figure 3 shows an example of a clone where all plaques hybridised with DNA of both genomes. Sometimes, however, more than one plaque had been picked up from the Petri dish in the first screening and a mixture with "positive" and "negative" clones could be seen in the second screening.

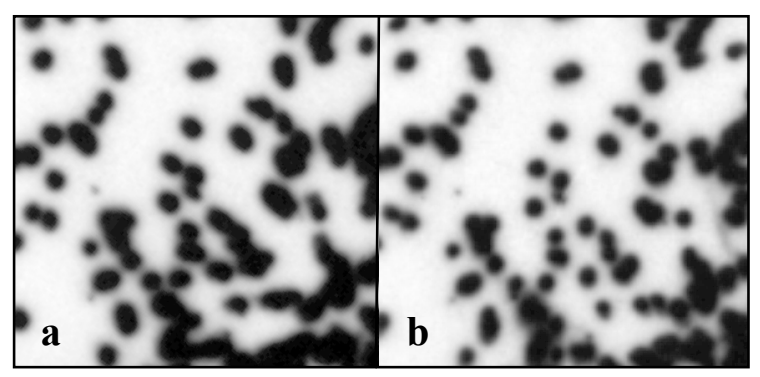

Figure 3. Autoradiogram of replica filters from a putative species-specific clone (lambda clone Bo-93) selected in the first screening, after hybridisation with $B$. oleracea (a) and $B$. rapa (b) total genomic DNA. 
In order to see if the DNA fraction used as insert was responsible for the low amount of clones with repetitive DNA sequences observed in the first phage library $(0.45 \%)$, two additional phage libraries were constructed. B. oleracea unfractionated total genomic DNA and a fraction between 1000-2000 bp, both digested with Tsp509l, were used to construct the second and the third library, respectively. About 12,000 plaques were screened for each library using only $B$. oleracea total DNA as probe. The amount of clones with repetitive DNA found was $2.4 \%$ for library 2 and $1.5 \%$ for library 3. These frequencies were somewhat higher than in the first library, but still much lower than would be expected taking in account that plant genomes have high amount of repetitive DNA. From these data it was concluded that the low frequency of repetitive DNA in the phage libraries was probably more related to the type of vector used in the library construction than to the DNA fraction used as insert. For this reason new libraries using plasmid DNA as vector were constructed.

\subsubsection{Plasmid library screening}

To construct $B$. oleracea plasmid libraries a DNA fraction ranging from 1000 to 2000 bp and unfractionated total genomic DNA digested with Tsp509I were cloned in the EcoRI site of pUC19. For simplification, the results of these two libraries will be presented together. Plasmid DNA from a total of 1164 white colonies, denominated as pBo2.1-205 (for clones from the fractionated library) and pBo1.1-959 (for clones from the total DNA library), were extracted, dot blotted on two replica filters and screened for repetitive DNA using either $B$. oleracea or $B$. rapa total DNA labelled with ${ }^{32} \mathrm{P}$ as probe. About $21 \%$ of the clones (246 clones) hybridised strongly with $B$. oleracea total DNA and were identified as containing repetitive DNA (Figure 4).

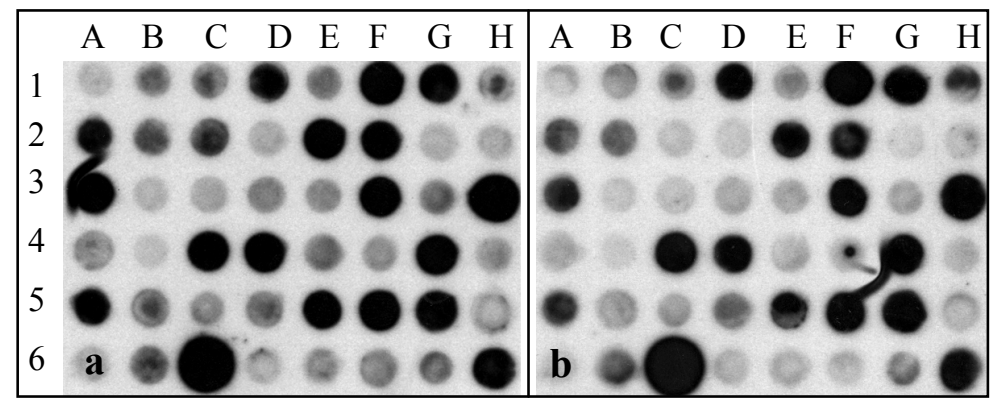

Figure 4. Dot-blot hybridisation of pBo clones with $B$. oleracea (a) and B. rapa (b) total genomic DNA. Clones with repetitive DNA (e.g. D1, E2, F2, C6) show strong hybridisation signals. 
After comparison of the dot-blot hybridisation patterns with both probes, none of the 1164 clones was clearly identified as species-specific, but some exhibited differences in the intensity of hybridisation with both genomic probes. For exhibiting stronger hybridisation with $\mathrm{C}$ genome DNA probe, 15 clones were selected as putative C genome-specific or -enriched clones for further Southern blot analyses. Dot blots from the clones confirmed as enriched in $\mathrm{C}$ genome are shown in Figure 5.

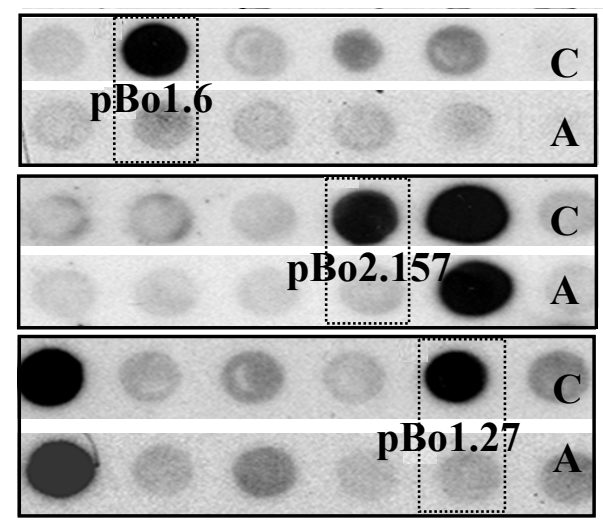

Figure 5. Dot-blot hybridisation of pBo clones confirmed as enriched in $\mathrm{C}$ genome after hybridisation with $B$. oleracea $(C)$ and $B$. rapa $(A)$ total genomic DNA.

\subsection{Genomic organisation of the putative C genome-specific or enriched clones}

The genomic organisation of the 15 selected clones was analysed by Southern blot hybridisation to genomic DNA of the A and $\mathrm{C}$ genomes of different Brassica species digested with EcoRI or HindIII.

Only three out of the 15 selected clones, pBo1.6, pBo1.27 and pBo2.157, were confirmed as enriched in $\mathrm{C}$ genome, showing differences in the number and intensity of bands hybridising with $A$ and $C$ genomic DNAs, independent of the enzyme used in DNA digestion. Ten out of the 15 selected clones, including the three confirmed as enriched in $\mathrm{C}$ genome, were hybridised to $B$. nigra DNA (B genome) and were also detected in this genome (data not shown). Figure 6 shows Southern blots hybridised with the three repetitive clones enriched in the $\mathrm{C}$ genome. When comparing the lanes of the blots, in Figure 6, where $\mathrm{C}$ genome DNA (lanes 1, 2, 7, 8), or A and C genome DNAs (lanes 3,4) were loaded with that where only A genome DNA were loaded (lanes 5,6 ), it is easily ascertained that clones pBo1.6, pBo1.27 and pBo2.157 gave 
much stronger signals with $\mathrm{C}$ genome DNA. The repetitive sequence cloned in pBo1.6 was clearly less abundant in the A genome than the sequences of the two others clones, showing only a prominent discrete band of about $2 \mathrm{~kb}$ length in EcoRI and $10 \mathrm{~kb}$ in Hindll digested DNA of the A and also of the B genome (data not shown) and a very faint smear. Strong, smeared signals with some prominent bands were observed after hybridisation with pBo1.6 in all species with $\mathrm{C}$ genome. Clones pBo1.27 and pBo2.157 showed a smear of hybridisation signals with both genomes, in both enzyme treatments, although few prominent bands were also present. The three clones hybridised preferentially with fragments of the high molecular weight DNA fraction from genomic DNAs digested with Hindlll, whereas fragments of the lower weight fraction were also seen when genomic DNAs digested with EcoRI were used.

From the remaining 12 clones, 10 exhibit similarly strong hybridisation signals on Southern blots with DNA of all genomes and two were not repetitive. The nonrepetitive nature of these clones was concluded from the observation that Southern blots hybridised with these clones needed a much longer exposition to X-ray films (over seven days) than blots hybridised with the repetitive clones (two-three days). Figure 7 shows hybridisation patterns of some repetitive but not species-specific clones.

Hybridisation with the different probes produced two kinds of signals: (1) strong smeared signal, extending over several centimetre of the lane, indicating the occurrence of related sequences at many different genomic loci, and/or (2) two to six prominent discrete bands (see Figures 6 and 7). Such discrete bands were mostly present in genomes $\mathrm{A}, \mathrm{B}$ and $\mathrm{C}$ as fragments of similar size, indicating their conservation in these different genomes.

It was not possible to determine if the sequences analysed were tandemly repeated or not, since a "ladder", typical from tandem repeated sequences, was absent on the blots with genomic DNA digested with EcoRI and HindIII.

Although none of the clones have been strictly species-specific, the three clones enriched in the $\mathrm{C}$ genome were sequenced and used in fluorescent in situ hybridisations, since they could give important information about the structure of the $\mathrm{A}$ and $\mathrm{C}$ genomes in $B$. napus. 


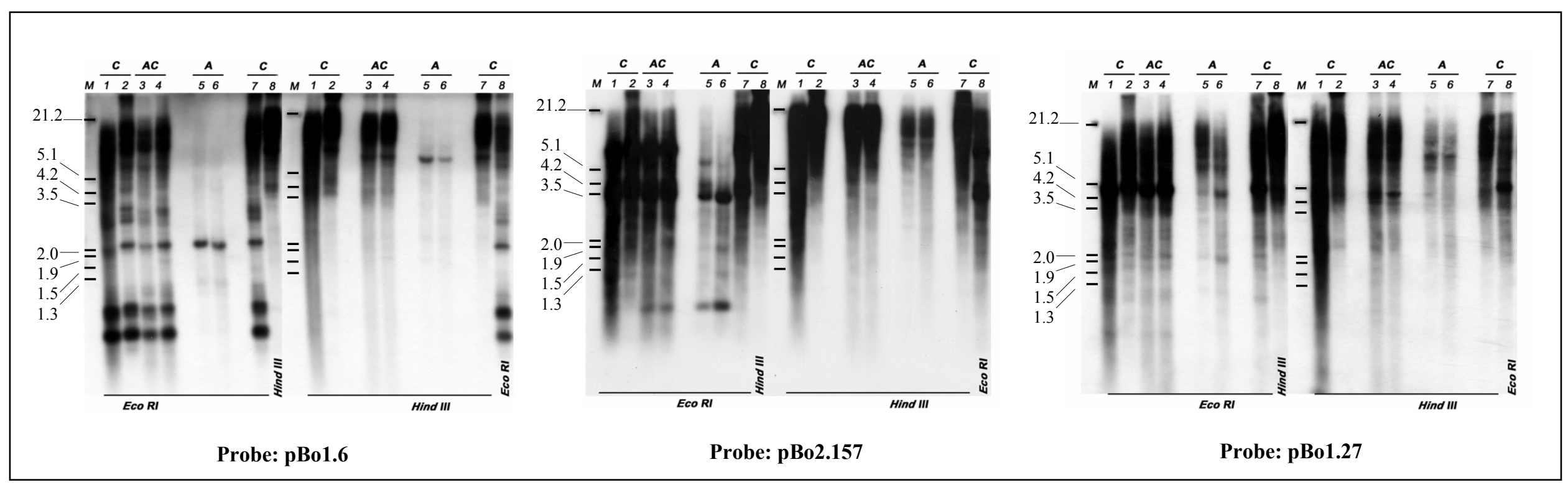

Figure 6. Southern blot hybridisation of genomic DNA digested with EcoRI or Hindlll from different Brassica with $C$ genome-enriched clones. Brassica species: B. oleracea Vitamina (lane 1) and Market Victor (lane 2); B. napus Express (lane 3) and Iris (lane 4); B. rapa NPZ-35 (lane 5) and Perko (lane 6); B. incana (lane 7) and B. oleracea alboglabra (lane 8). Molecular weight marker (Lambda EcoRl/Hindlll, lane $\mathrm{M}$ ) is given in $\mathrm{kb}$. 


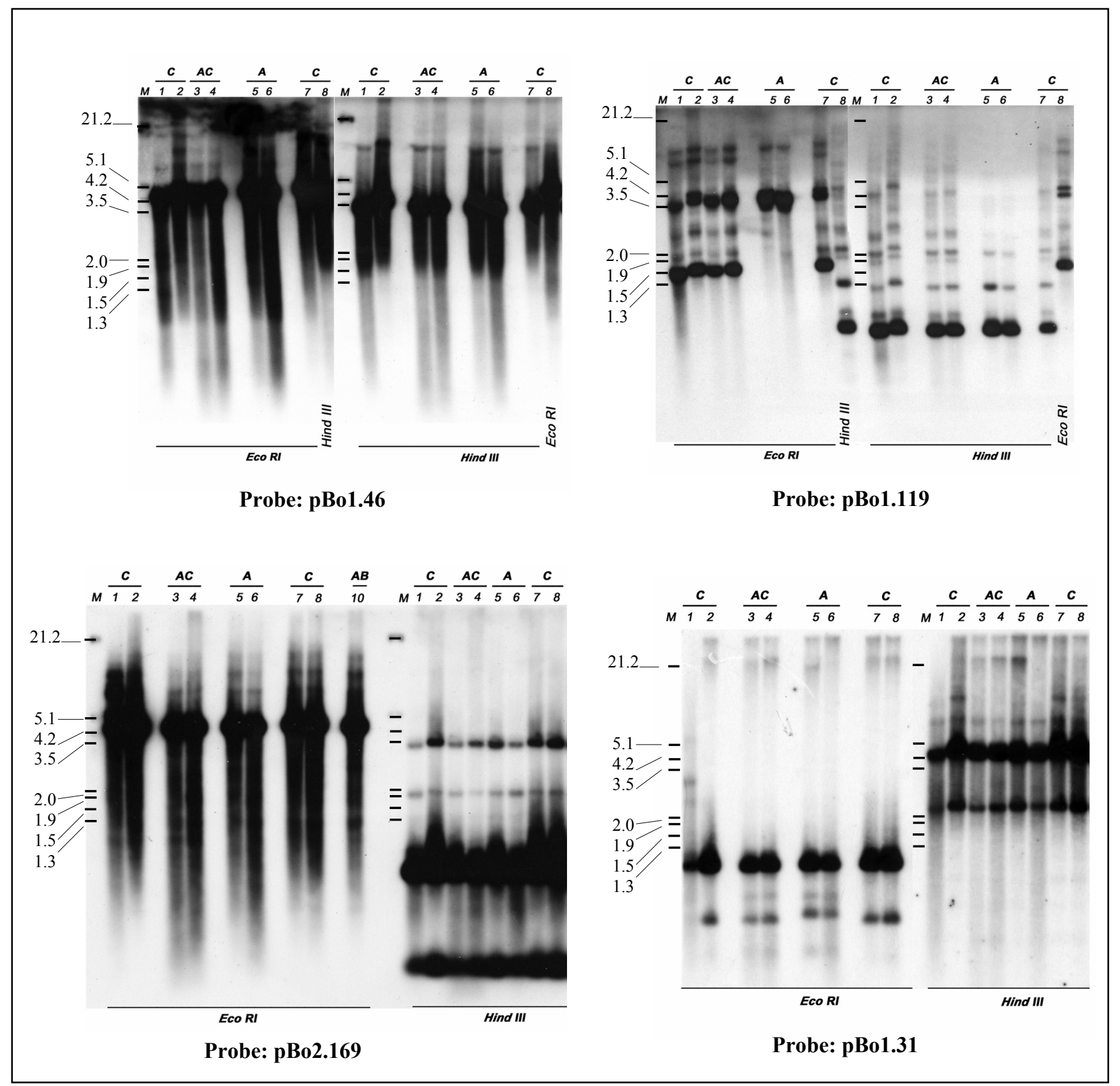

Figure 7. Southern blot hybridisation of genomic DNA digested with EcoRI or HindIII from different Brassica species with repetitive non species-specific clones. Brassica species: $B$. oleracea Vitamina (lane 1) and Market Victor (lane 2); B. napus Express (lane 3) and Iris (lane 4); B. rapa NPZ-35 (lane 5) and Perko (lane 6); B. incana (lane 7) and B. oleracea alboglabra (lane 8). Molecular weight marker (Lambda EcoRI/Hindlll, lane M) is given in $\mathrm{kb}$. 


\subsection{Sequence composition of repetitive DNA from Brassica oleracea and homology to published DNA sequences}

The size and the base composition of the inserts from the $C$ genome-enriched sequences, pBo1.6, pBo1.27 and pBo2.157, and two highly repetitive clones, pBo2.94 and pBo1.173, selected later as additional controls for in situ hybridisation, are presented in Table 2. The size of the cloned DNA fragments varied between 158 bp and 238 bp and the GC content varied from about $34.8 \%$ to $48.3 \%$. Figure 8 presents the nucleotide sequences of these clones. In the inserts of the $\mathrm{C}$ genomeenriched clones no restriction site was found for the enzymes EcoRI and HindIII, used for the genomic organisation analyses of these clones. However, clone pBo2.157 contains five nucleotide sequences from which HindlII restriction site could arise by single base change (underlined in Figure 8).

Table 2. Length and GC content of the sequenced pBo clones.

\begin{tabular}{ccc}
\hline pBo Clone & Length $(\mathrm{bp})$ & $\mathrm{G}+\mathrm{C}$ content (\%) \\
\hline 1.6 & 203 & 48.28 \\
1.27 & 182 & 43.41 \\
2.157 & 206 & 37.38 \\
2.94 & 238 & 37.82 \\
1.173 & 158 & 34.81 \\
\hline
\end{tabular}

All five clones showed similarity to previously described sequences of the EMBL/GenBank/DDBJ sequence databases. The data from the sequence alignments are summarised in Table 3 , including up to 5 homologous sequences from different organisms. In a segment varying between $116 \mathrm{bp}$ and $132 \mathrm{bp}$, the sequence pBo1.6 displayed between $85-89 \%$ identity with telomere-like DNA from many plant species. This sequence possessed 19 degenerated telomere motifs (15x TTT(G/C)GGG, 2x TATGGGG, 1x GTTGGGG, 1x TCTAGGG), and one perfect copy of the telomeric repeat of most plants (TTTAGGG), as shown in Figure 8 (see blocks). 


\begin{tabular}{|c|c|c|c|c|}
\hline pBo1.6 & 203bp; & $27 \mathrm{~A}$; & $78 \mathrm{~T}$; & 76 G. \\
\hline AATTTCCTCG & TAAAAAAAAC & ACGGACCTTT & GTATGGGGrT & TGGGGGTTGG \\
\hline GGTTTCGGQT & TTCGGQTTTC & GGG|TTTGGGG & TTTCGGGTTT & GGGG|TTTCGG \\
\hline GTTTCGGG|TT & TGGGG|TTTCG & GGITTAGGGT & ATGGGGTTTG & GGGTTTGGGG \\
\hline \multicolumn{5}{|c|}{ TTTCGGGTTT CGGG|rTTCTG ATTCTAGGGA TTTAAACATA ACACTCGTTA ATT } \\
\hline pBo1.27 & 182bp; & $56 \mathrm{~A}$; & $47 \mathrm{~T}$ & $48 \mathrm{G}$. \\
\hline AATTGGTTTA & TAGTCTTGGG & TTGCCTTCGG & AGATGATTGA & TGTTTGCATC \\
\hline GACAACTGCA & TGATCTACTG & GAAAGAAGAT & GACAAGTTAG & AAGAGTGTCG \\
\hline ATTCTGCAAA & AAATCACGAT & TCAAACCGCA & AGGCCGTGGG & AGGAATAGGG \\
\hline \multicolumn{5}{|c|}{ TACCGTACCA AAGGATGTGG TACCTACCAA TT } \\
\hline pBo2.157 & 206bp; & $68 \mathrm{~A}$; & $61 \mathrm{~T}$ & 53 G. \\
\hline AATTAGAACG & GATGTAGATT & ATGGTGTAGG & TACTGAGCAG & ATGGTAAATG \\
\hline ATCATTTTAG & AGGGGAAGAT & TTACCCAATG & CAGAAGCTAG & GAGATTTTAT \\
\hline GATATGTTGG & ATGCTGGAAA & GCAACCATTG & TACGAAGGTT & GCAGAGATGG \\
\hline \multicolumn{5}{|c|}{ TCATTCAGCT TTATCATCTG CTACAAGATT GATGGGCATT AAAACAGATT ATAATT } \\
\hline pBo2.94 & 238bp; & $67 \mathrm{~A}$; & $81 \mathrm{~T}$ & $40 \mathrm{G}$. \\
\hline AATTACCTGA & TTTGAAAGTG & GGATAACTTC & TTCATGCCAA & CTCCTATGAG \\
\hline \multicolumn{5}{|c|}{ ATTTATTCAA CTTCCTGGTG ATTCTCCACC ACTTTATGTA TCCAAATCAA CCTTTTCACA } \\
\hline AAGTGATTCA & TCCTGGTTTG & ATTGGAACGA & TGAAGAAGCT & GTGCTATTCC \\
\hline CGAACTGGGA & AACTGGAATC & ACCTGATTTG & AAAGTGGGAT & ААСТTCTTCT \\
\hline \multicolumn{5}{|c|}{ TGCCAACTCC TATGATATTT ATTCAATT } \\
\hline pBo1.173 & 158bp; & $53 \mathrm{~A}$ & $50 \mathrm{~T}$ & 27 G. \\
\hline AATTTATTAA & ATCTCATAGG & AGTTGGGATG & AAGAAGTTAT & CCСАCTTTCA \\
\hline AATCATGTGA & TTCCAGTTTC & CCAGTTTGGG & AATAAGACAG & CTTCTTCGTC \\
\hline
\end{tabular}

Figure 8. Nucleotide sequences, size and base composition of DNA fragments from $B$. oleracea cloned in pBo1.6, pBo1.27, pBo2.157, pBo2.94 and pBo1.173. The complete sequences are shown in groups of ten nucleotides from $5^{\prime}-3^{\prime}$ with the Tsp509I sites bordering the fragments shown in bold. The variations of the telomeric repeat TTTAGGG found in pBo1.6 is shown as blocks and the nucleotide sequences from which HindlII restriction site could arise by single base change found in pBo2.157 are underlined. 
The whole sequence of pBo2.157 showed high identity ( $98 \%$ of the whole sequence) with two sequences from Brassica napus in the databases. With one of them (accession number AJ245479) the similarity was in the region containing an Enhancer/Supressor-mutator (En/Spm)-type transposon like ORF and with the other (accession number X98373) the similarity was outside the coding region for the endo-polygalacturonase gene present in this sequence. When this last sequence was subjected as query for a search in the NCBI protein database high similarity also with $E n / S p m$-type transposons could be found in the region including the sequence homologous to $\mathrm{pBo} 2.157$. The sequence $\mathrm{pBo} 1.27$ exhibited also high identity $(87 \%$ of the whole sequence) with an En/Spm-type transposon like ORF from a clone of Brassica rapa.

Concerning the highly repetitive clones similarities varying from 89 to $98 \%$ were found with centromeric repeated DNA from Brassica species in the DNA databanks. In a pairwise sequence alignment, sequence $\mathrm{pBo} 2.94$ showed $90 \%$ homology with pBo1.173.

Moreover, an additional search in the Brassica oleracea sequence database from TIGR showed sequence identities of $99.5-100 \%$ with several sequences from this database, extending over the full length of the inserts, for all of the $C$ genomeenriched sequences. The degree of identity of sequences of this database with the sequence of the two high repeated clones was slightly lower than that for the $\mathrm{C}$ genome-enriched sequences: $98.3 \%$ homology for $\mathrm{pBo} 2.94$ and $96.2 \%$ for $\mathrm{pBo} 1.173$. 
Table 3. Comparison of the newly isolated repetitive DNA sequences from Brassica with sequences of the EMBL/GenBank/DDBJ databases.

\begin{tabular}{|c|c|c|c|c|}
\hline Clone (size in bp) & Homologous DNA sequence & $\begin{array}{c}\text { Database } \\
\text { accession number }\end{array}$ & $\begin{array}{l}\text { sequence identity } \\
\text { in bp }{ }^{a}(\%)\end{array}$ & E Value $^{\mathrm{b}}$ \\
\hline \multirow[t]{5}{*}{ pBo1.6 (203 bp) } & Chlorella vulgaris telomeric DNA & D26372 & $114 / 132(86)$ & $2 e^{-24}$ \\
\hline & Silene latifolia interstitial telomere-like repeat & AB085635 & $107 / 120(89)$ & $2 e^{-24}$ \\
\hline & Oryza sativa telomere sequence & AY367134 & $113 / 132(85)$ & $5 e^{-22}$ \\
\hline & Arabidopsis thaliana telomeric DNA & AC011621 & $113 / 132(85)$ & $5 e^{-22}$ \\
\hline & Nicotiana tabacum telomere sequence & D21066 & $113 / 132(85)$ & $5 e^{-22}$ \\
\hline \multirow[t]{2}{*}{ pBo1.27 (182 bp) } & Brassica rapa DNA for an En/Spm-type transposon & AB022082 & $160 / 182(87)$ & $9 e^{-45}$ \\
\hline & like ORF & & & \\
\hline \multirow[t]{2}{*}{ pBo2.157 (206 bp) } & Brassica napus DNA for an En/Spm-type transposon & AJ245479 & $202 / 206(98)$ & $1 e^{-102}$ \\
\hline & like ORF & X98373 & $202 / 206(98)$ & $1 e^{-102}$ \\
\hline
\end{tabular}


Table 3- continued

\begin{tabular}{|c|c|c|c|c|}
\hline Clone (size in bp) & Homologous DNA sequence & $\begin{array}{c}\text { Database } \\
\text { accession number }\end{array}$ & $\begin{array}{l}\text { Sequence identity } \\
\text { in } \mathrm{bp}^{\mathrm{a}}(\%)\end{array}$ & $E_{\text {Value }}{ }^{b}$ \\
\hline \multirow[t]{5}{*}{ pBo2.94 (238 bp) } & Canrep centromeric repetitive DNA from & X68786 & $224 / 230(97)$ & $1 e^{-109}$ \\
\hline & Brassica juncea & & & \\
\hline & Canrep centromeric repetitive DNA from $B$. napus & X61583 & $124 / 129(96)$ & $1 e^{-53}$ \\
\hline & B. rapa centromeric repetitive DNA & Z22947 & $194 / 217(89)$ & $4 e^{-63}$ \\
\hline & B. oleracea satellite DNA inverted direct repeat & M31436 & $131 / 136(96)$ & $5 e^{-53}$ \\
\hline \multirow[t]{5}{*}{ pBo1.173 (158 pb) } & Canrep centromeric repetitive DNA from & X68786 & $146 / 150(97)$ & $1 e^{-68}$ \\
\hline & Brassica juncea & & & \\
\hline & Canrep centromeric repetitive DNA from $B$. napus & X61583 & $123 / 127(96)$ & $6 e^{-55}$ \\
\hline & B. campestris centromeric repetitive DNA & Z22947 & $129 / 133(96)$ & $1 e^{-58}$ \\
\hline & B. oleracea satellite DNA inverted direct repeat & M31434 & $120 / 122(98)$ & $9 e^{-57}$ \\
\hline
\end{tabular}

${ }^{\text {a }}$ sequence identity= number (percentage) of base pairs that are identical in the query and the subject from the DNA databanks

${ }^{b}$ E Value- Describes the number of sequences expect to be found in a database just by chance and is the statistical significance threshold for reporting matches against database sequences. The default value used was 10 , such that 10 matches were expected to be found merely by chance. The BLAST service at $\mathrm{NBCl}$ was used for the analyses. 


\subsection{Cytogenetic characterisation and chromosome organisation of repetitive DNA sequences in Brassica napus and its relatives $B$. oleracea and $B$. rapa}

For the cytogenetical experiments the following Brassica varieties were used: $B$. napus Jockey, B. oleracea oleracea, B. rapa Rex, and B. carinata BRA 489/77.

\subsubsection{Cytogenetic characterisation of $B$. napus and its relatives}

The method for accumulation, fixation and squash preparation of Brassica chromosomes used in this work provided prometaphase and metaphase cells suitable for the cytogenetic characterisation of the three species analysed, namely, $B$. napus, B. oleracea and B. rapa.

Metaphase chromosome size and morphology after staining with the fluorochrome DAPI were used for the initial characterisation of the three Brassica species. In accordance with the literature, chromosome numbers of $B$. oleracea $(C C)$ and $B$. rapa (AA) were $2 n=18$ and 20 , respectively, whereas the diploid karyotype of $B$. napus (AACC) showed 38 chromosomes. Chromosomes of all three species were very small and similar in size and morphology. Most of the chromosomes from $B$. rapa were smaller than those from $B$. oleracea. Karyotypes of each species are shown in Figure 9. The length of the chromosomes varied between 1.0-2.6 $\mu \mathrm{m}$ in $B$. rapa, 1.8-2.7 $\mu \mathrm{m}$ in B. oleracea and and 0.8-2.5 $\mu \mathrm{m}$ in $B$. napus. With respect to the centromeric position, only metacentric and submetacentric chromosomes were found. B. rapa presented 12 metacentric and 8 submetacentric chromosomes, whereas $B$. oleracea presented 6 metacentric and 12 submetacentric chromosomes. The karyotype of $B$. napus consisted of 20 metacentric and 18 submetacentric chromosomes. Unquestionable identification of individual chromosomes was in most case not possible, due to their very small and similar sizes. Determination of chromosome origin in $B$. napus, whether from the $A$ or from the $C$ genome, was not possible on the basis of morphometric analysis alone. 
B. oleracea $(2 \mathrm{n}=18, \mathrm{CC})$

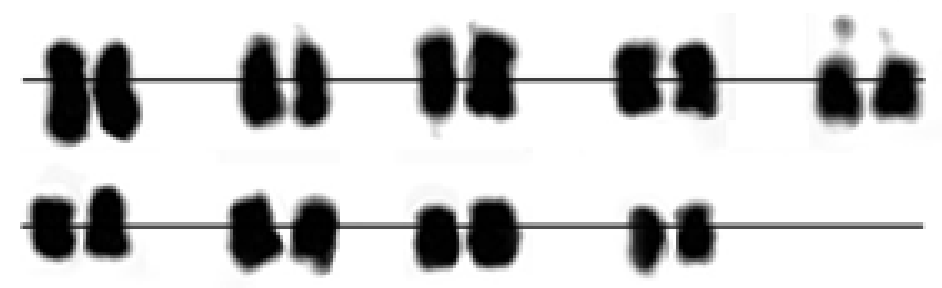

B. $\operatorname{rapa}(2 \mathrm{n}=20, \mathrm{AA})$

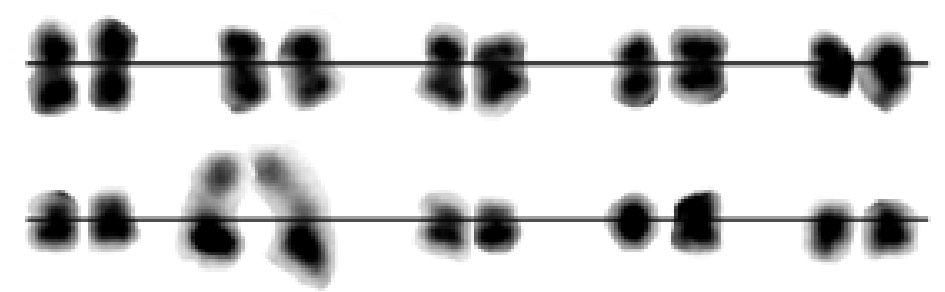

B. napus $(2 \mathrm{n}=38$, AACC $)$

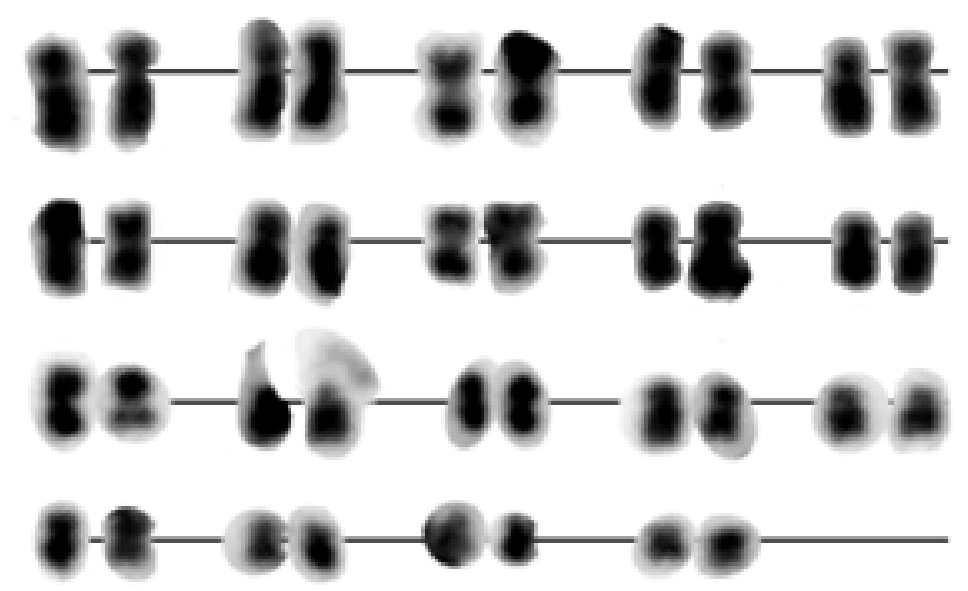

Figure 9. Karyotypes of $B$. oleracea, B. rapa and B. napus after DAPI staining, based on Figure $10 \mathrm{a}, \mathrm{b}$ and $\mathrm{c}$, respectively. Scale bar $=10 \mu \mathrm{m}$.

Despite the presence of some blocks of chromatin strongly stained with DAPI in the interphase nuclei of all three species analysed, DAPI staining alone did not produce any $\mathrm{DAPI}^{+}$banding pattern in the metaphase chromosomes (Figure 10). However, after the FISH procedure bands strongly stained with DAPI were frequently observed in interphase nuclei and in the centromeric region of the pro- and metaphase chromosomes. Interphase nuclei and metaphase chromosomes of $B$. oleracea and $B$. rapa as well as prometaphase chromosomes of $B$. napus stained with DAPI after FISH are shown in Figure 11. 


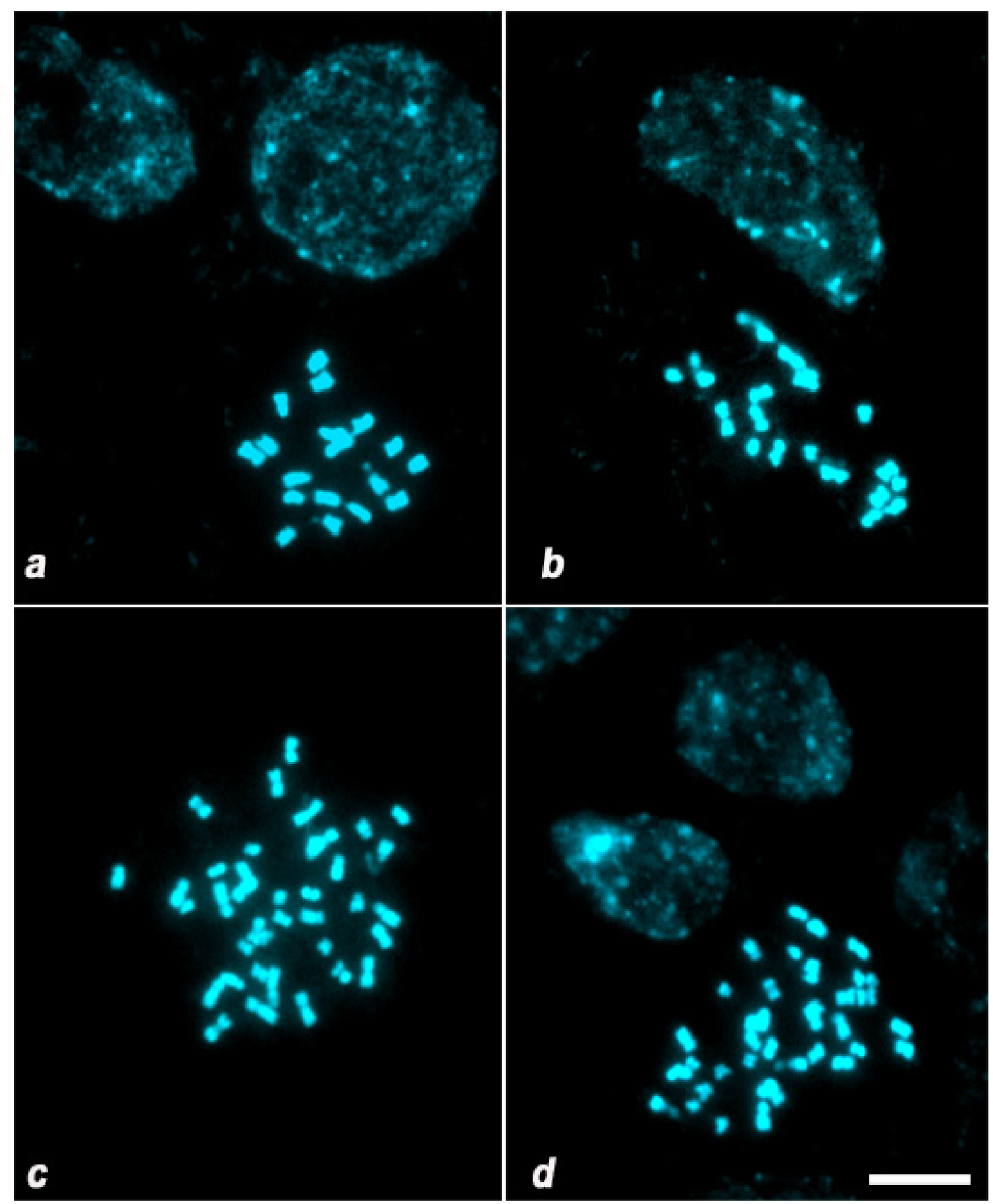

Figure 10. Interphase nuclei and mitotic metaphases of (a) B. oleracea, (b) B. rapa and (c, d) B. napus stained with DAPI. Scale bar= $10 \mu \mathrm{m}$ for all panels. 


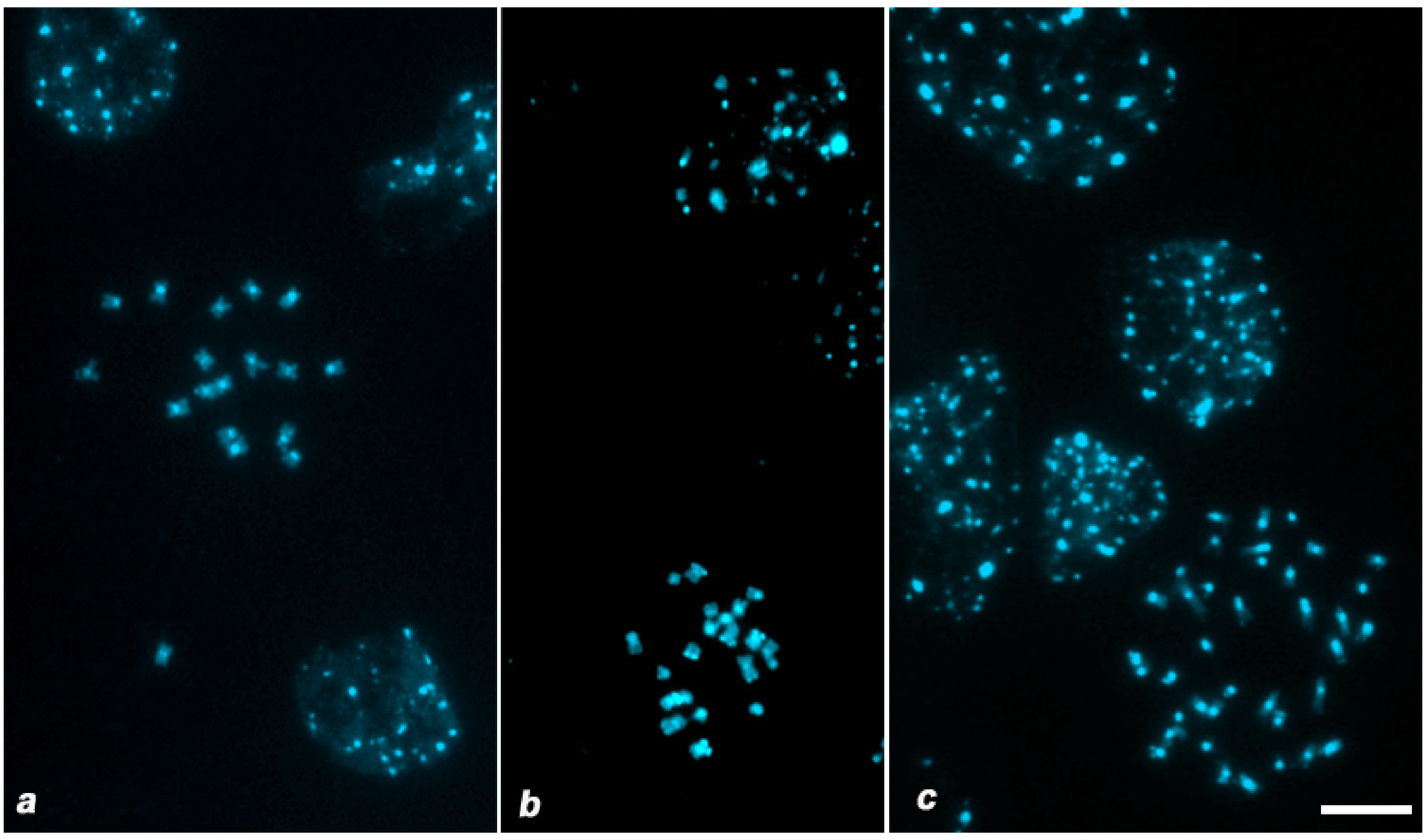

Figure 11. Interphase nuclei and mitotic metaphases of $B$. oleracea (a), B. rapa (b) and prometaphase of $B$. napus (c) stained with DAPI after FISH. Scale bar $=10 \mu \mathrm{m}$ for all panels. 


\subsubsection{Chromosome organisation of repetitive DNA sequences in Brassica}

For the establishment of the FISH procedure two probes were first used as controls: a 45S rDNA probe, generated by PCR, and the " $5+45 S$ rDNA" plasmid probe, containing part of both the $5 S$ and the $45 S$ rDNA genes. After labelling by PCR, nick translation or using the DIG-high prime DNA labelling kit, probes were tested in FISH experiments. Probes labelled with DIG-high prime DNA labelling kit were not suitable for FISH, giving high amount of background hybridisation in the cytological preparations, whereas probes labelled by PCR and nick translation provided suitable hybridisation signals. Therefore, PCR and nick translation were the labelling methods used in the subsequent experiments.

\section{S rDNA and "5+45S rDNA"}

Figures 12 and 13 show the results of FISH with probe $45 S$ rDNA and probe " $5+45 S$ rDNA", respectively, to the somatic metaphase chromosome complement of $B$. oleracea. In each image, the rDNA signals are large and discrete, and representative of those seen in a large number of cells analysed. With $45 S$ rDNA probe $B$. oleracea showed four hybridisation sites, one pair of large loci localised in the Nucleolus Organiser Region (NOR) of the satellite-carrying chromosomes, whereas the other pair of loci localised near the telomeric region and showed heteromorphism in size, with one large and one small locus (arrows in Figure 12 and 13). With probe " $5+45 S$ rDNA" hybridisation sites were present in six chromosomes from the diploid complement. Four chromosomes presented hybridisation sites as described for 45S rDNA, whereas the additional chromosome pair with hybridisation sites showed two adjacent loci localised near the centromeric region (see arrowheads in Figure 13). With both probes hybridisation signals from the small $45 \mathrm{~S}$ locus, localised near the telomeric region, were not always seen (Fig 13 e, g). 

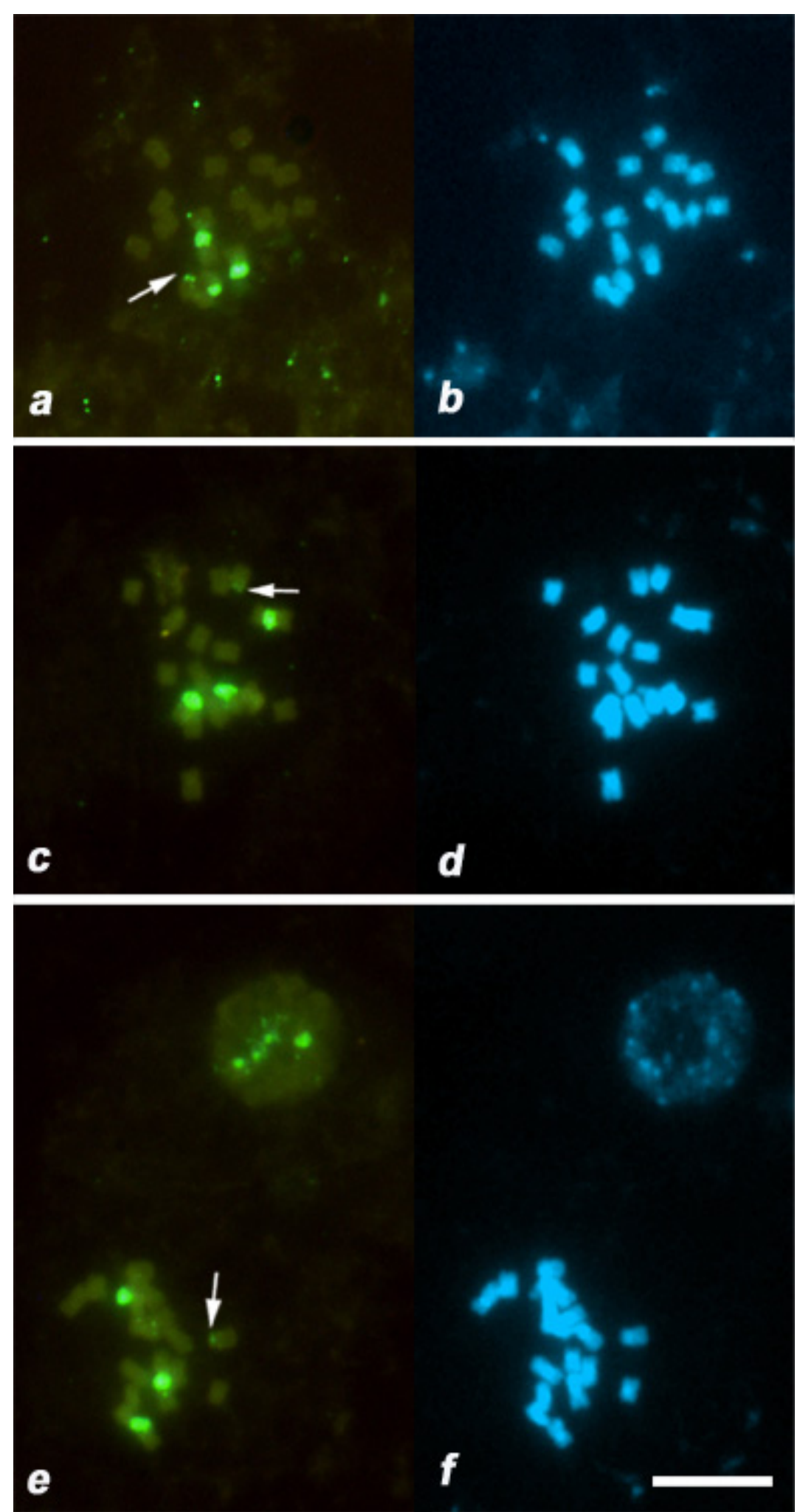

Figure 12. FISH with $45 \mathrm{~S}$ rDNA probe hybridised to somatic metaphase chromosomes of $B$. oleracea ( $a, c, e)$. Panels $b, d$ and $f$ show the same cells counterstained with DAPI. Arrows indicate the small locus. Scale bar $=10 \mu \mathrm{m}$ for all panels. 


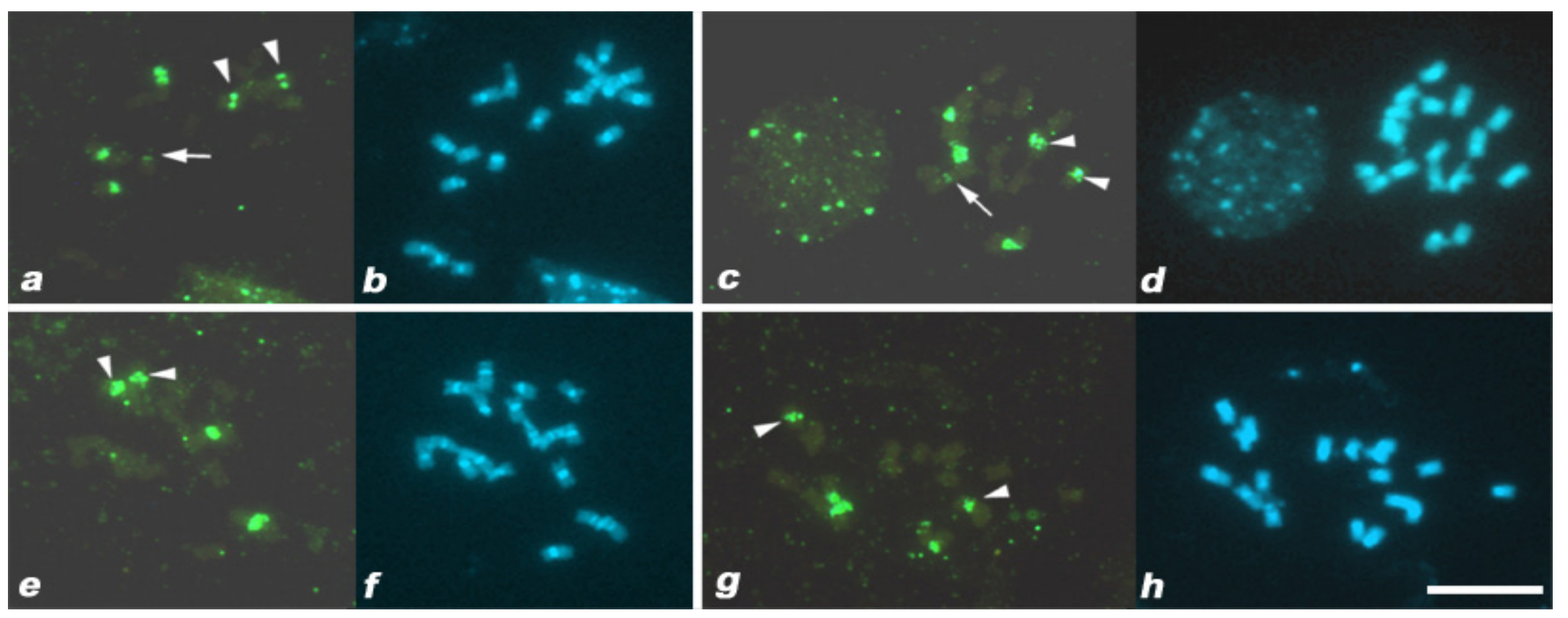

Figure 13. FISH with "5+45S rDNA" probe hybridised to somatic metaphase chromosomes of $B$. oleracea (a, c, e, g). Panels b, $d$, $f$ and $\mathrm{h}$ show the same cells counterstained with DAPI. Arrows and arrowheads indicate the small $45 \mathrm{~S}$ locus and the adjacent $5 \mathrm{~S}$ loci, respectively. Scale bar $=10 \mu \mathrm{m}$ for all panels. 
$B$. rapa and $B$. napus chromosomes were only probed with " $5+45 S$ rDNA" and showed, as in B. oleracea, clear rDNA signals in several metaphases (Figure 14). This probe allowed the identification of five chromosome types (based on Hasterok et al., 2001, with modification), named chromosomal type I to $\mathrm{V}$ (see schema for chromosomal types in Table 4 and arrows in Figure 14 e). Chromosomes of type I were large with a terminal hybridisation site. Chromosomes of type II were of intermediate sizes with a terminal hybridisation site and chromosomes of type III presented different lengths with one (or two very close) interstitial hybridisation site. Chromosomes of type IV, containing a terminal-subterminal hybridisation site, were much smaller than the other types and chromosomes of type $\mathrm{V}$, with varying sizes, showed no hybridisation site. Table 4 summarises the number of chromosomes from each type in the three species. Three, six and nine chromosome pairs were identified as containing rDNA genes in $B$. oleracea, $B$. rapa and $B$. napus, respectively.

Table 4. Number and types of chromosomes after FISH with probe "5+45S rDNA" in the diploid complement of $B$. napus and its progenitors.

\begin{tabular}{|c|c|c|c|c|c|c|c|}
\hline & & & \multicolumn{5}{|c|}{ Chromosomal type } \\
\hline Species & $2 n$ & Genome & 1 & II & $\| I^{a, b}$ & IV & $\mathrm{V}^{\mathrm{a}}$ \\
\hline B. oleracea & 18 & $\mathrm{CC}$ & 2 & 2 & 2 & 0 & 12 \\
\hline B. rapa & 20 & $\mathrm{AA}$ & 0 & 2 & 8 & 2 & 8 \\
\hline B. napus & 38 & AACC & 2 & 4 & 10 & 2 & 20 \\
\hline
\end{tabular}

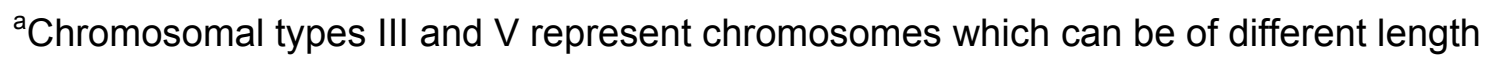
${ }^{\text {b}}$ Chromosomal type III may have one or two closely localised interstitial hybridisation site 


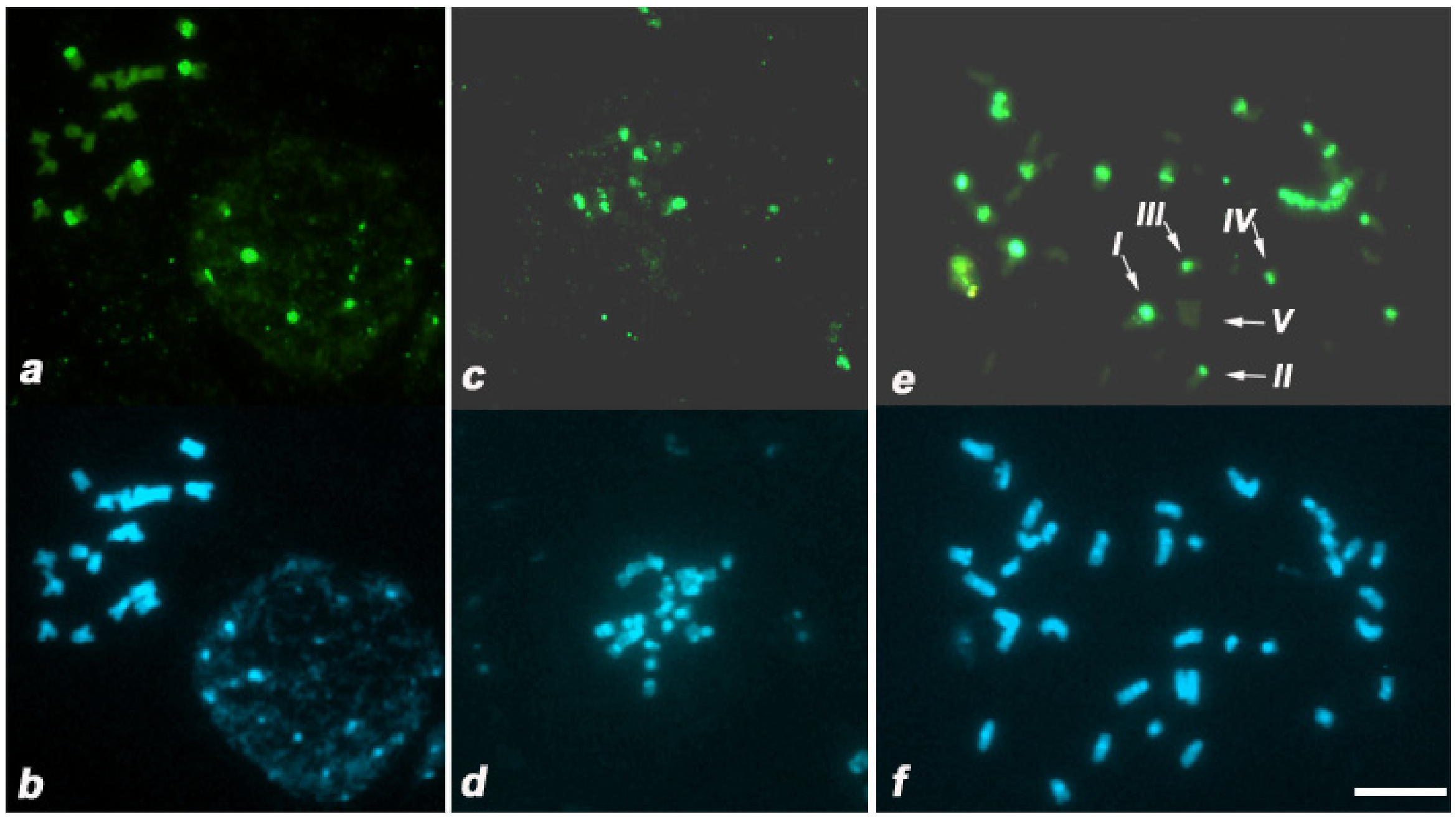

Figure 14. FISH with "5+45S rDNA" probe hybridised to somatic metaphase chromosomes of B. oleracea (a), B. rapa (c) and B. napus (e). Panels $b, d$ and $f$ show the same cells counterstained with DAPI. Chromosomal types I-V are indicated in e. Scale bar= $10 \mu \mathrm{m}$ for all panels. 


\section{pBo2.94 and pBo1.173}

Two additional controls were selected and investigated by $\mathrm{FISH}$ : pBo2.94 and pBo1.173. These clones were selected from the plasmid libraries, owing to the very strong hybridisation signals in the dot blot experiments with DNA from both the $A$ and the $\mathrm{C}$ genomes, indicating a high degree of repetition (like clone C6 in Figure 4). Experiments using these sequences as probes were performed in four species of Brassica: B. oleracea, B. rapa, B. napus and B. carinata. Large hybridisation sites, characteristic for tandemly repeated sequences, were found in all four species at the centromeric/ pericentromeric region of several chromosomes. These signals colocalised with brightly DAPI stained heterochromatic blocks. Table 5 summarises the number of signals found in each species and Figures 15 and 16 show the results of FISH with probes pBo2.94 and pBo1.173, respectively, to the somatic chromosome complement of Brassica species.

Table 5. Number of chromosomes with strong pericentromeric hybridisation sites for probe pBo2.94 and pBo1.173 in four Brassica species.

\begin{tabular}{llrr}
\hline Species & Genome (2n) & \multicolumn{2}{c}{ Probes } \\
\cline { 3 - 4 } & & $\mathrm{pBo2.94}$ & $\mathrm{pBo1.173}$ \\
\cline { 3 - 4 } B. oleracea & $\mathrm{CC}(18)$ & (not tested) & 12 \\
B. rapa & $\mathrm{AA} \mathrm{(20)}$ & $28-30$ & 16 \\
B. napus & AACC (38) & 12 & $28-30$ \\
B. carinata & BBCC (34) & & 12 \\
\hline
\end{tabular}




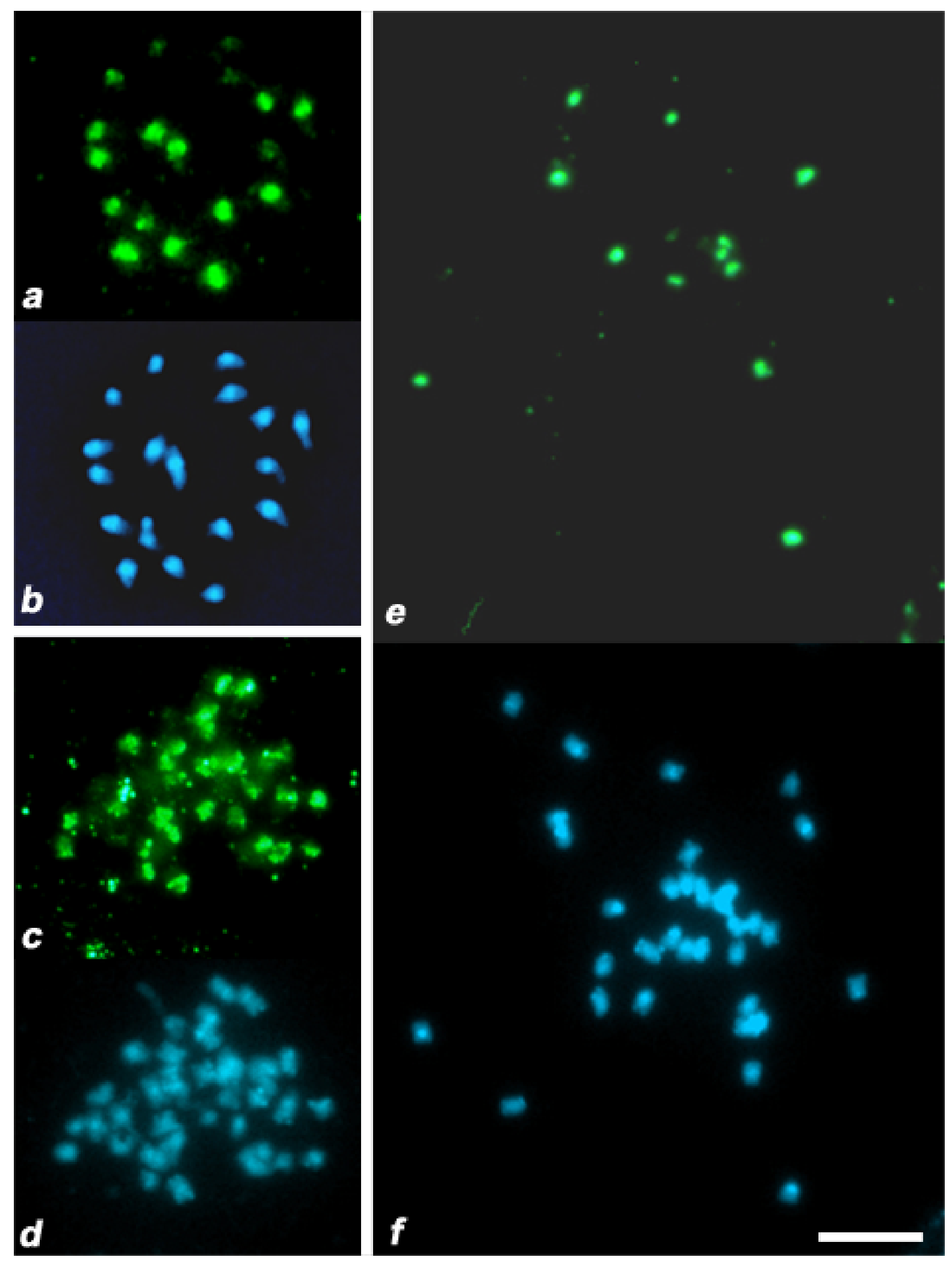

Figure 15. FISH with probe pBo2.94 hybridised to somatic metaphase chromosomes of $B$. oleracea (a), B. napus (c) and B. carinata (e). Panels b, $d$ and $f$ show the same cells counterstained with DAPI. Scale bar $=8 \mu \mathrm{m}$ for $\mathrm{a}, \mathrm{b}$ and $10 \mu \mathrm{m}$ for $\mathrm{c}-\mathrm{f}$. 


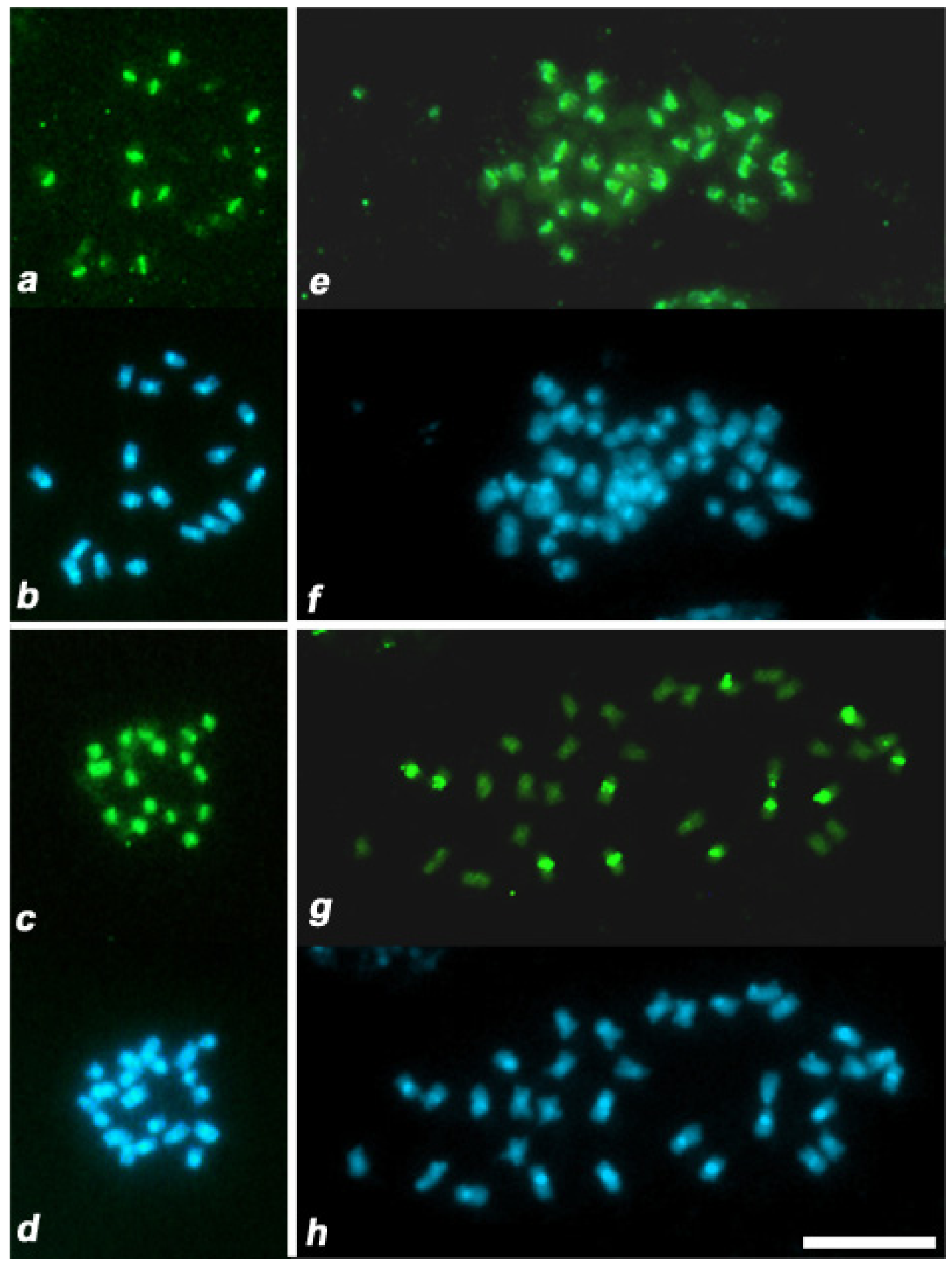

Figure 16. FISH with probe pBo1.173 hybridised to somatic metaphase chromosomes of B. oleracea (a), B. rapa (c), B. napus (e) and B. carinata (g). Panels $b, d, f$ and $h$ show the same cells counterstained with DAPI. Scale bar $=8 \mu \mathrm{m}$ for a-d and $10 \mu \mathrm{m}$ for e-h. 
While hybridisation signals could be detected in FISH with highly repetitive sequences, initially no signal could be seen using the sequences enriched in the $C$ genome. Since these probes were expected to produce signals weaker than that of pBo2.94 and pBo1.173, FISH experiments were repeated using pBo1.6, pBo1.27 and $\mathrm{pBo} 2.157$ as probes and analyses were carried out on a more sensitive microscope, in which even weak hybridisation signals could be visualised. The results are presented in Figures 17-20.

\section{pBo1.6}

As expected from the Southern blot analyses, probe pBo1.6 gave the most interesting results, differentiating the $\mathrm{A}$ and $\mathrm{C}$ genomes. Fluorescent in situ hybridisation showed that this repetitive sequence is present in all chromosomes of $B$. oleracea, but in none of the chromosomes of $B$. rapa for most cells. In $B$. oleracea signals were distributed in the interstitial and/or telomeric/subtelomeric region of all chromosomes (Figure $17 \mathrm{a}$ ). The amount of hybridisation signals varied among the chromosomes, with some chromosomes showing more hybridisation sites than others. In B. rapa no signal was detected in most of the cells and when detected they had a weaker intensity than in $B$. oleracea and were often detected as a single spot on only one chromatid in the telomeric/subtelomeric region of two to eight chromosomes (Figure $17 \mathrm{c}$ ).

$B$. napus showed also a variable number of chromosomes hybridising with the repetitive sequence pBo1.6. Eighteen to 24 chromosomes of $B$. napus presented hybridisation sites for pBo1.6 in the interstitial and/or telomeric/subtelomeric region. The amount of hybridisation signals varied, with larger chromosomes showing frequently more and stronger hybridisation signals than smaller ones, which showed few or no hybridisation signal at all (Figure $17 \mathrm{e}$ ). In some chromosomes of some cells, several hybridisation sites were detected along almost the whole chromosome length (see arrows in Figure $17 \mathrm{e}$ ). 

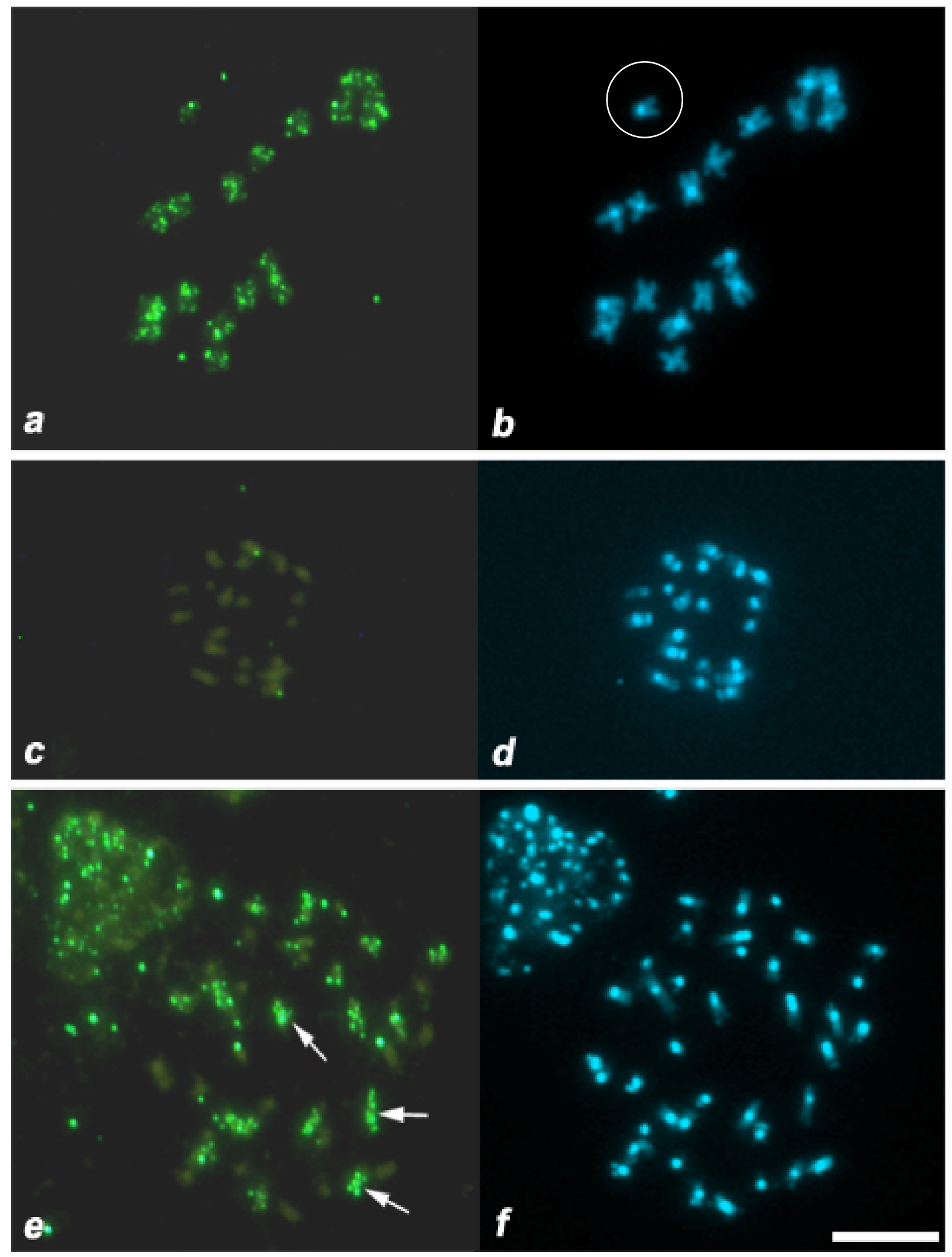

Figure 17. FISH with probe pBo1.6 hybridised to somatic metaphase chromosomes of $B$. oleracea (a), $B$ rapa (c) and $B$. napus (e). Panels $b, d$, and $f$ show the same cells counterstained with DAPI. Arrows in e indicate chromosomes labelled over its almost entire length. Circled chromosome in b was outside the metaphase plate. Scale bar $=10 \mu \mathrm{m}$ for all panels. 


\section{pBo1.27}

Probing B. oleracea chromosome spreads with labelled pBo1.27 resulted in dispersed hybridisation in all chromosomes giving signals of intermediate strength. Hybridisation sites were, however, not homogeneously distributed in the chromosome complement, with some chromosomes exhibiting more hybridisation sites than others (Figure $18 \mathrm{a}$ ). Probe pBo1.27 hybridised in $B$. rapa in the same way as for $B$. oleracea in all or almost all chromosomes, but the signals seemed to be weaker. Again some chromosomes showed more hybridisation sites than others (Figure $18 \mathrm{c}$ ). B. napus presented 14-16 chromosomes with dispersed signals of intermediate strength. The remaining chromosomes exhibited weak, very weak or no signal at all (Figure $18 \mathrm{e})$.

\section{pBo2.157}

The hybridisation pattern of probe pBo2.157 was very similar to that of pBo1.27, with dispersed hybridisation signals in the chromosomes of all three species. In $B$. oleracea all 18 chromosomes showed hybridisation signals of intermediate intensity (Figure $19 \mathrm{a}$ ), whereas in $B$. rapa signals seemed to be weaker and not in all chromosomes (Figure $19 \mathrm{c}$ ). Background hybridisation hampered the quantification of the chromosomes without signals in B. rapa. For B. napus it was also not possible to determine the number of chromosomes with hybridisation sites for pBo2.157, due to the low quality of the metaphases found after FISH with this sequence. However it was possible to identify several chromosomes labelled and also chromosomes with weak or no signal (Figure 19 e). 

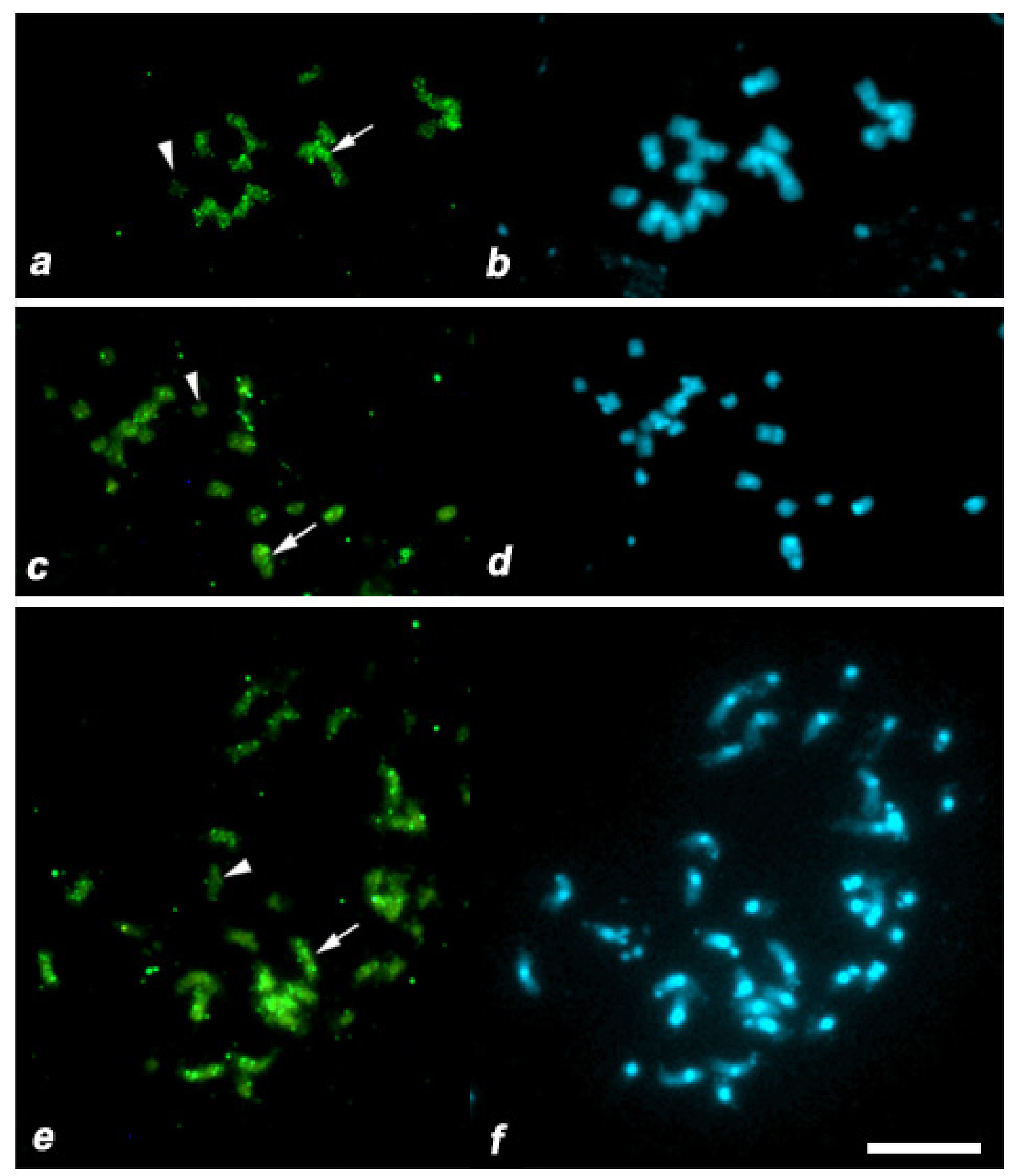

Figure 18. FISH with probe pBo1.27 hybridised to somatic metaphase chromosomes of $B$. oleracea (a), B. rapa (c) and B. napus (e). Panels b, $d$, and f show the same cells counterstained with DAPI. Chromosomes with less and more hybridisation sites are indicated in a, c and e by arrowheads and arrows, respectively. Scale bar= $10 \mu \mathrm{m}$ for all panels. 


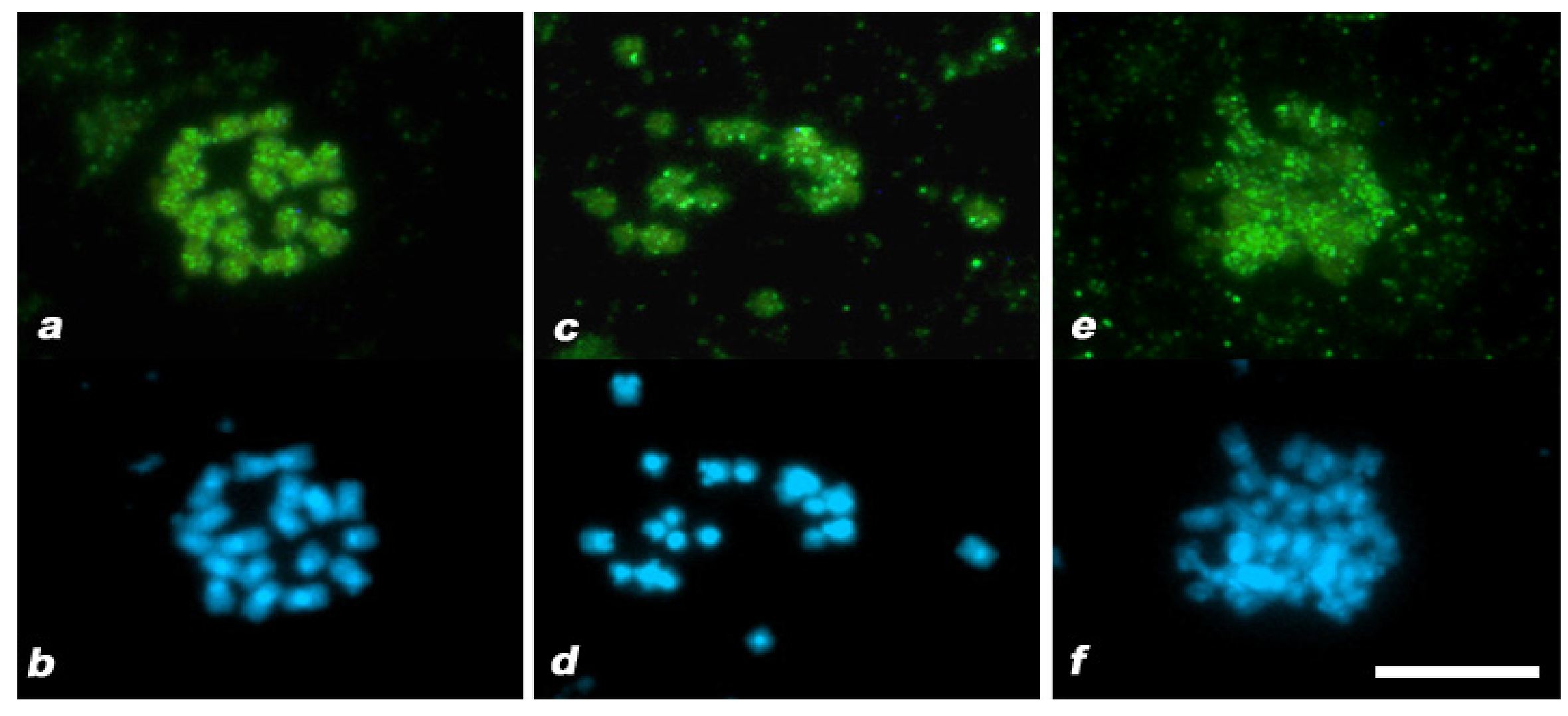

Figure 19. FISH with probe pBo2.157 hybridised to somatic metaphase chromosomes of $B$. oleracea (a), B. rapa (c) and B. napus (e). Panels $b, d$, and $f$ show the same cells counterstained with DAPI. Scale bar $=10 \mu \mathrm{m}$ for all panels. 
In general, hybridisation signals after FISH using probes pBo1.6, pBo1.27 and pBo2.157 were absent on the centromeric regions of Brassica chromosomes. In interphase nuclei hybridisation sites for the sequences enriched in the $\mathrm{C}$ genome were dispersed throughout the whole nucleus, whereas signals from pBo2.94 and pBo1.173 were found clustered in some regions, coinciding with most of the DAPI blocks from the interphase nuclei (Figure 20).
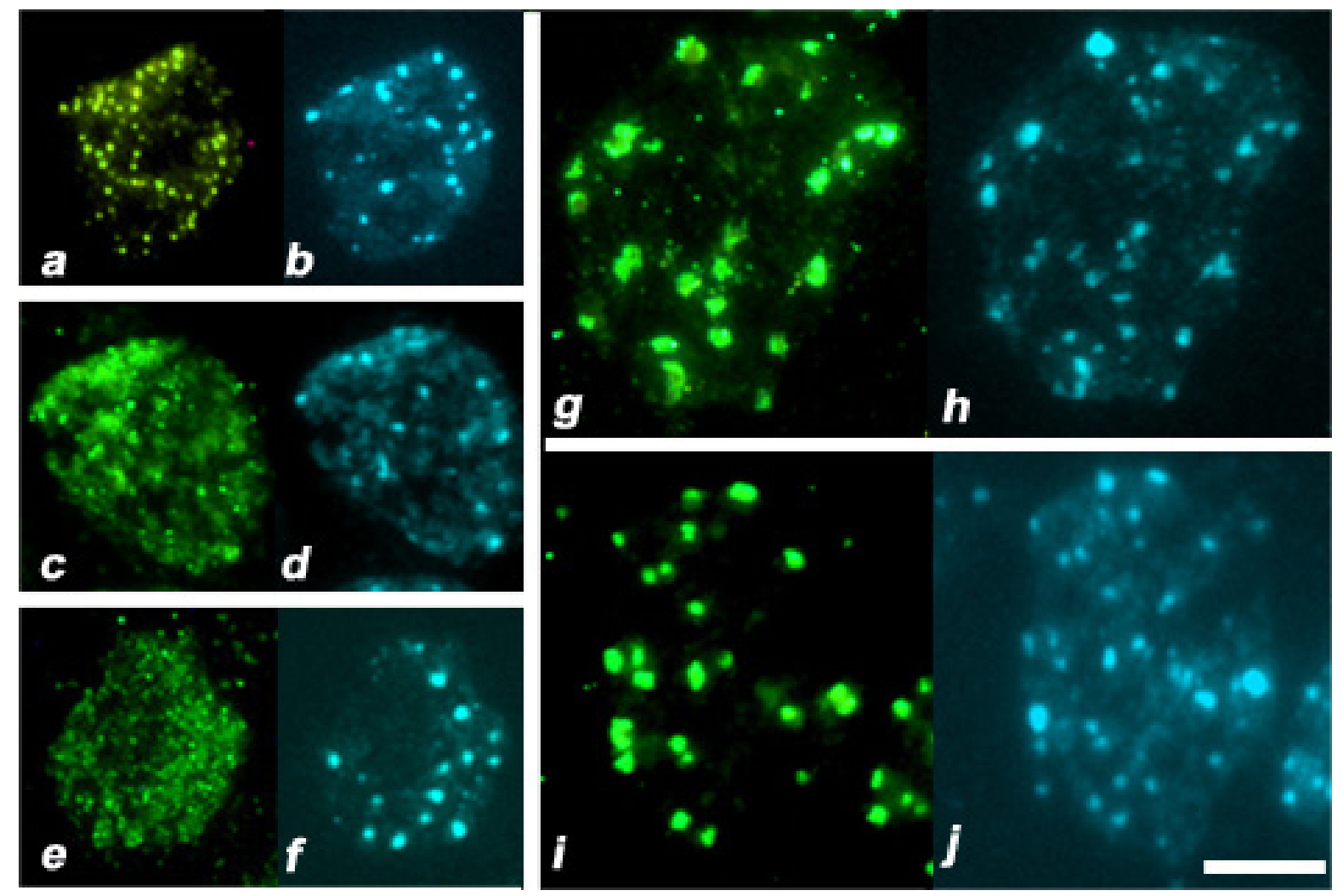

Figure 20. FISH with probes pBo1.6 (a), pBo1.27 (c) and pBo2.157 (e) hybridised to interphase nuclei of $B$. oleracea and with probes pBo2.94 (g) and pBo1.173 (i) hybridised to interphase nuclei of $B$. napus. Panels $b, d, f, h$ and $j$ show the same cells counterstained with DAPI. Scale bar= $10 \mu \mathrm{m}$ for all panels.

A short overview of the results obtained with fluorescent in situ hybridisation using the newly isolated repetitive sequences as probes and the homology of these repeats to known sequences is shown in Table 6. 
Table 6. Characteristics of newly isolated repetitive DNA sequences from $B$. oleracea. Homology to known sequences, chromosome location after FISH and frequency of signals on the chromosomes of B. oleracea, B. rapa and B. napus.

\begin{tabular}{|c|c|c|c|c|c|}
\hline \multirow{2}{*}{$\begin{array}{c}\text { Clone } \\
\text { (size in bp) }\end{array}$} & \multirow{2}{*}{$\begin{array}{l}\text { Homologous } \\
\text { sequences in } \\
\text { databases }\end{array}$} & \multirow{2}{*}{$\begin{array}{l}\text { Chromosomal } \\
\text { location }\end{array}$} & \multicolumn{2}{|c|}{ Frequency of signals in the genomes of: } & \multirow[b]{2}{*}{$\begin{array}{c}\text { B. napus } \\
(2 \mathrm{n}=38, \mathrm{AACC})\end{array}$} \\
\hline & & & $\begin{array}{l}\text { B. oleracea } \\
(2 \mathrm{n}=18, \mathrm{CC})\end{array}$ & $\begin{array}{c}\text { B. rapa } \\
(2 n=20, A A)\end{array}$ & \\
\hline $\begin{array}{l}\text { pBo1.6 } \\
(203)\end{array}$ & $\begin{array}{l}\text { telomere-like } \\
\text { DNA repeat }\end{array}$ & $\begin{array}{l}\text { telomeric and } \\
\text { interstitial }\end{array}$ & $\begin{array}{l}\text { frequent in all } \\
\text { chromosomes }\end{array}$ & $\begin{array}{l}\text { absent (or only in the telomere } \\
\text { from 2-8 chromosomes) }\end{array}$ & $\begin{array}{l}\text { frequent in } 18-24 \text { chromosomes } \\
\text { and rare or absent in the others }\end{array}$ \\
\hline $\begin{array}{l}\text { pBo1.27 } \\
(182)\end{array}$ & $\begin{array}{l}\text { Brassica rapa } \\
\text { DNA for an } \\
\text { En/Spm-type } \\
\text { transposon-like } \\
\text { ORF }\end{array}$ & $\begin{array}{l}\text { dispersed } \\
\text { over the } \\
\text { chromosomes }\end{array}$ & $\begin{array}{l}\text { frequent in most } \\
\text { and rare in some } \\
\text { chromosomes }\end{array}$ & $\begin{array}{l}\text { Similar to } \mathrm{C} \text { genome but less } \\
\text { frequent }\end{array}$ & $\begin{array}{l}\text { frequent in } 14-16 \text { chromosome } \\
\text { and rare or absent in the others }\end{array}$ \\
\hline $\begin{array}{l}\text { pBo2.157 } \\
(206)\end{array}$ & $\begin{array}{l}\text { Brassica napus } \\
\text { DNA for an } \\
\text { En/Spm-type } \\
\text { transposon-like } \\
\text { ORF }\end{array}$ & $\begin{array}{l}\text { dispersed } \\
\text { over the } \\
\text { chromosomes }\end{array}$ & $\begin{array}{l}\text { frequent in all } \\
\text { chromosomes }\end{array}$ & $\begin{array}{l}\text { less frequent than in } \mathrm{C} \text { genome } \\
\text { in some chromosomes and } \\
\text { absent in others }\end{array}$ & $\begin{array}{l}\text { frequent in some chromosomes } \\
\text { and less frequent, rare or absent } \\
\text { in others }\end{array}$ \\
\hline $\begin{array}{l}\text { pBo2. } 94 \\
(238)\end{array}$ & $\begin{array}{l}\text { Brassica } \\
\text { centromeric DNA } \\
\text { repeat }\end{array}$ & $\begin{array}{l}\text { in tandem in } \\
\text { the centromeric } \\
\text { region }\end{array}$ & $\begin{array}{l}\text { present in 12-14 } \\
\text { chromosomes }\end{array}$ & (not tested) & present in $28-30$ chromosomes \\
\hline $\begin{array}{l}\text { pBo1.173 } \\
(158)\end{array}$ & $\begin{array}{l}\text { Brassica } \\
\text { centromeric DNA } \\
\text { repeat }\end{array}$ & $\begin{array}{l}\text { in tandem in } \\
\text { the centromeric } \\
\text { region }\end{array}$ & $\begin{array}{l}\text { present in } 12 \\
\text { chromosomes }\end{array}$ & present in 16 chromosomes & present in $28-30$ chromosomes \\
\hline
\end{tabular}




\section{Discussion}

\subsection{Search for $B$. oleracea species-specific repetitive sequences}

In the present work B. oleracea repetitive sequences useful as molecular cytogenetic markers were searched to assist in the physical identification of highly homeologous $A$ and $C$ genome chromosomes or chromosome segments in $B$. napus $(2 n=36$, $A A C C)$. It is well know that the species $B$. oleracea $(2 n=18, C C)$ and $B$. rapa $(2 n=$ $20, A A)$ are very closely related. Several publications using molecular markers have shown the high homeology between these two genomes (Palmer et al., 1983, Song et al., 1988 and 1995, Parkin et al., 1995, Sharpe et al., 1995, Cheung et al., 1997). For instance, the nucleotide composition of a highly repetitive sequence family in $B$. rapa shows $98 \%$ sequence identity with that of $B$. oleracea (Lakshmikumaran and Ranade, 1990) and comparisons of rDNA intergenic spacer, which display extensive variation even among closely related species, revealed high sequence homology for these species (Bhatia et al., 1996). Meiotic studies in B. campestris (Syn: B. rapa)- B. alboglabra (Syn: B. oleracea var. alboglabra) addition lines have also revealed various degrees of homeology between the different chromosomes of the $\mathrm{A}$ and $\mathrm{C}$ genomes (Cheng et al., 1994). Moreover, the distinction between $A$ and $C$ genomes in $B$. napus through genomic in situ hybridisation was not possible, because of the high degree of cross-hybridisation between the chromosomes and the genomic DNA of both species used as probe (Snowdon et al., 1997a, Bellin and dos Santos, 2002). In view of this close relationship between $B$. oleracea and $B$. rapa, it was not expected to find a great number of $C$ genome-specific repetitive sequences. For this reason a phage library, that enables the screening of many clones in a short period of time, was initially chosen to screen for $B$. oleracea specific repetitive DNA.

To find repetitive DNA sequences from $B$. oleracea the strategy of shot-gun cloning of DNA fragments after digestion with Tsp509I, a frequent cutter restriction enzyme, was used, followed by selection of clones with repetitive DNA through replica plaque hybridisation using total DNA from $B$. oleracea and $B$. rapa as probes. After the plaque hybridisation, however, only $0.45 \%$ to $2.4 \%$ of the clones from the three libraries analysed could be identified as containing repetitive DNA. A much higher amount of repetitive DNA was expected to be found, since repetitive sequences form an important part of the eukaryotic DNA and in higher plants they may account for 20 
to more than $90 \%$ of the genome (Flavell, 1974, 1980). Also in Brassica species several families of repetitive sequences have been found (Ouyang and Buell, 2004).

In B. nigra, for example, Gupta et al. (1990) isolated a tandem repeated sequence that represents alone more than $2.5 \%$ of the haploid genome from this species and Beridze (1975) found, by gradient centrifugation, that the satellite DNA of $B$. nigra represents $37 \%$ of the nuclear genome. Uzunova (1994), isolating DNA probes for RFLP analyses in rapeseed, found that about $19 \%$ from 1650 clones of a B. napus plasmid library were of repetitive nature, indicated by the strong hybridisation signals with rapeseed total DNA. A Hindlll family of highly repetitive DNA sequences from $B$. napus represents alone $3.9 \%$ of the genome of $B$. oleracea (Xia et al., 1993).

A possible explanation for detecting only a low proportion of clones with repetitive DNA in the phage libraries may lie on the small amount of DNA present in each phage plaque in combination with the type of DNA used as probe, i.e. total genomic DNA. Probably the quantity of middle and low repetitive sequences present in the probe was not sufficient to produce hybridisation signals strong enough to be visualised and only plaques with highly repetitive sequences could be identified. Moreover, the species-specificity from the plaques selected in the phage library 1 was not confirmed. Differences in the replica membranes, caused for example from small air bubbles between the membrane and the agar and background hybridisations, giving false positive signals, are possible explanations for that observation. In conclusion, the phage libraries, in the way they were used, were not suitable for identification of species-specific repetitive sequences from the $B$. oleracea genome.

In contrast to the phage libraries, the plasmid libraries used in this work proved to be suitable for the screening of repetitive sequences present in the genome of $B$. oleracea. These libraries were constructed and analysed in the same way as the phage libraries but using pUC19 plasmid as vector. The proportion of the clones representing repetitive sequences $(21 \%)$ was in accordance with the expectation (see above). C genome-enriched clones were found in these libraries, but none of them was strictly $C$ genome-specific.

It could be asked whether the number of clones screened was high enough to find species-specific repetitive sequences. The number of clones that should be screened 
for this purpose can not be determined a priori and is rarely mentioned in other publications. However, there are some instances where this number was reported and in this case they are widely variable. For example, De Jeu et al. (1997) found species-specific repetitive DNA from Alstroemeria aurea by screening only 180 clones of transformed E. coli. Li et al. (1995) screened about 500 white colonies to find one specific repeated sequence from Haynaldia villosa, an annual relative of wheat. On the other hand, Calderini et al. (1997) screened about 800 clones from a partial plasmid DNA library to find species-specific repetitive DNA in Medicago and libraries consisting of 1000 and 700 recombinant clones were screened to find species-specific sequences from Solanum brevidens and S. tuberosum, respectively (Pehu et al., 1990). For Medicago, Calderini et al. (1997) found eight clones that showed hybridisation signals with $M$. corulea DNA but not with $M$. arborea, two closely related species. However, all Medicago clones bore the same sequence, showing that closely related species do not possess a high number of genomespecific repetitive DNA. In Avena sativa ( $2 n=6 x=42$, AACCDD genome), for instance, no repetitive sequences were identified that could distinguish between the $A$ and $D$ genomes, although $A / D$ and $C$ genome-specific DNA sequences were found (Ananiev et al, 2002).

For Brassica species, at least two B genome-specific repetitive sequences were found (Gupta et al., 1992, Kapila et al., 1996b), whereas only one paper reported an A genome-specific middle repetitive DNA (Iwabuchi et al., 1991). This B. rapaspecific repeat was isolated by screening about 1100 recombinant plasmids.

Considering that the genome size of $B$. oleracea is $0.630 \times 10^{9} \mathrm{bp} / 1 \mathrm{C}$ (Arumuganathan and Earle, 1991) and that the average size of the cloned DNA was $800 \mathrm{bp}^{1}$, the plasmid libraries together represent about $0.1 \%$ of this genome. The number of clones screened in the present work would probably be enough to find species-specific repetitive sequences if the homology of the genomes analysed would have been lower. As shown above, for several species, a smaller number of clones was sufficient for this purpose.

After the dot blot hybridisation several clones showed some differences in the intensity of hybridisation with the $\mathrm{A}$ and the $\mathrm{C}$ genome of Brassica. Fifteen such

\footnotetext{
${ }^{1}$ Inset size average is bases on the estimated length of the 15 selected clones, which varied from $150-1500 \mathrm{bp}$.
} 
clones were further analysed by Southern blot, but for only 3 the difference found in the first screening could be confirmed. The remaining clones were either repetitive in both genomes (10 clones) or not repetitive at all (2 clones). This result was not very surprising, since plasmid DNAs extracted with a rapid alkaline procedure were used in the dot blot experiments and DNAs extracted in this way are not free of contaminations, like proteins and RNAs. Differences in the hybridisations with dot blotted replica membranes should be expected and more precise and sensitive methods, like Southern blot hybridisation, are necessary to confirm possible positive results from the dot blot. However, possible experimental errors, like differences in the amount of plasmid DNA loaded in the replica membranes, mistakes in the identification of the loaded clones etc., can not be ruled out as possible causes for the high number of false positive clones found by the dot blot hybridisation.

An analysis of the hybridisation patterns for the 13 clones that were repetitive in the Southern blot hybridisation gives the impression that these clones are organised as dispersed sequence in the $B$. oleracea genome, since none of them showed a pattern of hybridisation like a ladder, typical for tandem repeated sequences. Sequences repeated in tandem usually show this ladder-like pattern of hybridisation when an enzyme that cuts the sequence at least one time is used to digest the genomic DNA investigated. This happens because the different units of the sequence, repeated in tandem, usually exhibit some nucleotide differences, caused by mutations during the evolution of the sequence since its amplification. The repeated units are then not exactly the same. If mutations occur in the recognition site of an enzyme, the enzyme will not cut the modified sequence and fragments of the genomic DNA with different sizes will hybridise with the probed sequence, causing a pattern of hybridisation similar to a ladder. Although the ladder-like pattern of hybridisation have not been found for the 13 repetitive clones analysed by Southern blot hybridisation, it is not possible to determine how these sequences are organised in the genome, since the organisation of an unknown DNA sequence can only be determined by Southern blot if several restriction enzymes are used to digest the genomic DNA. Another way to determine the organisation of repeated sequences in the genome is through in situ hybridisation. In this case the location can be seen directly on the chromosomes. Since the objective of the present work was the in situ localisation of selected sequences in Brassica, digestion with several enzymes, in order to find their genomic organisation by Southern blot, would not be required. 
The clear differences found in the intensity of hybridisation with the $\mathrm{A}$ and $\mathrm{C}$ genomes for the three $C$ genome-enriched clones show that these sequences are present in different copy-number in the genomes of $B$. oleracea and $B$. rapa. As high stringency conditions were used in the experiments (post-hybridisation washes were made in $0.5 \times \mathrm{SSC} / 0.05 \%$ SDS at $65^{\circ} \mathrm{C}$, giving stringencies of $84-88.6 \%^{2}$ for the different C genome-enriched sequences) the hybridisation patterns found can not be attributed to a high amount of imperfect DNA-DNA hybrids. The organisation of the $\mathrm{C}$ genomeenriched clones in the two genomes, whether in tandem or interspersed in the chromatin throughout the genome, could not be determined based only on the Southern blot analyses for the clones pBo1.6 and pBo1.27, since no recognition site for the enzymes EcoRl and Hindlll were found in their sequences. On the other hand, for pBo2.157 five recognition sites for Hindlll could occur as the result of a single base pair change, making it likely that many copies of this repetitive sequence in the C genome should contain a Hindlll recognition site. If $\mathrm{pBo} 2.157$ sequences were organised in tandem, ladder-like bands should consequently appear in genomic DNA digested with this enzyme. This was the case, for example, for tandemly repeated sequences from Glycine max, Nicotiana plumbaginifolia and Lens culinaris (Kolchinsky and Gresshoff, 1995, Chung-Mong et al., 1997, Galasso et al., 2001). These sequences showed a ladder-like hybridisation pattern after Southern blot hybridisation with genomic DNA digested with endonucleases that had only similar restriction site in the cloned sequences. However this was not the case for pBo2.157, indicating that this sequence is dispersed in the genome of Brassica. The subsequent in situ hybridisation using this sequence as probe confirmed its dispersed organisation. A more detailed discussion of the molecular data of the $\mathrm{C}$ genomeenriched clones ( $\mathrm{pBo1} .6, \mathrm{pBo} 1.27$ and $\mathrm{pBo} 2.157$ ) is presented together with the analyses of the chromosomal organisation of these sequences.

\subsection{Cytogenetic characterisation of $B$. napus and its relatives}

Morphological analysis is a fundamental method of chromosome identification. In some plant species, e.g. Crepis capillaris (Jamilena et al., 1994), the determination of chromosome length, centromere position and location of the secondary constriction is sufficient for the identification of all chromosome pairs in the karyotype. Mitotic metaphase chromosomes of Brassica species, however, do not have enough

\footnotetext{
${ }^{2}$ Calculated after Meinkoth and Wahl, 1984.
} 
morphological features for their identification since they are very small and similar in size. Nevertheless, the chromosome number, size and morphology were analysed in $B$. napus and its relatives, $B$. oleracea and $B$. rapa, in order to provide an initial karyotypic characterisation of these species.

B. rapa $(2 n=20, A A)$ presented a more asymmetrical karyotype than $B$. oleracea $(2 \mathrm{n}=18, \mathrm{CC})$. Chromosome size in $B$. rapa varied from 1.0 to $2.6 \mu \mathrm{m}$, whereas in $B$. oleracea they varied from $1.8-2.7 \mu \mathrm{m}$. Additionally, most of the chromosomes of $B$. rapa were smaller than that of B. oleracea (see Figure 9). Cheng et al. (1995) also observed that chromosomes of the $\mathrm{C}$ genome are larger than those of the $\mathrm{A}$ genome and the inspection of chromosome sizes in several publications also shows differences in size between $A$ and $C$ genome chromosomes (see for example pictures in Hasterock et al., 2001 and Snowdon et al., 2002). This is in accordance with the differences in genome size between these species (Arumuganathan and Earle, 1991; Narayan, 1998). Since the genome size of $B$. oleracea is larger (630 $\mathrm{Mbp}$ or $0.97 \mathrm{pg} / 1 \mathrm{C}$ ) than that of $B$. rapa (506 $\mathrm{Mpb}$ or $0.84 \mathrm{pg} / 1 \mathrm{C}$ ) and the chromosome number is smaller $(2 n=18$ in $B$. oleracea versus $2 n=20$ in $B$. rapa), then the chromosomes from the $A$ genome should be smaller than those of the $C$ genome, as described in the present work. In $B$. napus differences in chromosome size were also conspicuous, with chromosomes length varying between 0.8 to 2.5 $\mu \mathrm{m}$. It seems to be evident that larger chromosomes originate from the $\mathrm{C}$ genome whereas smaller ones originate from the A genome.

Concerning the morphology, only metacentric and submetacentric chromosomes were found in the metaphase of the three Brassica species analysed. This is consistent with the results reported on B. oleracea by Wang et al. (1989). However, subterminal and, in few cases, terminal chromosomes were reported for $B$. napus, $B$. rapa and B. oleracea (Olin-Fatih and Heneen, 1992, Cheng et al., 1995, Hasterock and Maluszynska, 2000a). These discrepancies might be the result of differences in varieties and/or methods used. The use of later prophases and prometaphases in several karyotype descriptions, in contrast with metaphases used in the present work, is probably the most important difference influencing the chromosome morphology, since Brassica chromosomes present distal arms not homogeneously condensed at later prophases/ prometaphase and differences in the arm ratio are probable strongly influenced by the total condensation of the chromosome arms. 
The metaphases of Brassica were analysed after staining with the fluorochrom DAPI. This dye stains preferentially AT rich regions of the chromosomal DNA (see Schweizer 1980, Kapuscinski, 1995) and in many species (e.g. Pinus densiflora, Hizume et al., 2001, Vicia, Navrátilová et al., 2003), it produces a characteristic banding pattern in the chromosomes that assist in their identification. In Brassica, however, no $\mathrm{DAPI}^{+}$band was produced in untreated chromosomes, in spite of the presence of DAPI positive chromocenters in interphase nuclei. However, after the FISH procedure the pericentromeric regions of most chromosomes and the telomeric regions of some chromosomes were strongly stained with DAPI in several cells (compare Figures 10 and 11), producing a kind of banding pattern. These banding patterns closely resembled the C-banding patterns described by Olin-Fatih and Heneen (1992), and were also observed in Brassica by Maluszynska and HeslopHarisson (1993) and Snowdon (1997) after ISH experiments. In some preparations the steps of the ISH procedure may remove some DNA from the chromosomes, or modify their organisation, in the same way as the C-banding procedure does.

It was demonstrated, previously and in the present work, that the pericentromeric region of many chromosomes of Brassica hybridises with probes that are A-T rich (ex. pBo2.94, 62\% of bases AT and pBo1.173, 65\% of bases AT) showing that at least pericentromeric regions of Brassica chromosomal DNA are in fact AT rich. Why the chromosomes of Brassica are uniformly stained with DAPI, in spite of the presence of AT rich regions in many of its chromosomes is perhaps related to the presence of AT-rich dispersed sequences in the Brassica genome, what may lead to an even DAPI staining and therefore mask other AT-rich heterochromatic segments in metaphase chromosomes. The absence of DAPI bands in condensed chromosomes in spite of evidences of AT-rich regions were also reported for other species, like in Vignia (Galasso et al., 1995), Citrus, Poncirus and Fortunella (Miranda et al., 1997, Guerra et al., 2000). 


\subsection{Chromosome organisation of rDNA and highly repeated sequences in Brassica}

\section{S rDNA and "5+45S rDNA"}

The localisation of rDNA genes in Brassica was reported in several publications (Maluszynska and Heslop-Harrison, 1993, Snowdon et al., 1997b, Fukui et al., 1998, Armstrong et al., 1998, Hasterock and Maluszyska 2000a, b, Schrader et al., 2000, Snowdon et al., 2002, Ziolkowiski and Sadowski, 2002), therefore rDNA probes were used as control to establish the FISH procedure in our laboratory, before using the selected clones as FISH probes. Frequently, formamide is used in the stringent washes to produce high stringency under low temperature. Snowdon et al. (2000a, 2002) have used stringent washes without formamide to localise the rDNA genes in Brassica and found the same result as previously when using formamide (Snowdon, 1997). To avoid the use of this harmful chemical all stringent washes used in the $\mathrm{FISH}$ experiments in the present work were performed in $0.1 \times \mathrm{SSC}$ at $42^{\circ} \mathrm{C}$, giving a stringency of about $73-78 \%{ }^{3}$ for the $\mathrm{C}$ genome-enriched sequences.

Chromosomes of $B$. oleracea, $B$. rapa and $B$. napus were hybridised with a plasmid probe, named here as "5+45S rDNA", containing a 1735 bp EcoRI fragment of the $18 \mathrm{~S}$ rDNA region from the 45S rDNA of Aedes aegypti and a 509 bp of 5S rDNA from Matthiola incana. These sequences were used as heterologous probes in barley chromosomes with excellent results (Brown et al., 1999). B. oleracea was additionally probed with the $25 \mathrm{~S}$ region of the $45 \mathrm{~S}$ rDNA, generated by $\mathrm{PCR}$, using genomic DNA of Brassica as template. The results obtained here are comparable with those reporter by Hasterock et al. (2001), who described the simultaneous localisation of $25 S$ and $5 S$ rDNA sites, visualised with different fluorophores, in Brassica diploids ( $B$. nigra, $B$. oleracea and $B$. rapa) and amphidiploids (B. carinata, $B$. juncea and $B$. napus). In the present study, however, the 5S and 45S rDNA loci were labelled with the same fluorophore and could not be accessed independently. Only in the case of $B$. oleracea the chromosome pair with two adjacent loci for 5S rDNA was easily identified by comparing the results of FISH with both probes (compare Figures 12 and 13). Regardless of the impossibility to distinguish the $5 S$ and $45 S$ rDNA loci, probe " $5+45 S$ rDNA" gave excellent results and was, in all three species, useful to identify four-five chromosome types carrying rDNA genes (see Table 4). Three, six

\footnotetext{
${ }^{3}$ Calculated after Meinkoth and Wahl, 1984.
} 
and nine chromosome pairs were identified as containing rDNA genes in $B$. oleracea, $B$. rapa and $B$. napus, respectively.

There are some differences concerning the number of chromosomes carrying these genes among the different reports, but the results presented here matched completely well with those described previously by Hasterock et al. (2001) if the probes for $5 \mathrm{~S}$ and $45 \mathrm{~S}$ rDNA are considered together. The different results found in the literature are attributed to differences between the varieties analysed or to differences in sensitivity to detect minor sites either due to the FISH protocol or to the microscope used in the studies.

The variety of $B$. oleracea used in our FISH experiments showed a heteromorphism in the size of the hybridisation site for $45 S$ rDNA for one pair of chromosomes. In situ hybridisation, like Southern blot hybridisation, is not a fully quantitative technique, but large differences in hybridisation signal strength at different loci correspond to major differences in copy number of the tandem repeat unit (Maluszynska and HeslopHarrison, 1993). In the $B$. oleracea variety used in this work there was an obvious variation in the copy number of the 45S rDNA in one pair of homologous chromosomes carrying this gene. The hybridisation signals at this locus were sometimes even missed in one chromosome of the pair, probably because of difficulties to detect the small number of repeats from the rDNA gene array at this locus. Ribosomal RNA genes in plants are highly variable both in copy number and in intergenic spacer length. Analysis of inheritance indicates that copy number change is rapid, occurring even among somatic cells of individual plants (Rogers and Bendich, 1987). Moreover, rapid changes in rDNA-repeat copy number at single loci were demonstrated in tissue culture from wheat (Leitch et al., 1993). Variation in the size of the 45S rDNA signal in a locus was found in cytotypes from Phaseolus vulgaris (Pedrosa et al., 2003) and heteromorphism in the size of the signal for rDNA between homologous chromosomes have also been reported (e.g. 5S rDNA in Passiflora glandulosa, de Melo and Guerra, 2003; 45S rDNA in aphid Acyrthosiphon pisum, Mandrioli et al., 1999). As B. oleracea is normally strictly cross pollinated (Becker et al., 1999), and the variety oleracea is its wild form, heterozygosity for different loci may be expected. 


\section{pBo2.94 and pBo1.173}

After the establishment of the FISH procedure with the rDNA probes, the repetitive clones selected in this work (pBo1.6, pBo1.27 and pBo2.157) were tested by in situ hybridisation. However when using the microscope Zeiss Axiolab Epiflorescence, no signal could be visualised with none of these probes. The absence of signal was interpreted as possibly being related to the degree of repetition of the sequences in the genome. Therefore, two high repetitive clones (pBo2.94 and pBo1.173), that showed very strong hybridisation signals with both the $A$ and $C$ genomes in the dot blot experiments, were selected and tested by FISH. In situ hybridisation showed that both probes hybridise with the pericentromeric region of several chromosomes giving very bright signals. Based on these results, it was concluded that the hybridisation signals produced with the $\mathrm{C}$ genome-enriched sequences were not strong enough to be detected by the available microscope, probable because of its degree of repetition and/or organisation in the genomes. A more sensitive microscope (Olympus BX60, from the Institute of Human Genetics, Göttingen) was subsequently used and this interpretation was confirmed. Small hybridisation signals, dispersed along the chromosomes, could be detected for all sequences analysed, although unspecific background hybridisation signals also became more evident.

Since clones pBo2.94 and pBo1.173 hybridised with the pericentromeric region of several chromosomes from all three Brassica species (see Table 5), we were interested to know whether they were members of a family of highly repetitive sequences from Brassica described in the literature or were representatives of a new tandemly repeated centromeric sequence. Therefore, these clones were sequenced and subjected to a DNA database comparison. The results showed that they were members of the Brassica HindllI repeat family, related to tRNA genes, that is represented in the GenBank/EMBL/DDBJ/PDB database by more than 20 accessions from B. oleracea, B. rapa, B. napus, B. juncea, B. carinata and Diplotaxis erucoides (Benslimane et al., 1986, Reddy et al., 1989, Harbinder and Lakshmikumaran, 1990, Lakshmikumaran and Ranade, 1990, Xia et al., 1993, 1994, Harrison and Heslop-Harrison, 1995).

The chromosomal location of representatives from this HindllI repeat family was first investigated by Iwabuchi et al. (1991), in B. rapa, by Xia et al. (1993) in B. napus and by Harrison and Heslop-Harrison (1995) in all species from the "U's triangle". 
Concerning the number of chromosomes containing representatives of this repeat there are some differences between our results and that previously reported. For $B$. rapa, pBo1.173 hybridised to the centromeric region of eight chromosomes pairs, in accordance with the results reported by Harrison and Heslop-Harrison (1995) for the repeat isolated from B. rapa (pBcKB4, 350 bp) under low stringency conditions. Iwabuchi et al. (1991) detected, however, homologous of this repeat (also isolated from B. rapa - the BT11, $175 \mathrm{bp}$ ) at all 10 pairs of $B$. rapa chromosomes. According to Harrison and Heslop-Harrison (1995) this difference results from the use of lower stringency conditions in hybridisation and washing by Iwabuchi and co-workers. This may also explain the higher number of $B$. napus chromosomes hybridising with pBo1.173 and pBo2.94 in the present work (28-30 centromeric regions), and with the homologous sequence pxc3h2 (ca. 350 bp) reported by Xia et al. (1993, 24-30 centromeric regions), when compared with those 26 centromeric regions reported by Harrison and Heslop-Harrison (1995). For B. carinata 12 sites of hybridisation were found, in accordance with Harrison and Heslop-Harrison (1995). In B. oleracea we have detected 12-14 chromosomes hybridising strongly with pBo2.94 and only 12 with pBo1.173, whereas Harrison and Heslop-Harrison (1995) reported 14 hybridisation sites for pBcKB4. Armstrong et al. (1998), using the same clone as Harrison and Heslop-Harrison (pBcKB4) to hybridise B. oleracea var. alboglabra found only 12 chromosomes strongly labelled. These results show that differences between varieties, and not only the hybridisation condition used, are probably involved in the differences found among the reports. Moreover, it is possible that different members of this family of repeats are better represented in some chromosomes. Harrison and Heslop-Harrison (1995) showed that different hybridisation conditions altered the number of labelled chromosomes, indicating that the sequences present on different chromosomes have somewhat diverged.

It is interesting to notice that the highest homology found for clones pBo2.94 and $\mathrm{pB} 1.173$ in the database was with a representative isolated from $B$. juncea (AABB) (97\% similarity in a region of 224 bp and 146 bp respectively for pBo2.94 and $\mathrm{pB}$ 1.173). This indicates that variants from this family of repeated DNA with very similar sequences are present in both the $A$ and $C$ genome, since our repeats were isolated from the $C$ genome and the sequence from $B$. juncea originated almost certainly from the A genome (see below). 
Also interesting to notice is that Harrison and Heslop-Harrison (1995) found no hybridisation of pBcKB4 in the B genome of Brassicacea, either by Southern blot nor by in situ hybridisation, whereas Xia et al. (1993) have detected a low amount of pxc3h2 in $B$. nigra DNA by Southern and dot blot hybridisation. Compared pairwise, pBcKB4 and canrep (the consensus sequence including pxc3h2) share $88 \%$ sequence identity. According to Harrison and Heslop-Harrison (1995) differences in Southern blot results may lie in the methods used by the authors. We have not tested pBo2.94 and pBo1.173 in Southern blot hybridisations, but the presence of only 12 chromosomes with hybridisation sites for these sequences in $B$. carinata $(B B C C)$ is in accordance with that reported by Harrison and Heslop-Harrison (1995) and indicates the absence of this sequence in the $B$ genome. If this repeat is really present in $B$. nigra its copies are probable scattered in the $B$ genome and are not recognised as FISH signals. If so, than this sequences probably amplified in the genome after the divergence of $B$. nigra but before the separation of $B$. oleracea and $B$. rapa, and supports that the Brassica $A$ and $C$ genomes are more closely related than both with the $\mathrm{B}$ genome.

As shown above centromeres of $\mathrm{A}$ and $\mathrm{C}$ chromosomes from Brassica contain the AT rich Hindlll family of highly repeated DNA. However, this repeat is not the only one present in Brassica A and $\mathrm{C}$ genome centromeres, since some chromosomes with centromeric heterochromatic blocks did not possess this sequence and three pairs of chromosomes from B. rapa were shown to be enriched with a speciesspecific middle repetitive G-C rich (58\%) DNA sequence (Iwabuchi et al., 1991). This G-C rich sequence shows no similarity to the members of the family that includes $\mathrm{pBo} 2.94$ and $\mathrm{pBo1.173}$. It is possible that other sequences, so far not identified, enrich the centromeres of some Brassica chromosomes. However, the three repetitive sequences cloned in our pBo libraries were dispersed in the chromosomes from Brassica and frequently it was possible to observe that they were less represented or absent in the centromeric region. 


\subsection{Characterisation of newly isolated dispersed repetitive sequences of Brassica}

\section{pBo1.27 and pBo2.157}

Sequence analyses of the DNA inserted in clones pBo1.27 (182 bp) and pBo2.157 (205 pb) showed high similarity with open reading frames (ORFs) similar to Enhancer/Supressor-mutator (En/Spm)-type transposon. This plant transposon superfamily was first described in the maize genome (reviewed by Kunze et al., 1997). En/Spm-like transposon sequences were found in a variety of distantly related plant species (Staginnus et al., 2001). Both sequences, pBo1.27 and pBo2.157, possess an intact ORF, coding for 60 and 68 aminoacids, respectively. Search in the protein database confirmed the homology of these sequences with En/Spm-like transposons at the protein level (data not shown). The sequences of the two clones were, however, not homologous to one another and in the Southern blot experiments they showed different patterns of hybridisation with genomic DNA from Brassica species. This suggests that $\mathrm{pBo} 1.27$ and $\mathrm{pBo} 2.157$ represent different groups of $\mathrm{En} / \mathrm{Spm}$-like elements in Brassica. Evolutionary diverse lineages from this transposon superfamily were also found in chickpea (Cicer arietinum), where En/Spm-like transposon sequences were investigated in detail (Staginnus et al., 2001). The chromosomal localisation of these sequences in Brassica, determined through $\mathrm{FISH}$, showed a dispersed distribution of these elements in all three genomes investigated. Dispersed genomic organisation is a very common feature of plant repeats, especially those which originate from transposable elements (for references see Nouzova et al., 1999).

Southern blot hybridisations showed that pBo1.27 and pBo2.157 are more frequent in the $\mathrm{C}$ genome than in the A genome of Brassica. At the chromosomal level, however, this difference was less evident, probably because of the high degree of amplification of the hybridisation sites necessary for the visualisation of these sequences in FISH experiments. In relation to the evolution of these sequences, it is possible that ancestor sequences of pBo1.27 and pBo2.157 were already present in the progenitor of $B$. oleracea and $B$. rapa and the amplification or elimination of these ancestor sequences took place in a different degree in each species after their separation, resulting in different copy numbers of both elements in the $A$ and $C$ genomes. To our knowledge, this is the first report about the chromosomal 
localisation by FISH of sequence-like DNA transposon elements (class 2 elements) in Brassica.

\section{pBo1.6}

Among the clones selected in this work, pBo1.6 was the most informative. Southern blot hybridisation using this sequence as probe showed the presence of only one discrete band in $B$. rapa in contrast to a smear of hybridisation signals with several discrete bands in $B$. oleracea and in $B$. napus. This repeat is clearly underrepresented in the A genome and the in situ hybridisation showed the $\mathrm{C}$ genome-specificity of this sequence at the chromosomal level (see Figure 17). Species-specificity only at the chromosomal level, but not in Southern blot hybridisations, was shown for a sequence, pT10, isolated from $B$. rapa by tho et al. (1991). Clone pT10 was a chimera of two distinct sequences, one species-specific for the A genome and the other also present in the $\mathrm{C}$ genome. When hybridised in situ, however, pT10 hybridised only with chromosomes from the A genome, showing that, in spite of the presence of a part of its DNA in the $\mathrm{C}$ genome, at the chromosomal level this sequence was specific for $B$. rapa chromosomes.

All chromosomes from $B$. oleracea hybridised with pBo1.6, whereas in most cells of $B$. rapa no hybridisation signal was detected. Interestingly in $B$. napus frequently more than 18 chromosomes hybridised with pBo1.6, suggesting that this sequence may have either spread to A genome chromosomes and amplified after the formation of this natural hybrid or that sequences present in a small amount in the $A$ chromosomes have amplified in the polyploid genome. In tetraploid cotton ( $G$. barbadense, AD genome) FISH analysis have also showed that some A genome dispersed repeats appear to have spread to D genome chromosomes (Zhao et al., 1998b). Alternatively, the ancestral B. rapa involved in the origin of rapeseed could contain more copies from this sequence than the varieties used in the present work. However, a large variation in copy number between varieties is not to be expected for this sequence, since different varieties of $B$. rapa were used for Southern blot and in situ hybridisations and the same result was found. Noteworthily, larger chromosomes in $B$. napus were more strongly labelled than smaller ones. As $B$. oleracea has larger chromosomes than $B$. rapa, the chromosomes strongly labelled with pBo1.6 must be originated from the $C$ genome. Since $B$. rapa and $B$. oleracea are very closely 
related, we assume that the pBo1.6 is a relatively young sequence and that its amplification in the $\mathrm{C}$ genome occurred after the separation of these two species.

The C genome specificity at the chromosomal level makes pBo1.6 a useful sequence for the analyses of transgenic rapeseed. It has been suggested that transgene introgressed into the $C$ genome of $B$. napus would be considerably less likely to be introgressed into wild Brassica populations than those present on $A$ genome chromosomes, because $B$. napus $(x) B$. oleracea hybrids are extremely rare and transgene-carrying $\mathrm{C}$ genome chromosomes will be eliminated from wild $B$. napus $(\mathrm{x})$ $B$. rapa backcross offspring due to the absence of homologues (for references see Snowdon et al., 2002). If this is right, the selection of $B$. napus plants with transgene inserted on $\mathrm{C}$ genome chromosomes can be assisted by FISH using the transgene and pBo1.6 as probes.

The molecular analyses of pBo1.6 showed high similarity between this sequence and telomeric-like DNA from several species (see Table 3). This sequence possessed 19 degenerated telomere motifs, and one perfect copy of the telomeric repeat of most plant species (see blocks in Figure 8), first isolated from Arabidopsis (Richards and Ausubel, 1988). Interestingly, Sinapsis arvensis, another species from the family Brassicaceae, presented also a species-specific tandem repeated DNA family (pSA) which exhibited high similarity with Arabidopsis- telomeric repeat. However, pSA was not detected in $B$. oleracea DNA in Southern blot hybridisation under high stringency conditions (Kapila et al.,1996a), and when compared with pBo1.6 similarity in only a very small region (55bp) is found (data not shown).

Since pBo1.6 is highly homologous to the telomeric sequence of most plants ( $85 \%$ similarity with a TTTAGGG tract of the same size) it should be expected that the telomeric repeats at the very ends of the Brassica chromosomes would hybridise with pBo1.6 under hybridisation conditions that allow more than 15\% of mismatches, as the one used in this work. When genomic DNA of an organism with long telomeres are digested with six-base cutting restriction enzymes and hybridised with oligonucleotides corresponding to perfect telomeric repeats a smear of hybridisation signals is obtained, since no restriction site for enzymes is present in the tandem array of telomere repeats and the number of repeats units is variable between different chromosomes of a cell. Besides, degenerated telomeric repeats are present in several organisms (Richards, 1995, Riethman et al., 2004). In our Southern 
hybridisation using $\mathrm{pBo} 1.6$ as probe, after $72 \mathrm{~h}$ of exposition of the membranes to $\mathrm{X}$ ray films, it was possible to see a smear of DNA fragments in the high-molecularweight range in species with the $C$ genome. In addition, several smaller fragments of different sizes were also labelled with this probe. However, in species with only the $A$ or $B$ genomes (data not shown), just one discrete band, of about $2 \mathrm{~kb}$ in DNA digested with $E c o R I$ or $10 \mathrm{~kb}$ in DNA digested with Hindlll, and only a very faint smear were present. After one week of exposition, however, this smear became stronger and some additional weakly hybridising discrete bands appeared in $\mathrm{A}$ and $\mathrm{B}$ genomes (data not shown). In the FISH experiments for most cells of $B$. rapa, as well as in $B$. oleracea and $B$. napus, where pBo1.6 hybridised in several other sites, no signal was consistently detected at the telomeres. There are two possible explanations for the absence of hybridisation signals at the very ends of Brassica chromosomes in FISH with pBo1.6 under low stringency, or even if the telomeric repeat of Arabidopsis would be used: (1) presence of a different type of telomeric repeat or (2) short telomeres with only a small number of telomeric repeat units, that, together with technical limitations, would produce no FISH signal.

(1) It could be speculated that Brassica chromosomes do not possess a telomeric repeat sequence similar to the Arabidopsis repeat, as has been reported for monocotyledonous species of the families Alliaceae, Asparagales and Asphodelaceae (Fuchs et al., 1995, Pich and Schubert, 1998, Adams et al., 2000a, 2001, Weiss and Scherthan, 2002, Sýkoravá et al., 2003b, Weiss-Schneeweiss et al., 2004) and in three dicotyledonous species from the family Solanaceae: Cestrum, Vestia and Sessea (Sykorava et al., 2003a). However, Richards and Ausubel (1988) found that pAtT4, the telomeric repeat isolated from $A$. thaliana, hybridised to genomic DNA from $B$. rapa and $B$. carinata at high stringency conditions, whereas Uzunova et al. (1995) reported the hybridisation of this probe in $B$. napus, with an unscorable banding pattern. Moreover telomerase expression was found in $B$. oleracea, using primers complementary to Arabidopsis telomeric sequences in a telomere repeat amplification protocol (TRAP) (Fitzgerald et al., 1996). These data together show that the Arabidopsis-telomeric repeat (TTTAGGG) is also present in Brassica species, as would be expected since they are member of the same family.

(2) A small number of the telomeric repeats at the chromosome ends would produce very small hybridisation sites for a telomeric specific probe at this region and FISH 
procedure may be unadequate to consistently detect such sites. The average length of telomeric repeat arrays are species and cell type specific and varies significantly among plants, ranging from $2-5 \mathrm{~kb}$ in A. thaliana (Richards and Ausubel, 1988), 60$160 \mathrm{~kb}$ in tobacco (Fajkus et al, 1995) and 13-223 kb in tomato (Zhong et al., 1998). In Lotus japonicus Pedrosa et al. (2002) suggested that the telomeric tracts were relatively short, since FISH with an Arabidopsis-like telomeric probe showed signals only in some chromosomes which, in addition, were very weak. Also, in A. thaliana only weak hybridisation signals were visible when the Arabidopsis-type telomeric sequence was used as probe (Weiss-Schneeweiss, personal communication). When hybridising pBo1.6 to $B$. rapa chromosome spreads no hybridisation site was detected in most of the cells. When signals were detected they were weaker in intensity than in B. oleracea and were often present as a spot in only one chromatid (see Figure 17c). Moreover, variable numbers of chromosomes (two to eight) showed labelling in the different metaphases analysed. Because of these inconsistent results the possibility that such signals represent background hybridisations can not be ruled out. However, labelling of only one chromatid with some probes has already been reported in different FISH studies and it was proposed that the size of the hybridisation site in the genome (Clark et al., 1989, Gustafson et al., 1990, Benabdelmouna et al., 1999), or technical artefacts (Lorite et al., 2002) were responsible for that observation.

The variation in the number of FISH signals for pBo1.6 and the often labelling of only one chromatid in Brassica may be related to the size of the telomere in the species analysed. As far as we know, the length of telomeric repeats has not been determined for Brassica. However, preliminary data indicate that they may be similar to those of $A$. thaliana (Richards, personal communication). If so, than a consistent detection of hybridisation sites will depend on the FISH procedure used. Hybridisation and detection efficiency can be influenced by several factors during FISH experiments, including mechanical damage or degradation of the homologous site, as proposed for Brassica pachytene chromosomes (Ziolkowiski and Sadowski, 2002), or inappropriate amplification of the small hybridisation sites, causing technical artefacts. The FISH procedure applied in the present work, where chromosomal and probe DNA were denaturated separately, may often cause mechanical damage of small sites. In addition, the small size of Brassica chromosomes may disturb the 
chromosomal analyses, making the interpretation of hybridisation patterns more difficult than in species with large chromosomes.

At the chromosomal level pBo1.6 presented several hybridisation sites, at telomeric/subtelomeric and also at interstitial positions, in the $\mathrm{C}$ genome. The presence of telomeric or telomere-like repeats in non-telomeric locations has been detected in a great number of species (for reference see Richards, 1995, Lorite et al., 2002). In Arabidopsis, Chlorella vulgaris, Silena latifolia, Nicotiana tomentosiformis, among others, variant or degenerated units of the TTTAGGG repeats were found adjacent to cloned telomeres or in subtelomeric regions (Richards et al., 1992, Higashiyama et al., 1995, Buzek et al., 1997, Hokáková and Fajkus, 2000). The explanations for the occurrence of interstitial repeats are diverse. In many eukaryotes, interstitial telomeric sequences may be remnants of chromosome rearrangements that occurred during genome evolution. Interstitial telomeric sequences may also arise from a random short sequence array with fortuitous homology to telomeric repeats, which may become extend by slippage during replication (for references see Biessmann and Mason, 1994). The replication slippage is a commonly observed replication error, which occurs at repetitive sequences when the new strand mispairs with the template strand. The slipping of DNA polymerase III from the DNA template strand at the repeat region and the subsequent reattachment at a more distant site can cause the newly created DNA strand to contain an expanded section of DNA. Microsatellite polymorphisms, for example, are mainly caused by replication slippage (Dieringer and Schlotterer, 2003). Other possibilities to explain the emergence of telomere-like interstitial repeats are that telomeric repeats are attached by telomerase or recombination to extrachromosomal linear fragments, which may then integrate into the genome. Telomeric repeats can also be attached to transposable elements and are distributed by them to interstitial regions (for references see Biessmann and Mason, 1994). Which mechanism was responsible for the high amount of telomere-like sequences in the $\mathrm{C}$ genome remains to be investigated.

As far as we are aware, pBo1.6 is the first clone characterised as containing a sequence that hybridises preferentially to all chromosomes of the $C$ genome. Snowdon (1997) used a RAPD fragment of $2.2 \mathrm{~kb}$, that could only be amplified from species with the $\mathrm{C}$ genome, as FISH probe and found hybridisation on all $B$. oleracea 
chromosomes in an interspersed pattern, whereas in B. rapa hybridisation was restrict to only a small number of chromosomes. Unfortunately, this fragment was neither characterised by Southern blot nor sequenced making impossible to establish a relationship between this sequence and pBo1.6. So far only one sequence that differentiate the $A$ and $C$ genomes, isolated from $B$. rapa, was characterised at the molecular level and localised in situ (Iwabuch et al., 1991).

The discovery of a sequence highly enriched in the $\mathrm{C}$ genome of Brassica opens the opportunity for detailed studies regarding the subsequent evolution of DNA sequences in polyploids with the $\mathrm{C}$ genome and may enable the reliable identification of the genomic location of transgene inserts in genetically modified oilseed rape. 


\section{Summary}

\section{"Isolation, molecular characterisation and chromosomal location of repetitive DNA sequences in Brassica"}

Plant genomes contain high amounts of repetitive DNA sequences, of which several are present in many species within a taxonomic family, whereas others can exhibit species- or genome-specificity. Genome-specific repetitive sequences can for example be used as chromosome landmarkers for the discrimination of genomes in natural or artificial hybrids at a very early stage of development.

Rapeseed, $B$. napus $(2 \mathrm{n}=38, A A C C)$, is a natural hybrid derived from the closely related species $B$. rapa $(2 n=20, A A)$, turnip rape, and $B$. oleracea $(2 n=18, C C)$, cabbage. The discovery of repetitive sequences specific to the $C$ genomes of Brassica, besides providing information on chromosome and genome evolution in this group, might allow the identification of some or all $\mathrm{C}$ genome chromosomes from $B$. napus. The aim of this work was to find repetitive sequences able to differentiate at the chromosomal level the highly homeologous $A$ ( $B$. rapa) and $C$ (B. oleracea) genomes of Brassica in order to assist in the physical identification of $B$. napus chromosomes. For this purpose, $C$ genome specific repetitive sequences were searched in genomic DNA libraries from $B$. oleracea.

Phage and plasmid libraries were screened using either $B$. oleracea or $B$. rapa total genomic DNA as probe in plaque and dot-blot hybridisations of replica filters. In the screening of more than 100,000 plaques from the phage libraries only $0.45 \%-2.40 \%$ of the clones exhibited strong hybridisation signals, indicating the presence of repetitive DNA in their inserts. Since only a very small amount of the clones could be identified as containing repetitive DNA, phage libraries seem not to be suitable for the identification of species-specific repetitive sequences from $B$. oleracea, when total genomic DNA is used as probe.

In the plasmid libraries 1164 clones were screened by dot-blot hybridisation of replica filters. In these libraries ca. $21 \%$ of the clones exhibited strong hybridisation signals with $B$. oleracea genomic DNA and could be identified as containing repetitive sequences. Fifteen clones, which showed stronger hybridisation signals with the Cthan with the A-genome DNA, were selected for further Southern blot analyses, to verify the dot-blot results. Three clones (pBo1.6, pBo1.27 and pBo2.157) were 
confirmed as more frequent in the $\mathrm{C}$ genome ("C genome enriched clones"). These clones, as well as two highly repetitive clones (pBo2.94 und pBo1.173), which showed very strong hybridisation signals with both the $A$ and the $C$ genome DNAs in the dot blot experiments, were sequenced, compared with DNA sequence databases and localised through FISH on the chromosomes of $B$. oleracea, $B$. rapa and $B$. napus. The highly repetitive clones were also tested in $B$. carinata (Ethiopian mustard). In addition, the ribosomal RNA loci of the $A$ and $C$ genomes were localised by FISH on Brassica chromosomes using different rDNA probes.

In accordance with the literature, three, six and nine chromosome pairs were identified as containing $5 \mathrm{~S}$ and/or $45 \mathrm{~S}$ rDNA loci in $B$. oleracea, $B$. rapa and $B$. napus, respectively. The highly repetitive clones, pBo2.94 (238 bp) und pBo1.173 (158 bp), were identified as homologous to already described centromeric sequences from Brassica (up to $97 \%$ sequence identity). Accordingly, these clones were localised in the centromeric regions of $12,12-14,16$ and 28-30 chromosomes from $B$. carinata, B. oleracea, B. rapa and B. napus, respectively.

Sequence analyses of the $\mathrm{C}$ genome enriched clones showed that two of them, pBo1.27 (182 bp) and pBo2.157 (205 bp), have high similarity with En/Spmtransposon-like sequences ( $87 \%$ and $98 \%$ sequence identity, respectively). The chromosomal localisation of these sequences in Brassica by FISH showed a dispersed distribution of these elements in the $A$ and the $C$ genome. The higher frequency of these sequences in the $C$ genome was, however, more evident in the Southern blot hybridisations than in the FISH, probably because of the high degree of amplification necessary for the visualisation of the hybridisation sites in FISH.

The third clone, pBo1.6 (203 bp), displayed in a segment varying between $116 \mathrm{bp}$ and 132 bp up to $89 \%$ sequence identity with telomere-like DNA from many plant species. This sequence was localised through FISH at telomeric/subtelomeric and interstitial regions of all chromosomes from $B$. oleracea, whereas in $B$. rapa no signal was detected in most of the cells. In $B$. napus chromosomes with and without hybridisation signals were found. Frequently more than 18 chromosomes hybridised with pBo1.6 in this polyploid, suggesting that the sequence may have either spread to A genome chromosomes and amplified after the formation of this hybrid or that sequences present in a small amount in the A chromosomes have been amplified in the polyploid genome. 
The discovery of a sequence highly enriched in the $\mathrm{C}$ genome of Brassica opens the opportunity for detailed studies regarding the subsequent evolution of DNA sequences in polyploid genomes. Moreover, pBo1.6 may be useful in applied genetics for the determination of the chromosomal location of transgene DNA in genetically modified oilseed rape. 


\section{Zusammenfassung}

\section{"Isolierung, molekulare Charakterisierung und chromosomale Lokalisierung von repetitiven DNA Sequenzen in Brassica"}

Pflanzengenome enthalten einen großen Anteil repetitiver DNA. Verwandte Arten haben viele identische repetitive Sequenzen, aber einige von innen sind auch artoder genomspezifisch. Diese genomspezifischen repetitiven Sequenzen können z.B. als Chromosomen-Marker zur Unterscheidung von Genomen in etablierten oder neu hergestellten Arthybriden in sehr frühen Entwicklungsstadien verwendet werden.

Raps, $B$. napus $(2 \mathrm{n}=38, A A C C)$, ist ein natürlicher Hybrid der sehr eng verwandten Arten Rübsen, B. rapa $(2 n=20, A A)$, und Kohl, B. oleracea $(2 n=18, C C)$. Um eine bessere Charakterisierung der Rapschromosomen zu erreichen, wurden artspezifische repetitive DNA Sequenzen von $B$. oleracea gesucht, welche das $A$ und C Genome im Raps unterscheiden können. Diese Sequenzen sollen bei der Fluoreszenz in situ Hybridisierung (FISH) als genom- oder chromosomenspezifische Marker dienen.

Phagen- und Plasmid-Bibliotheken wurden jeweils durch Plaque- und Dot-BlotHybridisierung untersucht, wobei die Gesamt DNAs des A- und des C- Genoms als Sonde verwendet wurden. In den Phagen-Bibliotheken wurden mehr als 100.000 Plaques getestet. Nach der Hybridisierung von Replicafiltern mit $B$. oleracea oder $B$. rapa Gesamt-DNA zeigten nur 0,45\%-2,40\% aller Klone der Bibliotheken starke Hybridisierungssignale und konnten als repetitive Sequenzen erkannt werden. $\mathrm{Da}$ nur ein sehr geringer Anteil der Klone in den Bibliotheken repetitive Sequenzen aufwies, sind Phagen-Bibliotheken offensichtlich schlecht für die Suche nach repetitiven artspezifischen Sequenzen geeignet, wenn Gesamt DNA als Sonde verwendet wird.

In den Plasmid-Bibliotheken wurden 1164 Klone mit Hilfe der Dot-Blot-Hybridisierung getestet. Nach der Hybridisierung von Replicafiltern zeigten ca. 21\% der Klone starke Hybridisierungsignale mit $B$. oleracea Gesamt-DNA, und wurden als repetitiven Ursprungs identifiziert. Die Hybridisierungsmuster der Dot-Blot-Filter mit beiden Sonden wurde verglichen und $15 \mathrm{Klone}$, welche stärkere Hybridisierungsintensitäten mit dem C-Genom zeigten, wurden weiter über eine Southern-Blot Hybridisierung analysiert, um die Dot-Blot Ergebnisse zu prüfen. Drei Klone (pBo1.6, pBo1.27 und 
pBo2.157) konnten in dieser Untersuchung als häufiger im C-Genom vorkommend bestätigt werden ("C-Genom-angereicherte Klone“). Diese Klone, sowie zwei hochrepetitive Klone (pBo2.94 und pBo1.173), welche in der Dot-Blot-Hybridisierung gleichstarke Signale für das A- und C- Genom gezeigt haben, wurden sequenziert, mit DNA-Datenbanken verglichen und mit Hilfe der FISH in den Chromosomen von B. oleracea, B. rapa und B. napus lokalisiert. Die hoch-repetitiven Klone wurden darüber hinaus auch in $B$. carinata (Abessinischer Senf) untersucht. Weiterhin wurde durch FISH, mit Hilfe ribosomaler DNA (rDNA) Sonden, die ribosomalen RNA Loci in den Chromosomen der A und C Genome von Brassica lokalisiert.

In Übereinstimmung mit der Literatur wurden in B. oleracea, B. rapa und B. napus jeweils drei, sechs und neun Chromosomenpaare mit $5 \mathrm{~S}$ und/oder 45S rDNA Loci gefunden. Die hoch-repetitiven Klone, pBo2.94 (238 Bp) und pBo1.173 (158 Bp), waren homolog zu schon beschriebenen Zentromer-Sequenzen von Brassica (bis zu $97 \%$ Sequenzidentität) und wurden durch FISH in den Zentromeren von 12, 12-14, 16 beziehungsweise $28-30$ Chromosomen in $B$. carinata, $B$. oleracea, $B$. rapa und $B$. napus lokalisiert.

Von den C-Genom-angereicherten Klonen zeigten zwei, pBo1.27 (182 Bp) und pBo2.157 (206 Bp), Homologien mit dem En-Spm-Transposon-ähnlichen Element (jeweils $87 \%$ und $98 \%$ Sequenzidentität). Durch FISH konnte gezeigt werden, dass sie verstreut auf verschiedenen Chromosomen des A- und C-Genoms von Brassica liegen. Die größere Häufigkeit dieser Sequenzen im C-Genom war aber in der Southern-Blot Hybridisierung deutlicher erkennbar als in der FISH, möglicherweise weil die Signale in der FISH Methode mehrfach verstärkt werden mussten.

Der dritte Klon, pBo1.6 (203 Bp), zeigte in einer Region von 116-132 Bp bis zu 89\% Sequenzidentität mit Telomer-ähnlichen Sequenzen. In der FISH hybridisierte dieser Klon mit den Telomeren/Subtelomeren und den interstitiellen Regionen von allen Chromosomen von B. oleracea, während diese Sequenz in B. rapa in den meisten Zellen keine Hybridisierungssignale zeigte. In B. napus sind beide Typen von Chromosomen (mit und ohne Hybridisierungssignale) gefunden worden. In den meisten Zellen von B. napus waren aber mehr als 18 Chromosomen markiert. Das weist darauf hin, dass pBo1.6 entweder in einige Chromosomen des A-Genoms des Polyploides übertragen und amplifiziert wurde oder dass die schon in geringer Zahl vorhandenen pBo1.6 Sequenzen des A-Genoms selbst amplifiziert wurden. 
Die Entdeckung einer Sequenz, die im C-Genom von Brassica häufiger vorkommt als im A-Genom, eröffnet eine Gelegenheit zu detaillierten Untersuchungen der auf die interspezifische Bastardierung folgende Evolution der DNA Sequenzen in solchen Polyploiden. In der Angewandten Genetik wird diese Entdeckung möglicherweise die zuverlässige genomische Lokalisierung von transgener DNA in genetisch verändertem Raps ermöglichen. 


\section{References}

ADAMS, S. P., LEITCH, I. J., BENNETT, M. D., LEITCH, A. R. (2000a). Aloe L.- a second plant family without (TTTAGGG)n telomeres. Chromosoma 109: 201205.

ADAMS, S. P., LEITCH, I. J., BENNETT, M. D., CHASE, M. W., LEITCH, A. R. (2000b). Ribosomal DNA evolution and phylogeny in Aloe (Asphodelaceae). Am. J. Bot. 87: 1578-1583.

ADAMS, S. P., HARTMAN, T. P. V., LIM, K. Y., CHASE, M. W., BENNETT, M. D., LEITCH, I. J., LEITCH, A. R. (2001). Loss and recovery of Arabidopsis-type telomere repeat sequences 5'-(TTTAGGG)n-3' in the evolution of a major radiation of flowering plants. Proc. R. Soc. London Ser. B 268: 1541-1546.

AHUJA, M. R. (2001). Recent advances in molecular genetics of forest trees. Euphytica 121: 173-195.

ANAMTHAWAT-JÓNSSON, K., HESLOP-HARRISON, J. S. (1992). Species specific DNA sequences in the Triticeae. Hereditas 116: 49-54.

ANANIEV, E. V., VALES, M. I., PHILLIPS, R. L., RINES, H. W. (2002). Isolation of $A / D$ and $C$ genome specific dispersed and clustered repetitive DNA sequences from Avena sativa. Genome 45: 431-441.

ARMSTRONG, K. C., KELLER, W. A. (1981). Chromosome pairing in haploids of Brassica campestris. Theor. Appl. Genet. 59: 49-52.

ARMSTRONG, K.C., KELLER, W.A. (1982). Chromosome pairing in haploids of Brassica oleracea. Can. J. Gen. Cytol. 24: 735-739.

ARMSTRONG, S. J., FRANSZ, P., MARSHALL, D. F., JONES, G. H. (1998). Physical mapping of DNA repetitive sequences to mitotic and meiotic chromosomes of Brassica oleracea var. alboglabra by fluorescence in situ hybridisation. Heredity 81: 666-673.

ARUMUGANATHAN, K., EARLE, E. D. (1991). Nuclear DNA content of some important plant species. Plant Mol. Biol. Rep. 9: 208-219. 
AVRAMOVA, Z. V. (2002). Heterochromatin in animals and plants. Similarities and differences. Plant Physiol. 129: 40-49.

BECKER, H. C., LÖPTIEN, H., RÖBBELEN, G. (1999). Breeding: an overview. In: GÓMEZ-CAMPO, C. (Ed.) Biology of Brassica Coenospecies. Developments in Plant Genetics and Breeding. pp. 413-460. Elsevier Science, Amsterdam, Netherlands.

BEDBROOK, J. R., O'DELL, M., FLAVELL, R. B. (1980). Amplification of rearranged repeated DNA sequences in cereal plants. Nature 288: 133-137.

BELLIN, U., DOS SANTOS, K. G. B. (2002). Beurteilung der Rekombinationsfähigkeit von Brassica-Arthybriden durch Unterscheidung der Genome mit Hilfe von GISH. Vortr. Pflanzenzüchtung. 54: 373-376.

BenABdelmounA, A., PELTIER, D., HUMBERT, C., ABIRACHEDDARMENCY, M. (1999). Southern and fluorescent in situ hybridization detect three RAPD-generated PCR products useful as introgression markers in Petunia. Theor. Appl. Genet. 98: 10-17.

BENNETT, M. D., LEITCH, I. J. (1997). Nuclear DNA amounts in angiosperms583 new estimates. Ann. Bot. (London) 80, 169-196

BENNETT, M. D, BHANDOL, P., LEITCH, I. J. (2000). Nuclear DNA amounts in angiosperms and their modern uses - 807 new estimates. Ann. Bot. (London) 86: 859-909.

BENSlimANE, A. A., DRON, M., HARTMANN, C., RODE, A. (1986). Small tandemly repeated DNA sequences of higher plants likely originate from a tRNA gene ancestor. Nucleic Acids Res. 14: 8111-8119.

BERIDZE, T. (1975). DNA nuclear satellites of the genus Brassica: Variation between species. Biochim. Biophys. Acta 395: 274-279.

BERNATZKY, R., TANKSLEY, S. D. (1986). Toward a saturated linkage map in tomato based on isozymes and random cDNA sequences. Genetics 111: 887898. 
BHATIA, S., NEGI, M. S., LAKSHMIKUMARAN, M. (1996). Structural analysis of the rDNA intergenic spacer of Brassica nigra: evolutionary divergence of the spacers of the three diploid Brassica species. J. Mol. Evol. 43: 460-468.

BIESSMANN, H., MASON, J. M. (1994). Telomeric repeat sequences. Chromosoma 103: 154-161.

BIESSMANN, H., MASON, J. M. (1997). Telomere maintenance without telomerase. Chromosoma 106: 63-69.

BIRNBOIM, H. C., DOLY, J. (1979). A rapid alkaline extraction procedure for screening recombinat plasmid DNA. Nuclei Acids Res. 7: 1513-1523.

BOURNIVAL, B., OBANNI, M., ABAD, A., OHM, H., MACKENZIE, S. (1994). Isolation of a new species-specific repetitive sequence from Thinopyrum elongatum and its use in the studies of alien translocations. Genome 37: 97104.

BOWEN, N. J. , JORDAN, I. K. (2002). Transposable elements and the evolution of eukaryotic complexity. Curr. Issues Mol. Biol. 4: 65-76.

BROWN, G. B., AMARASINGHE, V., KISS, G., CARLSON, J. E. (1993). Preliminary karyotype and chromosomal localization of rDNA loci for white spruce by fluorescence in situ hybridization. Genome 36: 310-316.

BROWN, S., STEPHENS, J. L., LAPITAN, N. L. V., KNUDSON, D. L. (1999). FISH landmarks for barley chromosomes (Hordeum vulgare L.). Genome 42: 274-281.

BUSCH, W., MARTIN, R., HERRMANN, R. G., HOHMANN, U. (1995). Repeated DNA sequences isolated by microdissection: I. Karyotyping of barley (Hordeum vulgare L.). Genome 38: 1082-1090.

BUZEK, J., KOUTNIKOVA, H., HOUBEN, A., RIHA, K., JANOUSEK, B., SIROKY, J., GRANT, S., VYSKOT, B. (1997). Isolation and characterization of $X$ chromosome-derived DNA sequences from a dioecious plant Melandrium album. Chromosome Res. 5: 57-65. 
CALDERINI, O., PUPILLI, F., PAOLOCCI, F., ARCIONI, S. (1997). A repetitive and species-specific sequence as a tool for detecting the genome contribution in somatic hybrids of the genus Medicago. Theor. Appl. Genet. 95: 734-740.

CAO, M., SLEPER, D. A. (2001). Use of genome-specific repetitive DNA sequences to monitor chromatin introgression from Festuca mairei into Lolium perenne. Theor. Appl. Genet. 103: 248-253.

CHEN, C. M., WANG, C. T., WANG, C. J., HO, C. H., KAO, Y. Y., CHEN, C. C. (1997). Two tandemly repeated telomere-associated sequences in Nicotiana plumbaginifolia. Chromosome Res. 5: 561-568.

CHEN, C. C., CHEN, C. M., HSU, F. C., WANG, C. J., YANG, J. T., KOA, Y. Y. (2000a). The pachytene chromosomes of maize as revealed by fluorescence in situ hybridization with repetitive DNA sequences. Theor. Appl. Genet. 101: 30-36.

CHEN, C., YAN, H., ZHAI, W., ZHU, L., SUN, J. (2000b). Identification and chromosomal location of a new tandemly repeated DNA in maize. Genome 43: 181-184.

CHENG, B. F., HENEEN, W. K., CHEN, B. Y. (1994). Meiotic studies on a Brassica campestris-alboglabra monosomic addition line and derived $B$. campestris primary trisomics. Genome 37: 584-589.

CHEUNG, W. Y., ChAMPAGNE, G., HUBERT, N., LANDRY, B. S. (1997). Comparison of the genetic maps of Brassica napus and Brassica oleracea. Theor. Appl. Genet. 94: 569-582.

CHENG, B. F., HENEEN, W. K., CHEN, B. Y. (1995). Mitotic kyryotypes of Brassica campestris and Brassica alboglabra and identification of the $B$. alboglabra chromosome in an addition line. Genome 38: 313-319.

CHUNG-MONG, C., CHI-TING, W., CHUNG-JU, W., CHIA-HSING, H., YEN-YU, K., CHI-CHANG, C. (1997). Two tandemly repeated telomere-associated sequences in Nicotiana plumbaginifolia. Chromosome Res. 5: 561-568. 
CLARK, M., KARP, A., ARCHER, S. (1989). Physical mapping of the B-hordein loci on barley chromosome 5 by in situ hybridization. Genome 32: 925-929.

CUADRADO, A., CEOLONI, C., JOUVE, N. (1995). Variation in highly repetitive DNA composition of heterochromatin in rye studied by fuorescence in situ hybridization. Genome 38: 1061-1069.

DE JEU, M. J., LASSCHUIT, J., KUIPERS, A. G. J., KAMSTRA S. A., VISSER, R. G. F. (1997). Characterization and localization of repetitive DNA sequences in the ornamental Alstroemeria aurea Graham. Theor. Appl. Genet. 94: 982-990.

DE MELO N. F., GUERRA M. (2003). Variability of the 5S and 45S rDNA sites in Passiflora L. species with distinct base chromosome numbers. Ann. Bot. (London) 92: 309-316.

DECHYEVA, D., GINDULLIS, F., SCHMIDT, T. (2003). Divergence of satellite DNA and interspersion of dispersed repeats in the genome of the wild beet Beta procumbens. Chromosome Res. 11: 3-21.

DIERINGER, D., SCHLOTTERER, C. (2003). Two distinct modes of microsatellite mutation processes: Evidence from the complete genomic sequences of nine species. Genome Res. 13: 2242-2251.

DONG, J., KHARB, P., CERVERA, M., HALL, T. C. (2001). The use of FISH in chromosomal localization of transgenes in rice. Methods in Cell Sci. 23: 105113.

FAHLESON, J., LAGERCRANTZ, U., MOURAS, A., GLIMELIUS, K. (1997). Characterisation of somatic hybrids between Brassica napus and Eruca sativa using species-specific repetitive sequences and genomic in situ hybridisation. Plant Sci. 123: 133-142.

FAJKUS, J., KOVARIK, A., KRALOVICS, R., BEZDEK, M. (1995). Organization of telomeric and subtelomeric chromatin in the higher plant Nicotiana tabacum. Mol. Gen. Genet. 247: 633-638.

FAO. http://faostat.fao.org/. 
FITZGERALD, M. A. S., MCKNIGHT, T. D., SHIPPEN D. E. (1996). Characterization and developmental patterns of telomerase expression in plants. Proc. Natl. Acad. Sci. U.S.A. 93: 14422-14427.

FLAVELL, R. (1980). Molecular characterization and organization of plant chromosomal DNA sequences. Ann. Rev. Plant Physiol. 31: 569-596.

FLAVELL, R. B., BENNETT, M. D., SMITH, J. B., SMITH, D. B. (1974). Genome size and the proportion of repeated nucleotide sequence DNA in plants. Biochem. Genet. 12: 257-269.

FREDIANI, M., GELATI, M. T., MAGGINI, F., GALASSO, I., MINELLI, S., CECCARELLI, M., CIONINI, P. G. (1999). A family of dispersed repeats in the genome of Vicia faba: structure, chromosomal organization, redundancy modulation, and evolution. Chromosoma 108: 317-324.

FRANSZ, P. F., STAM, M., MONTIJN, B., TEN HOOPEN, R., WIEGANT, J., KOOTER, J. M., OUD, O., NANNINGA, N. (1996). Detection of single- copy genes and chromosome rearrangements in Petunia hybrida by fluorescence in situ hybridization. Plant J. 9: 767-774.

FUCHS, J., BRANDES, A., SCHUBERT, I. (1995). Telomere sequence localization and karyotype evolution in higher plants. Plant Syst. Evol. 196: 227-241.

FUKUI, K., NAKAYAMA, S., OHMIDO, N., YOSHIAKI, H., YAMABE, M. (1998). Quantitative karyotyping of three diploid Brassica species by imaging methods and localisation of $45 \mathrm{~S}$ rDNA loci on the identified chromosomes. Theor. Appl. Genet. 96: 325-330.

GALASSO, I., SCHMIDT, T., PIGNONE, D., HESLOP-HARRISON, J. S. (1995). The molecular cytogenetics of Vigna unguiculata (L.) Walp: the physical organization and characterization of 18S-5.8S-25S rRNA genes, 5S rRNA genes, telomere-like sequences, and a family of centromeric repetitive DNA sequences. Theor. Appl. Genet. 91: 928-935. 
GALASSO, I., SCHMIDT, T., PIGNONE, D. (2001). Identification of Lens culinaris ssp. culinaris chromosomes by physical mapping of repetitive DNA sequences. Chromosome Res. 9: 199-209.

GOUBELY, C., ARNAUD, P., TATOUT, C., HESLOP-HARRISON. J.S., DERAGON, J.-M. (1999). S1 SINE retroelements are methylated at symmetrical and non-symmetrical positions in Brassica napus: identification of a preferred target site for asymmetrical methylation. Plant Mol. Biol. 39: 243255.

GREWAL, S. I. S., ELGIN, S. C. R. (2002). Heterochromatin: New possibilities for the inheritance of structure. Curr. Opin. Genet. Dev. 12: 178-187.

GUERRA, M., SANTOS, K. G. B., SILVA, A. E. B., EHRENDORFER, F. (2000). Heterochromatin banding patterns in Rutaceae-Aurantioideae - a case of parallel chromosomal evolution. Am. J. Bot. 87: 735-747.

GUPTA, V., JAGANNATHAN, V., LAKSHMIKUMARAN, M. S. (1990). A novel ATrich tandem repeat of Brassica nigra. Plant Science 68: 223-229.

GUPTA, V., LAKSHMISITA, G., SHAILA, M. S., JAGANNATHAN, V., LAKSHMIKUMARAN, M. S. (1992). Characterization of species-specific repeated DNA sequences from Brassica nigra. Theor. Appl. Genet. 90: 397402.

GUSTAFSON, J. P., BUTLER, E., MCINTYRE, C. L. (1990). Physical mapping of a low-copy DNA sequence in rye (Secale cereale L.). Proc. Natl. Acad. Sci. U.S.A. $87:$ 1899-1902.

HARBINDER, S., LAKSHMIKUMARAN, M. (1990). A repetitive sequence from Diplotaxis erucoides is highly homologous to that of Brassica campestris and B. oleracea. Plant Mol. Biol. 15 : 155-156.

HARRISON, G. E., HESLOP-HARRISON, J. S. (1995). Centromeric repetitive DNA in the genus Brassica. Theor. Appl. Genet. 90, 157-165.

HASTEROK, R., MALUSZYNSKA, J. (2000a). Cytogenetic analysis of diploid Brassica species. Acta Biol. Cracov. Ser. Bot. 42: 145-163. 
HASTEROK, R., MALUSZYNSKA, J. (2000b). Nucleolar dominance does not occur in root tip cells of allotetraploid Brassica species. Genome 43: 574-579.

HASTEROK, R., JENKINS, G., LANGDON, T., JONES, R. N., MALUSZYNSKA, J. (2001). Ribosomal DNA is an effective marker of Brassica chromosomes. Theor. Appl. Genet. 103: 486-490.

HESLOP-HARRISON, J. S. (2000). Comparative genome organization in plants: from sequence and markers to chromatin and chromosomes. Plant Cell 12: 617-635.

HIGASHIYAMA, T., MAKI, S., YAMADA, T. (1995). Molecular organization of Chlorella vulgaris chromosome I: presence of telomeric repeats that are conserved in higher plants. Mol. Gen. Genet. 246: 29-36.

HIZUME, M., SHIBATA, F., MARUYAMA, Y., KONDO, T. (2001). Cloning of DNA sequences localized on proximal fluorescent chromosome bands by microdissection in Pinus densiflora. Chromosoma 110: 345-351.

HORÁKOVÁ, M., FAJKUS, J. (2000). TAS49- a dispersed repetitive sequence isolated from subtelomeric regions of Nicotiana tomentosiformis chromosomes. Genome 43: 273-84.

HOUBEN, A., WANNER, G., HANSON, L., VERLIN, D., LEACH, C. R., TIMMIS, J. N. (2000). Cloning and characterisation of polymorphic heterochromatic segments of Brachycome dichromosomatica. Chromosoma 109: 433-433.

HOWELL, E. C., BARKER, G. C., JONES, G. H., KEARSEY, M. J., KING, G. J., KOP, E. P., RYDER, C. D., TEAKLE, G. R., VICENTE, J. G., ARMSTRONG, S. J. (2002). Integration of the cytogenetic and genetic linkage maps of Brassica oleracea. Genetics 161: 1225-1234.

ITOH, K., IWABUCHI, M., SHIMAMOTO, K. (1991). In situ hybridization with species-specific DNA probes gives evidence for asymmetric nature of Brassica hybrids obtained by X-ray fusion. Theor. Appl. Genet. 81: 356-362. 
IWABUCHI, M., ITOH, K., SHIMAMOTO, K. (1991). Molecular and cytological characterization of repetitive DNA sequences in Brassica. Theor. Appl. Genet. 81: 349-355.

IWANO, M., SAKAMOTO, K., SUZUKI, G., WATANABE, M., TAKAYAMA, S., FUKUI, K., HINATA, K., ISOGAI, A. (1998). Visualization of a selfincompatibility gene in Brassica campestris L. by multicolor FISH. Theor. Appl. Genet. 96: 751-757.

JACKSON, S. A., CHENG, Z., WANG, M.-L., GOODMAN, H. M., JIANG, J. (2000). Comparative FISH mapping of a 431-kb Arabidopsis thaliana BAC contig reveals the role of chromosomal duplications in the expansion of the Brassica rapa genome. Genetics 156: 833-838.

JAMILENA, M., REJON, C. R., REJON, M. R. (1993). Repetitive DNA sequence families in Crepis capillaris. Chromosoma 102: 272-278.

JAMILENA, M., REJÓN, C. R., REJÓN, M. R. (1994). A molecular analysis of the origin of the Crepis capillaris B chromosome. J. of Cell Sci. 107: 703-708.

JAMILENA, M., GARRIDO-RAMOS, M., REJÓN, M. R., REJÓN, C. R., PARKER, J. S. (1995). Chracterisation of repeated sequences from microdissected $B$ chromosomes of Crepis capillaris. Chromosoma 104: 113-120.

JASINSKA, A., KRZYZOSIAK, W. J. (2004). Repetitive sequences that shape the human transcriptome. FEBS Lett. 567: 136-141.

JENKINS, G., HEAD, J., FORSTER, J. W. (2000). Probing meiosis in hybrids of Lolium (Poaceae) with a discriminatory repetitive genomic sequence. Chromosoma 109: 280-286.

JIANG, J., GILL, B. S. (1994). New 18S.26S ribosomal RNA gene loci: Chromosomal landmarks for the evolution of polyploid wheats. Chromosoma 103: $179-185$

JIN, W. W., LI, Z. Y., FANG, Q., ALTOSAAR, I., LIU, L. H., SONG, Y. C. (2002). Fluorescence in situ hybridization analysis of alien genes in Agrobacteriummediated Cry1A(b)-transformed Rice. Ann. Bot. (London) 90: 31-36. 
KAMISUGI, Y., NAKAYAMA, S., O'NEIL, C. M., MATHIAS, R. J., TRICK, M., FUKUI, K. (1998). Visualization of the Brassica self-incompatibility S-locus on identified oilseed rape chromosomes. Plant Mol. Biol. 38: 1081-1087.

KAMSTRA, S. A., KUIPERS, A. G. J., DE JEU, M. J., RAMANNA, M. S., JACOBSEN, E. (1997). Physical localisation of repetitive DNA sequences in Alstroemeria: karyotyping of two species with species-specific and ribosomal DNA. Genome 40: 652-658.

KAPILA, R., DAS, S., SRIVASTAVA, P. S., LAKSHMIKUMARAN, M. (1996a). A novel species-specific tandem repeat DNA family from Sinapis arvensis: Detection of telomere-like sequences. Genome 39: 758-766.

KAPILA, R., NEGI, M. S., THISEY, P., DELSENY, M., SRIVASTAVA, P. S., LAKSHMIKUMARAN, M. (1996b). A new family of dispersed repeats from Brassica nigra: characterization and localization Theor. Appl. Genet. 93 : 1123-1129.

KAPUSCINSKI, J. (1995). DAPI: a DNA-specific fluorescent probe. Biotech. Histochem. 70. 220-233.

KIDWELL, M. G. (2002). Transposable elements and the evolution of genome size in eukaryotes. Genetica 115: 49-63.

KITAMURA, S., INOUE, M., OHMIDO, N., FUKUI, K. (2000). Quantitative chromosome maps and rDNA localization in the T subgenome of Nicotiana tabacum L. and its putative progenitors. Theor. Appl. Genet. 101: 1180-1188.

KO, J.-M., DO, G.-S., SUH, D.-Y., SEO, B.-B., SHIN, D.-C., MOON, H.-P. (2002). Identification and chromosomal organization of two rye genome-specific RAPD products useful as introgression markers in wheat. Genome 45: 157-164.

KOHLI, A., TWYMAN, R. M., ABRANCHES, R., WEGEL, E., STOGER, E., CHRISTOU, P. (2003). Transgene integration, organization and interaction in plants. Plant Mol. Biol. 53: 247-258.

KOLCHINSKY, A., GRESSHOFF, P. M. (1995). A major satellite DNA of soybean is a 92- base pairs tandem repeat. Theor. Appl. Genet. 90: 621-626. 
KUBIS, S., HESLOP-HARRISON J. S., SCHMIDT, T. (1997). A family of differentially amplified repetitive DNA sequences in the genus Beta reveals genetic variation in Beta vulgaris subspecies and cultivars. J. Mol. Evol. 44: 310-320.

KUBIS, S., SCHMIDT, T., HESLOP-HARRISON, J. S. (1998). Repetitive DNA as a major component of plant genomes. Ann. Bot. (London) 82: 45-55.

KUBIS, S. E., CASTILHO, A. M. M. F., VERSHININ, A. V., HESLOP-HARRISON, J. S. (2003). Retroelements, transposons and methylation status in the genome of oil palm (Elaeis guineensis) and the relationship to somaclonal variation. Plant Mol. Biol. 52: 69-79.

KUMAR, A., BENNETZEN, J. L. (1999). Plant retrotransposons. Annu. Rev. Genet. 33: 479-532.

KUNZE, R., SAEDLER, H., LÖNNIG, W. (1997). Plant transposable elements. Adv. Bot. Res. 27: 332-470.

LAGERCRANTZ, U. (1998). Comparative mapping between Arabidopsis thaliana and Brassica nigra indicates that Brassica genomes have evolved through extensive genome replication accompanied by chromosome fusions and frequent rearrangements. Genetics 150: 1217-1228.

LAGERCRANTZ, U., LYDIATE, D. J. (1996). Comparative genome mapping in Brassica. Genetics 144: 1903-1910.

LAKSHMIKUMARAN, M., RANADE, S. A. (1990). Isolation and characterization of a highly repetitive DNA of Brassica campestris. Plant Mol. Biol. 14: 447-448.

LAPITAN, N. L. V. (1992). Organization and evolution of higher plant nuclear genomes. Genome 35: 171-181.

LEE, S. H., DO, G. S., SEO, B. B. (1999). Chromosomal localization of 5 S rRNA gene loci and the implications for relationships within the Allium complex. Chromosome Res. 7: 89-93. 
LEITCH, A. R., SCHWARZACHER, T., WANG, M. L. (1993). Molecular cytogenetic analysis of repeated sequences in a long wheat suspension culture. Plant Cell Tissue Organ Cult. 33: 287-296.

LEVAN, A., FREDGA, K., SANDBERG, A. A. (1964). Nomenclature for centromeric position on chromosomes. Hereditas 52: 201-220.

LI, B., OESTREICH, S., DE LANGE, T. (2000). Identification of human Rap1: implications for telomere evolution. Cell 101: 471-83.

LI, M., QIAN, W., MENG, J., LI, Z. (2004). Construction of novel Brassica napus genotypes through chromosomal substitution and elimination using interploid species hybridization. Chromosome Res. 12: 417-426.

LI, W. L., CHEN, P. D., QI, L. L., LIU, D. J. (1995). Isolation, characterization and application of a species-specific repeated sequence from Haynaldia villosa. Theor. Appl. Genet. 90: 526-533.

LIM, K.-B., WENNEKES, J., DE JONG, J. H., JACOBSEN, E., VAN TUYL, J. M. (2001). Karyotype analysis of Lilium longiflorum and Lilium rubellum by chromosome banding and fluorescence in situ hybridisation. Genome 44: 911918.

LiM, K. Y., MATYASEK, R., LiChtenstein, C. P., LeitCH, A. R. (2000). Molecular cytogenetic analyses and phylogeny of the Nicotiana section Tomentosae. Chromosoma 109: 245-258.

LORITE, P., CARRILlO, J. A., PALOMEQUE, T. (2002). Conservation of (TTAGG)n telomeric sequences among ants (Hymenoptera, Formicidae). J. Hered. 93: 282-285.

LUBARETZ, O., FUCHS, J., AHNE, R., MEISTER, A. (1996). Karyotyping of three Pinaceae species via fluorescent in situ hybridization and computer-aided chromosome analysis. Theor. Appl. Genet. 92: 411-416.

LUKENS, L., ZOU, F., LYDIATE, D., PARKIN, I., OSBORN, T. (2003). Comparison of a Brassica oleracea genetic map with the genome of Arabidopsis thaliana. Genetics 164: 359-372. 
MACAS, J., POZARKOVA, D., NAVRATILOVA, A., NOUZOVA, M., NEUMANN, P. (2000). Two new families of tandem repeats isolated from genus Vicia using genomic self-priming PCR. Molecular Gen. Genet. 263: 741-751.

MACAS, J. Í, MÉSZÁROS, T., NOUZOVÁ, M. (2002). PlantSat: a specialized database for plant satellite repeats. Bioinformatics 18: 28-35.

MANDRIOLI, M., BIZZARO, D., GIUSTI, M., MANICARDI, G. C., BIANCHI, U. (1999). The role of rDNA genes in $X$ chromosome association in the aphid Acyrthosiphon pisum. Genome 42: 318-386.

MALUSZYNSKA, J., HESLOP-HARRISON, P. (1993). Physical mapping of rDNA loci in Brassica species. Genome 36: 774-781.

MCKNIGHT, T. D., RIHA, K., SHIPPEN, D. E. (2002). Telomeres, telomerase, and stability of the plant genome. Plant Mol. Biol. 48: 331-337.

MEINKOTH, J., WAHL, G. (1984). Hybridization of nucleic acids immobilized on solid supports. Anal. Biochem. 138: 267-284.

MIRANDA, M., IKEDA, F., ENDO, T., MORIGUCHI, T., OMURA, M. (1997). Comparative analysis on the distribution of heterochromatin in Citrus, Poncirus and Fortunella chromosomes. Chromosome Res. 5: 86-92.

MOLNAR, S. J., GUPTA, P. K., FEDAK, G., WHEATCROFT, R. (1989). Ribosomal DNA repeat unit polymorphism in 25 Hordeum species. Theor. Appl. Genet. 78: 387-392.

MOSCONE, E. A., MATZKE, M. A., MATZKE, A. J. M. (1996). The use of combined $\mathrm{FISH} / \mathrm{GISH}$ in conjunction with DAPI counterstaining to identify chromosomes containing transgene inserts in amphidiploid tobacco. Chromosoma 105: 231-236.

MOSCONE, E. A., KLEIN, F., LAMBROU, M., FUCHS, J., SCHWEIZER, D. (1999). Quantitative karyotyping and dual-color FISH mapping of 5S and 18S25S rDNA probes in the cultivated Phaseolus species (Leguminosae). Genome 42: 1224-1233. 
MURATA, M., HESLOP-HARRISON, J. S., MOTOYOSHI, F. (1997). Physical mapping of the $5 \mathrm{~S}$ ribosomal RNA genes in Arabidopsis thaliana by multi-color fluorescence in situ hybridization with cosmid clones. Plant J. 12: 31-37.

NARAYAN, R. K. J. (1998). The role of genomic constraints upon evolutionary changes in genome size and chromosome organization. Ann. Bot. (London) 82: $57-66$.

NAVRÁTILOVÁ, A., NEUMANN, P., MACAS, J. (2003). Karyotype analysis of four Vicia species using in situ hybridization with repetitive sequences. Ann. Bot. (London) 91: 921-926.

NEUMANN, P., NOUZOVA, M., MACAS, J. (2001). Molecular and cytogenetic analysis of repetitive DNA in pea (Pisum sativum L.). Genome 44: 716-728.

NOUZOVA, M., KUBALAKOVA, M., DOLEZELOVA, M., KOBLIZKOVA, A., NEUMANN, P., DOLEZEL, J., MACAS, J. (1999). Cloning and characterization of new repetitive sequences in field bean (Vicia faba L.). Ann. Bot. (London) 83: 535-541.

OLIN-FATIH, M., HENEEN, W. K. (1992). C-banded karyotypes of Brassica campestris, B. oleracea and B. napus. Genome 35: 583-589.

OUYANG, S., BUELL, C. R. (2004). The TIGR Plant Repeat Databases: a collective resource for the identification of repetitive sequences in plants. Nucleic Acids Res. 32: 360-363.

PALMER, J. D., SHIELDS, C. R., COHEN, D. B., ORTON, T. J. (1983). Chloroplast DNA evolution and the origin of amphidiploid Brassica species. Theor. Appl. Genet. 65: 181-189.

PARDUE, M.-L., DEBARYSHE, P. G. (1999). Telomeres and telomerase: more than the end of the line. Chromosoma 108: 73-82.

PARKIN, I. A. G., SHARPE, A. G., KEITH, D. J., LYDIATE, D. J. (1995). Identification of the A and $\mathrm{C}$ genomes of amphidiploid Brassica napus (oilseed rape). Genome 38: 1122-1131. 
PEHU, E., THOMAS, M., POUTALA, T., KARP, A., JONES, M. G. K. (1990). Species-specific sequences in the genus Solanum: identification, characterization, and application to study somatic hybrids of S. brevidens and S. tuberosum. Theor. Appl. Genet. 80: 693-698.

PEDROSA, A., JANTSCH, M. F., MOSCONE, E. A., AMBROS, P. F., SCHWEIZER, D. (2001). Characterisation of pericentromeric and sticky intercalary heterochromatin in Ornithogalum longibracteatum (Hyacinthaceae). Chromosoma 110: 203-213.

PEDROSA, A., SANDAL, N., STOUGAARD, J., SCHWEIZER, D., BACHMAIR, A. (2002). Chromosomal map of the model legume Lotus japonicus. Genetics 161: $1661-1672$.

PEDROSA, A., VALLEJOS, C., BACHMAIR, A., SCHWEIZER, D. (2003). Integration of common bean (Phaseolus vulgaris L.) linkage and chromosomal maps. Theor. Appl. Genet. 106: 205-212.

PICH, U., SCHUBERT, I. (1998). Terminal heterochromatin and alternative telomeric sequences in Allium cepa. Chromosome Res. 6: 315-321.

PLANTSAT. (2004). http://w3lamc.umbr.cas.cz/PlantSat/.

PRAKASH, S., HINATA, K. (1980). Taxonomy, cytogenetics and origin of crop Brassicas, a review. Opera. Bot. 55: 3-57.

PRAKASH, S., TSUNODA, S. (1980). Cytogenetics of Brassica. In: Swaminathan, M. S., Gupta, P. K., Sinha, U. (Eds.) Cytogenetics of crop plants. pp 481-513. Macmillan India Limited, New Delhi, India.

RAINA, S. N., OGIHARA, Y. (1995). Ribosomal DNA repeat unit polymorphism in 49 Vicia species. Theor. Appl. Genet. 90: 477-486.

RAINA, S. N., MUKAI, Y., KAWAGUCHI, K., GOEL, S., JAIN, A. (2001). Physical mapping of 18S-5.8S-26S and 5S ribosomal RNA gene families in three important vetches ( Vicia species) and their allied taxa constituting three species complexes. Theor. Appl. Genet. 103: 839-845. 
RAN, Y., HAMMETT, K. R. W., MURRAY, B. G. (2001). Phylogenetic analysis and karyotype evolution in the genus Clivia (Amaryllidaceae). Ann. Bot. (London) 87: 823-830.

REDDY, A. S., SRIVASTAVA, V., GUHA-MUKHERJEE, S. (1989). A tandemly repeated DNA sequence from Brassica juncea. Nucleic Acids Res. 17: 5849.

RICHARDS, E. J. (1995). Plant Telomeres. In: GREIDER, C., BLACKBURN, E.H. (Eds.) Telomeres. Cold Spring Harbor Laboratory Press, Cold Spring Harbor.

RICHARDS, E. J., AUSUBEL, F. M. (1988). Isolation of a higher eukaryotic telomere from Arabidopsis thaliana. Cell 53: 127-136.

RICHARDS, E. J., GOODMAN, H. M., AUSUBEL, F. M. (1991). The centromere region of Arabidopsis thaliana chromosome 1 contains telomere-similar sequences. Nucleic Acids Res. 19: 3351-3357.

RICHARDS, E. J., CHAO, S., VONGS, A., YANG, J. (1992). Characterization of Arabidopsis thaliana telomeres isolated in yeast. Nucleic Acids Res. 20: 40394046.

RIETHMAN, H., AMBROSINI, A., CASTANEDA, C., FINKLESTEIN, J., HU, X.-L., MUDUNURI, U., PAUL, S., WEI, J. (2004). Mapping and Initial Analysis of Human Subtelomeric Sequence Assemblies. Genome Res. 14: 18-28.

RIHA, K., SHIPPEN, D. E. (2003). Telomere structure, function, and maintenance in Arabidopsis. Chromosome Res. 11: 263-275.

RÖBBELEN, G. 1960. Beitrage zur Analyse des Brassica Genome. Chromosoma 11: 205-228.

ROGERS, S. O., BENDICH, A. J. (1987). Ribosomal RNA genes in plants: variability in copy number and in the intergenic spacer. Plant Mol. Biol. 9: 509520.

ROGERS, S. O., BENDICH, A. J. (1988). Extraction of DNA from plant tissues. Plant Mol. Biol. Manual A6: 1-10. 
ROKKA, V.-M., CLARK, M. S., KNUDSON, D. L., PEHU, E., LAPITAN, N. L. V. (1998). Cytological and molecular characterization of repetitive DNA sequences of Solanum brevidans and Solanum tuberosum. Genome 41: 487494.

ROSA, E. A. S. (1999). Chemical Composition. In: GÓMEZ-CAMPO, C. (Ed.) Biology of Brassica Coenospecies. Developments in Plant Genetics and Breeding. pp. 315-346. Elsevier Science, Amsterdam, Netherlands.

SADDER, M.T., WEBER, G. (2001). Karyotype of maize (Zea mays L.) mitotic metaphase chromosomes as revealed by fluorescence in situ hybridization (FISH) with cytogenetic DNA markers. Plant Mol. Biol. Rep. 19: 117-123.

SANTINI, S., CAVALLINI, A., NATALI, L., MINELLI, S., MAGGINI, F., CIONINI, P. (2002). Ty1/copia- and Ty3/gypsy-like DNA sequences in Helianthus species. Chromosoma 111: 192-200.

SCHELFHOUT, C. J., SNOWDON, R. J., COWLING, W. A., WROTH, J. M. (2004). A PCR based B-genome specific marker in Brassica species. Theor. Appl. Genet. 190: 917-921.

SCHMIDT, R. (2002). Plant genome evolution: lessons from comparative genomics at the DNA level. Plant Mol. Biol. 48: 21-37.

SCHMIDT, T., JUNG, C., METZLAFF, M. (1991). Distribution and evolution of two satellite DNAs in the genus Beta. Theor. Appl. Genet. 82: 793-799

SCHMIDT, T., HESLOP-HARRISON, J. S. (1994). Variability and evolution of highly repeated DNA sequences in the genus Beta. Genome 36: 1074-1079.

SCHMIDT, T., HESLOP-HARRISON, J. S. (1998). Genomes, genes and junk: the large scale organization of plant chromosomes. Trends Plant Sci. 3: 195-199.

SCHRADER, O., BUDAHN, H., AHNE, R. (2000). Detection of 5S and 25S rRNA genes in Sinapis alba, Raphanus sativus and Brassica napus by double fluorescence in situ hybridization. Theor. Appl. Genet. 100: 665-669.

SCHWEIZER, D. (1980). Fluorescent chromosome banding in plants: application, mechanisms, and implications for chromosome structure. In: Davies D. R., 
Hopwood D. A. (Eds.) The plant genome. John Innes Charity, Norwich, pp. 6172.

SHARPE, A. G., PARKIN, I. A. G., KEITH, D. J., LYDIATE, D. J. (1995). Frequent nonreciprocal translocations in the amphidiploid genome of oilseed rape (Brassica napus). Genome 38: 1122-1131.

SHIBATA, F., HIZUME, M. (2002). The identification and analysis of the sequences that allow the detection of Allium cepa chromosomes by GISH in the allodiploid A. wakegii. Chromosoma 111: 184-191.

SKARZHINSKAYA, M., FAHLESON, J., GLIMELIUS, K., MOURAS, A. (1998). Genome organization of Brassica napus and Lesquerella fendleri and analysis of their somatic hybrids using genomic in situ hybridization. Genome 41: 691701.

SNOWDON, R.J. (1997). Fluorescence in situ hybridisation techniques for Brassica species: Methodological development and practical applications. Dissertation, Justus-Liebig-Universität Gießen, 1997.

SNOWDON, R. J. , KÖHLER, W., FRIEDT, W., KÖHLER, A. (1997a). Genomic in situ hybridisation in Brassica amphidiploids and hybrids. Theor. Appl. Genet. 95: 1320-1324.

SNOWDON, R. J, KÖHLER, W., KÖHLER, A. (1997b). Chromosomal localisation and characterisation of rDNA loci in the Brassica A and C genomes. Genome 40: $582-587$.

SNOWDON, R. J., KÖHLER, A.; KÖHLER, W., FRIEDT, W. (1999). FISHing for new rapeseed lines: the application of molecular cytogenetic techniques to Brassica breeding. Proceedings, 10th International Rapeseed Congress, September 1999, Canberra, Australia.

SNOWDON, R. J., FRIEDT, W., KÖHLER A., KÖHLER W. (2000a). Molecular cytogenetic localisation and characterisation of $5 S$ and $25 S$ rDNA loci for chromosome identification in oilseed rape (Brassica napus L.). Ann. Bot. (London) 86: 201-204. 
SNOWDON, R. J., WINTER, H., DIESTEL, A., SACRISTÁN, M. D. (2000b). Development and characterisation of Brassica napus-Sinapis arvensis addition lines exhibiting resistance to Leptosphaeria maculans. Theor. Appl. Genet. 101: 1008-1014.

SNOWDON, R. J., BÖTTINGER, P., PICKARDT, T., KÖHLER, F., FRIEDT, W. (2001). Physical localisation of transgenes on Vicia faba chromosomes. Chromosome Res. 9: 607-610.

SNOWDON, R. J., FRIEDRICH, T., FRIEDT, W., KÖHLER, W. (2002). Identifying the chromosomes of the $\mathrm{A}$ and $\mathrm{C}$ genome diploid Brassica species $B$. rapa (syn. campestris) and B. oleracea in their amphidiploid B. napus. Theor. Appl. Genet. 104: 533-538.

SONG, K., OSBORN, T., WILLIAMS, P. H. (1988). Brassica taxonomy based on nuclear restriction fragment length polymorphysms (RFLPs). 1. Genome evolution of diploid and amphidiploid species. Theor. Appl. Genet. 75: 784794.

SONG, K., TANG, K., OSBORN, T. C. (1995). Rapid genome change in synthetic polyploids of Brassica and its implications for polyploid evolution. Proc. Natl. Acad. Sci. U.S.A. 92: 7719-7723.

STAGINNUS, C., HUETTEL, B., DESSEL, C., SCHMIDT, T., KAHL, G. (2001). A PCR-based assay to detect $\mathrm{En} / \mathrm{Spm}$-like transposon in plants. Chromosome Res. 9: 591-605.

SVITASHEV, S., BRYNGELSSON, T., LI, X.-M., WANG, R. R.-C. (1998). Genome-specific repetitive DNA and RAPD markers for genome identification in Elymus and Hordelymus. Genome 41: 120-128.

SVITASHeV, S., ANANIEV, E., PAWLOWSKI, W. P., SOMERS, D. A. (2000). Association of transgene integration sites with chromosome rearrangements in hexaploid oat. Theor. Appl. Genet. 100: 872-880.

SYKOROVA, E., LIM, K. Y., CHASE, M. W., KNAPP, S., LEITCH, I. J., LEITCH, A. R., FAJKUS, J. (2003a). The absence of Arabidopsis-type telomeres in 
Cestrum and closely related genera Vestia and Sessea (Solanaceae): first evidence from eudicots. Plant J. 34: 283-291.

SÝKOROVÁ, E., LIM, K. Y., KUNICKÁ, Z., CHASE, M. W., BENNETT, M. D., FAJKUS, J., LEITCH, A. R. (2003b). Telomere variability in the monocotyledonous plant order Asparagales. Proc. R. Soc. London Ser. B 270: 1893-1904.

U, N. (1935). Genome analysis in Brassica with special reference to the experimental formation of $B$. napus and peculiar mode of fertilization. Jpn. J. Bot. 7: 389-452.

UZUNOVA, M. (1994). Erstellung einer RFLP- Karte von Raps (Brassica napus L.) und Kartierung erster züchterisch wichtiger Gene. Cuvillier Verlag Göttingen. Zugl. Diss. Univ. Göttingen.

UZUNOVA, M., ECKE, W., WEISSLEDER, K., RÖBBELEN, G., (1995). Mapping the genome of rapeseed (Brassica napus L.). I. Construction of an RFLP linkage map and localization of QTLs for seed glucosinolate content. Theor. Appl. Genet. 90: 194-204.

VALÁRIK, M., ŠIMKOVÁ, H., ŠAFÁŘ, J., DOLEŽELOVÁ, M., DOLEŽEL, J. (2002). Isolation, characterization and chromosome localization of repetitive DNA sequences in bananas (Musa spp.). Chromosome Res. 10: 89-100.

VERSHININ, A. V., HESLOP-HARRISON, J. S. (1998). Comparative analysis of the nucleosomal structure of rye, wheat and their relatives. Plant Mol. Biol. 36: 149-161.

VISCHI, M., JURMAN, I., BIANCHI, G., MORGANTE, M. (2003). Karyotype of Norway spruce by multicolor FISH. Theor. Appl. Genet. 107: 591-597.

WANG, X.-H., LUO, P., SHU, J.-J. (1989). Giemsa N-banding pattern in cabbage and Chinese kale. Euphytica 41: 17-21.

WANG, Z.-X., KURATA, N., SAJI, S., KATAYOSE, Y., MINOBE, Y. (1995). A chromosome 5-specific repetitive DNA sequence in rice (Oryza sativa L.). Theor. Appl. Genet. 90: 907-913. 
WANG, Y. P., SNOWDON, R. J., RUDLOFF, E., WEHLING, P., FRIEDT, W., SONNTAG, K. (2004). Cytogenetic characterization and fae1 gene variation in progenies from asymmetric somatic hybrids between Brassica napus and Crambe abyssinica. Genome 47: 724-731.

WEISS, H., SCHERTHAN, H. (2002). Aloe ssp.- plants with vertebrate-like telomeric sequences. Chromosome Res. 10: 155-164.

WEISS-SCHNEEWEISS, H., RIHA, K., JANG, C. G., PUIZINA, J., SCHERTHAN, H., SCHWEIZER, D. (2004). Chromosome termini of the monocot plant Othocallis siberica are maintained by telomerase, which specifically synthesises vertebrate-type telomere sequences. Plant J. 37: 484-493.

XIA, X., SELVARAJ, G., BERTRAND, H. (1993). Structure and evolution of a highly repetitive DNA sequence from Brassica napus. Plant Mol. Biol. 21: 213224.

XIA, X., ROCHA, P.S., SElVARAJ, G., BeRTRAND, H. (1994). Genomic organization of the canrep repetitive DNA in Brassica juncea. Plant Mol. Biol. 26: 817-832.

ZANE, L., BARGELLONI, L., PATARNELLO, T. (2002). Strategies for microsatellite isolation: a review. Mol. Ecol. 11: 1-16.

ZHANG, X., WESSLER, S. R. (2004). Genome-wide comparative analysis of the transposable elements in the related species Arabidopsis thaliana and Brassica oleracea. Proc. Natl. Acad. Sci. U.S.A. 101: 5589-5594.

ZHAO, X., WING, R. A., PATERSON, A. H. (1995). Cloning and characterization of the majority of repetitive DNA in cotton (Gossypium L.). Genome 38: 11771188.

ZHAO, X., JI, Y., DING, X., STELlY, D. M., PATERSON, A. H. (1998a). Macromolecular organization and genetic mapping of a rapidly evolving chromosome-specific tandem repeat family (B77) in cotton (Gossypium). Plant. Mol. Biol. 38: 1031-1042. 
ZHAO, X.-P., SI, Y., HANSON, R. E., CRANE, C. F., PRICE, H. J., STELLY, D. M., WENDEL, J. F., PATERSON, A. H. (1998b). Dispersed repetitive DNA has spread to new genomes since polyploid formation in cotton. Genome Res. 8: 479-492.

ZHONG, X. B., FRANSZ, P. F., WENNEKES-EDEN, J., RAMANNA, M. S., VAN KAMMEN, A., ZABEL, P., DE JONG, J. H. (1998). FISH studies reveal the molecular and chromosomal organization of individual telomere domains in tomato. Plant J. 13: 507-517.

ZIOLKOWSKI, P. A., SADOWSKI, J. (2002). FISH-mapping of rDNAs and Arabidopsis BACs on pachytene complements of selected Brassicas. Genome 45: 189-197. 


\section{Acknowledgement}

I am very grateful to Prof. Heiko Becker and Dr. Ulrike Bellin for providing me the opportunity to conduct this project and for the encouragement and support during all these years. Many thanks for the interest to read the manuscripts of this thesis and for the very useful suggestions and discussions. I wish to express my gratitude to "Ulli" for the supervision, friendship and many helps during my work and to Heiko for his patience, gentleness and respectful way of dealing with us students.

My gratitude extends to Dr. W. Ecke for his suggestions during the work with molecular genetic techniques and corrections/suggestions of the manuscript, very important for the improvement of this thesis.

My sincere thanks goes to Prof. Marcelo Guerra (Depto. de Botânica, UFPE, Brazil), for his enthusiasm to critically read the manuscript, in spite of his very busy schedule, and for the many valuable suggestions.

My sincere gratitude to Prof. Köhler, for kindly accept to be the second referee of this thesis and Profs. Karlovisky and Finkeldey for their interest to be my examiners.

Many thanks to Dr. J. Neesen (Institut für Humangenetik, Göttingen), for making available the Olympus microscope, indispensable for the conclusion of the FISH experiments.

My thanks also to Prof. Dr. A. Graner (Genbank- IPK, Gaterleben) for supplying part of the seeds used in this work, and to Prof. Dr. Knudson (Department of Entomology, Colorado State University, USA) for providing the plasmid probe "5+45SrDNA".

The financial support of the DAAD (German Academic Exchange Service), during the language course (1998), and the scholarship provided by CNPq (Brazilian National Council for Scientific and Technological Development) in 1999 are acknowledged. The Deutsche Forschungsgemeinschaft is acknowledged for the financial support for the research project.

Many thanks are given to all friends and colleges of "our institute" for the friendship, advices and good work atmosphere. I am particularly grateful to Anja 
Kramer and Lilli Nehlin, for their interest to read the manuscript, Mahmoud Zeid and Rubens Marschalek, for the many helps, Kerstin Diekmann, for the indispensable technical assistance during the FISH experiments, J. Hippe and U. Ammermann, for solving many of my "computer problems", $\mathrm{H}$. Heise, for some home assembled instruments used in this work, W. Link and C. Möllers, for correcting the Zusammenfassung and abstracts.

My thanks also to Dr. Andrea Pedrosa-Harand (Institute of Botany, University of Vienna, Austria) for helpful discussions concerning the FISH results and Dr. Weiss-Schneeweiss (Institute of Botany, University of Vienna, Austria) and Prof. E. Richards (Department of Biology, Washington University, USA) for personal communications.

My especial thanks goes to my mother, my family and my friends, especially those from the "Freudeskreis-Goethe-Institut-98" and from our small "Brazilian community in Göttingen" (particularly families Cattanio, Dahn-Batista, Ide, Marschalek), also to families Nehlin and Kramer/Stenzel, for the moral/emotional support, indispensable when we are living abroad.

Finally, my most especial thanks goes to my beloved daughter Isabelle and husband Martin for patiencie, motivation, inspiration, and exceptional capacity to show me every day how exciting, fun and beautiful life can be... 


\section{Curriculum Vitae}

\section{Personal data}

Name:

Karla Galvão Bezerra dos Santos.

Nationality: Brazilian.

Date of birth: $\quad$ 04. November 1970.

Place of birth: $\quad$ Olinda, Pernambuco (PE), Brazil.

\section{Education}

$1975-1985$

Primary school at the Colégio da Sagrada Família, Recife, PE, Brazil.

1986 - 1988: $\quad$ Secondary school at the Colégio Contato, Recife, PE, Brazil.

1989 -1992: $\quad$ Course of Biological Sciences at the Federal Univerity of Pernambuco, Recife, PE, Brazil.

1994 - 1996: $\quad$ Master Degree in Genetics and Molecular Biology at the Federal University of Rio Grande do Sul, Porto Alegre, Rio Grande do Sul, Brazil.

2000 -2004: $\quad$ Ph. D. in Plant Breeding at the Institute of Agronomy and Plant Breeding, Georg-August University, Göttingen, Germany.

\section{Professional Career}

1993:

1997 - 1998:

1999:

2000 - 2004:
Assistant scientist at the Federal University of Pernambuco, Recife, PE, Brazil.

Lecturer for Human Genetics, Genetics and Cytogenetics at the Department of Genetic, Federal University of Pernambuco, Recife, PE, Brazil.

Assistant scientist at the Karyotype Evolution Department, Institute of Plant Genetics and Crop Plant Research (IPK), Gatersleben, Germany.

Assistant scientist and lecturer for the Practical Course of Plant Cytogenetics at the Institute of Agronomy and Plant Breeding, Georg-August University, Göttingen, Germany. 